\title{
Recent Developments in the Aeroelasticity of Morphing Aircraft
}

\author{
R.M. Ajaj ${ }^{\mathrm{a} 1}$, M.S. Parancheerivilakkathil ${ }^{\mathrm{a}}$, M.R. Amoozgar ${ }^{\mathrm{b}}$, M.I. Friswell ${ }^{\mathrm{c}}$, and W.J. Cantwell ${ }^{\mathrm{a}}$ \\ ${ }^{a}$ Department of Aerospace Engineering, Khalifa University of Science and Technology, Abu Dhabi, UAE \\ ${ }^{b}$ Department of Engineering and Technology, University of Huddersfield, Huddersfield, UK, HDI 3DH \\ ${ }^{c}$ College of Engineering, Swansea University, Swansea, UK, SAI 8EN
}

\begin{abstract}
This paper presents an extensive review of the developments in the aeroelasticity of morphing aircraft that occurred in the last decade (from 2009 to 2020). It focuses mainly on fixed-wing aircraft and highlights some representative examples from rotary-wing aircraft. Morphing wings are usually associated with significant changes in the aerodynamic loads, structural/elastic properties, and inertial properties and hence the aeroelastic behavior. The change in aeroelastic behavior can also affect the flight dynamics, stability, and control of air-vehicles. The main motivation for this paper is the fact that it is not fully possible to assess and quantify the benefits of morphing technologies without accounting for aeroelastic effects. The literature on the aeroelasticity of morphing aircraft can be split into two main themes: Aeroelastic Stability and Aeroelastic Control. The first theme (Aeroelastic Stability) includes studies conducted on morphing concepts to ensure that they satisfy certain aeroelastic requirements/constraints and that such requirements/constraints do not limit the potential benefits of morphing. The second theme (Aeroelastic Control) includes studies that utilized morphing technologies to improve aeroelastic characteristics and/or control flight loads. It is evident that in both themes, the aeroelasticity of morphing aircraft has been analyzed using analytical, numerical, or computational tools with a very limited number of wind-tunnel and/or flight tests. In this paper, research activities and studies concerned are categorized according to the morphing degree of freedom they address. For each degree of freedom, research activities are arranged according to the theme they fit under. Aeroelastic frameworks developed for generic morphing applications are also reviewed. In addition, various aeroelastic models used are highlighted and discussed. Finally, trends and research gaps are identified and discussed and main conclusions are drawn.
\end{abstract}

\section{Keywords}

Aeroelasticity; Morphing Aircraft; UAVs; Flutter; Divergence; Loads Alleviation

\footnotetext{
${ }^{1}$ Rafic Ajaj, Assistant Professor, Khalifa University, Abu Dhabi, UAE, 127788, rafic.ajaj@ku.ac.ae.
} 


\section{Introduction}

Morphing aircraft have generated significant interest as a potential technology and future trend to meet the ambitious goals of the EU ACARE2020 [1] and FlightPath2050 [2] documents in reducing fuel burn, noise, and emissions. A morphing aircraft continuously adjusts its wing geometry to enhance flight performance, control authority, and multi-mission capability [3-6] as shown in Figure 1.

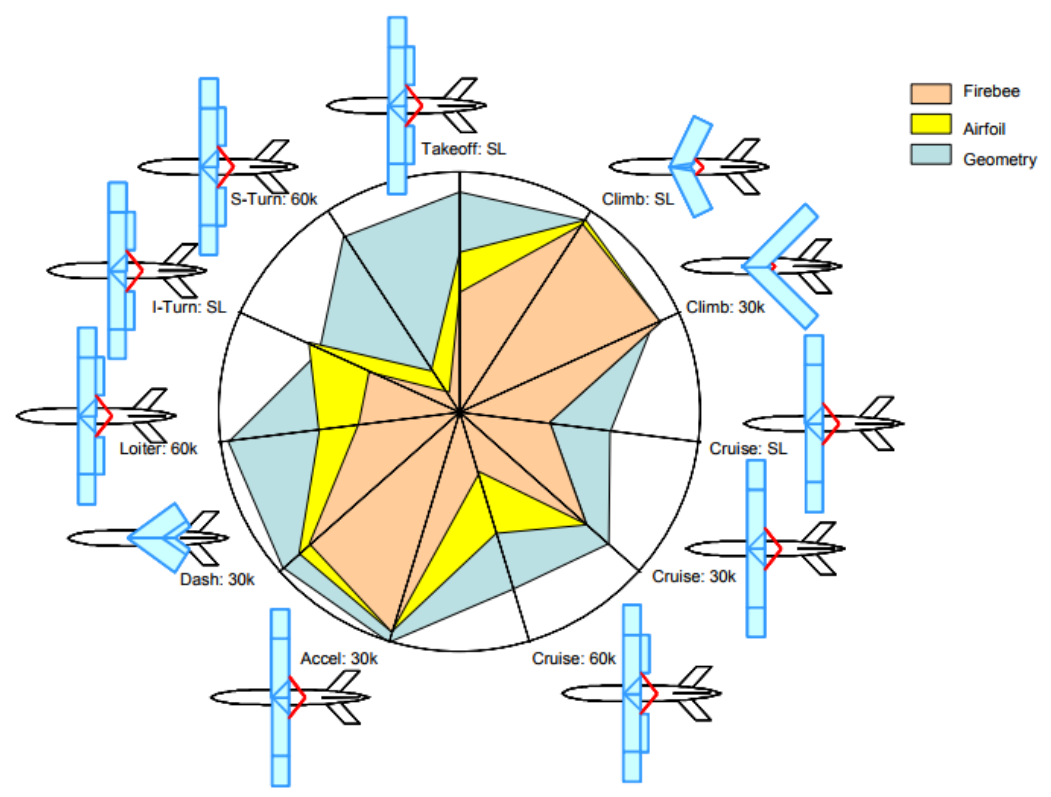

Figure 1. Morphing Aircraft optimized to perform multiple missions [4].

According to the NATO RTO technical team, morphing is the real-time adaptability of the vehicle to enable a multi-point optimized performance [7]. Adaptive wing geometry can potentially increases the overall system performance through load control and alleviation $[5,8$ 10]. Morphing degrees of freedom can be divided into three main categories: planform morphing (span, sweep and chord), out of plane morphing (twist, dihedral/gull, and spanwise bending), and airfoil morphing (thickness and camber) as shown in Figure 2.

The idea of morphing is not new. The Wright Brothers' Flier achieved roll control by changing the twist of the wing using an actuating cable controlled directly by the pilot [5]. The interest in morphing aircraft as the technology of the future is not limited to small scale aircraft (Unmanned Aerial Vehicles) but also large aircraft manufacturers, such as Boeing and Airbus, are investigating the possibility of adding morphing technologies to their aircraft to enhance fuel efficiency and reduce operating costs. For example, the latest version of the Boeing 777 (B777x) aircraft will employ a folding wingtip capability to be activated only on the ground during taxiing to and from the gates, thereby allowing the aircraft to operate from smaller airports and fit within their gate limitations while having a large wingspan during flight. 


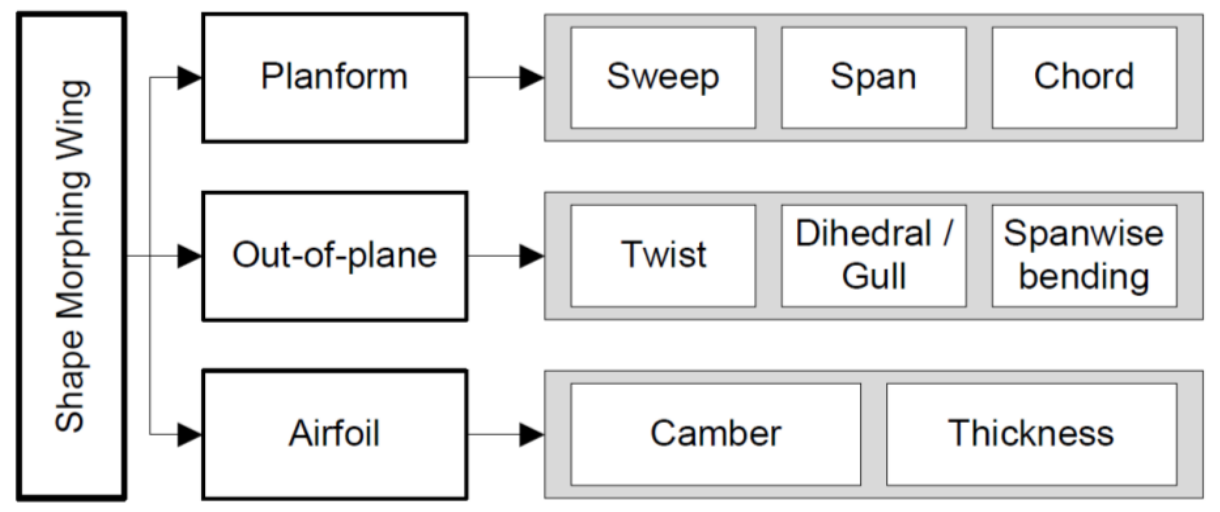

Figure 2. Morphing wing concepts [5].

In the literature, researchers have focused on developing wing concepts that facilitate morphing. However, little effort has been dedicated to study the aeroelasticity of these morphing concepts. Understanding the aeroelasticity of these concepts is essential in order to robustly quantify their benefits and mature their technology readiness level. It can be seen throughout this paper that the aeroelasticity of morphing wings has started to gain some momentum. The majority of papers in the literature have performed aeroelastic studies on specific morphing wing concepts while a very limited number of papers have focused on developing generic aeroelasticity frameworks [11-21]. It should be noted that a number of comprehensive attempts, that review morphing aircraft concepts and various modeling methods, exist in literature. For example, Barbarino et al. [5] presented an extensive review on morphing technologies up to 2011. Similarly, Li et al. [22] reviewed methods and tools that have been used in modeling and analyzing morphing concepts. They classified morphing technology based on different parameters such as special materials and relative techniques [23-26], geometry change [27-30] or actuator concept [31], special actuators [32], and other applications [10,33]. Currently, a comprehensive review on the recent developments in the aeroelasticity of morphing aircraft doesn't exist. It is extremely important for the success of morphing aircraft to fill this gap by reviewing the literature and highlighting the main trends and providing insights on future directions. This is the main motive for preparing this comprehensive review paper.

Aeroelastic effects have significant influence on the design and flight performance of aircraft. The aeroelastic phenomena refer to the interaction of aerodynamic, inertia, and elastic forces. The first recorded aviation-related aeroelastic phenomenon occurred in 1916 on the Handley Page $\mathrm{PO} / 400$ bomber due to violent tail oscillation which caused the elevators to move asymmetrically, producing extreme distortion of the rear fuselage. Aeroelasticity plays an important role in the airworthiness and certification of air-vehicles. In fact, during certification a defined range of load cases and all possible aeroelastic phenomena should be considered to ensure that no critical load value is exceeded and potentially disastrous scenarios can be avoided [34]. Aeroelastic effects are 
not limited to aircraft with conventional control surfaces, but also to flight vehicles with morphing technologies.

Morphing aircraft can offer improvements in the flight performance and reductions in weight, noise, and emissions [35-38]. They may also improve the safety of flight through enhancement of gust alleviation capabilities and stall characteristics [39]. The severe and rapid changes in geometry, mass distribution, center of gravity, shear center, and aerodynamic center associated with morphing wings have a great impact on the stability, flight dynamics, control, and aeroelasticity of the aircraft. In addition, a number of morphing concepts have utilized flexible skins and compliant structures, both of which have significant impact on the aeroelastic characteristics during normal operating conditions and off-design conditions. In fact, the aeroelasticity of a morphing aircraft must be carefully considered early in the design process. The general form of the aeroelastic equation for an aircraft can be expressed as:

$$
\mathbf{A} \ddot{\boldsymbol{q}}+(\rho V \mathbf{B}+\mathbf{D}) \dot{\boldsymbol{q}}+\left(\rho V^{2} \mathbf{C}+\mathbf{E}\right) \boldsymbol{q}=0
$$

where A, B, C, D, E are the structural inertia, aerodynamic damping, aerodynamic stiffness, structural damping and structural stiffness matrices respectively, $\boldsymbol{q}$ are generalized coordinates (typically model coordinates), $\rho$ is density and $V$ is air speed.

In literature, research activities focused on the aeroelasticity of morphing aircraft can be split into two main themes namely: Aeroelastic Stability and Aeroelastic Control. The first theme (Aeroelastic Stability) deals with studying the aeroelastic behavior of morphing concepts to ensure they can operate and offer their benefits with suffering from aeroelastic instabilities. The second theme (Aeroelastic Control) utilizes morphing concepts for aeroelastic purposes mainly to control the aeroelastic loads. This paper reviews developments in the aeroelasticity of morphing wings that have occurred over the last ten years. This includes static and dynamic aeroelasticity of fixed wing aircraft with some representative examples from rotary wing aircraft. Analytical, numerical, experimental, and hybrid (includes analytical and experimental or numerical and experimental) analysis are considered. This review does not consider flapping wings, flexible wings, and aeroelastic tailoring. The research papers are categorized according to the morphing degrees of freedom considered and the theme they fit. The tools and software used are also presented and discussed. Section 2 of the paper presents the aeroelastic studies conducted on different morphing wings. It also presents discussions and observations for each degree of freedom. Section 3 presents generic aeroelastic frameworks developed for morphing aircraft applications. In Section 4, main challenges are identified and major trends are highlighted. Finally, Section 5 presents the conclusions and highlights future trends. 


\section{Literature Review}

As stressed before, research activities are categorized according to the morphing degrees of freedom: Planform, Out-of-plane, and Airfoil.

\subsection{Planform Morphing}

Wing planform alteration includes changes in span, sweep, and chord.

\subsubsection{Span}

Aircraft with large wingspans have extended range/endurance but lack maneuverability and experience a larger root bending moments. In contrast, aircraft with a small wingspans are maneuverable and agile, but have limited range/endurance [5]. Variable wingspan combines the benefits of both large and small wingspans into a single aircraft, making span morphing an emerging technology that is attractive for multi-mission UAVs. Studies in the literature have adopted span morphing for enhanced flight performance, roll control, and flutter suppression [40, 41]. Variable wingspan technologies are usually associated with large changes in the inertia, elastic and aerodynamic forces. Therefore, studying their aeroelastic behavior is vital for their maturity. Figure 3 shows a number of aircraft with span morphing wing that have been built and flown in past. It is apparent that the majority of aircraft equipped with span morphing, that has been built recently, are small size UAVs.

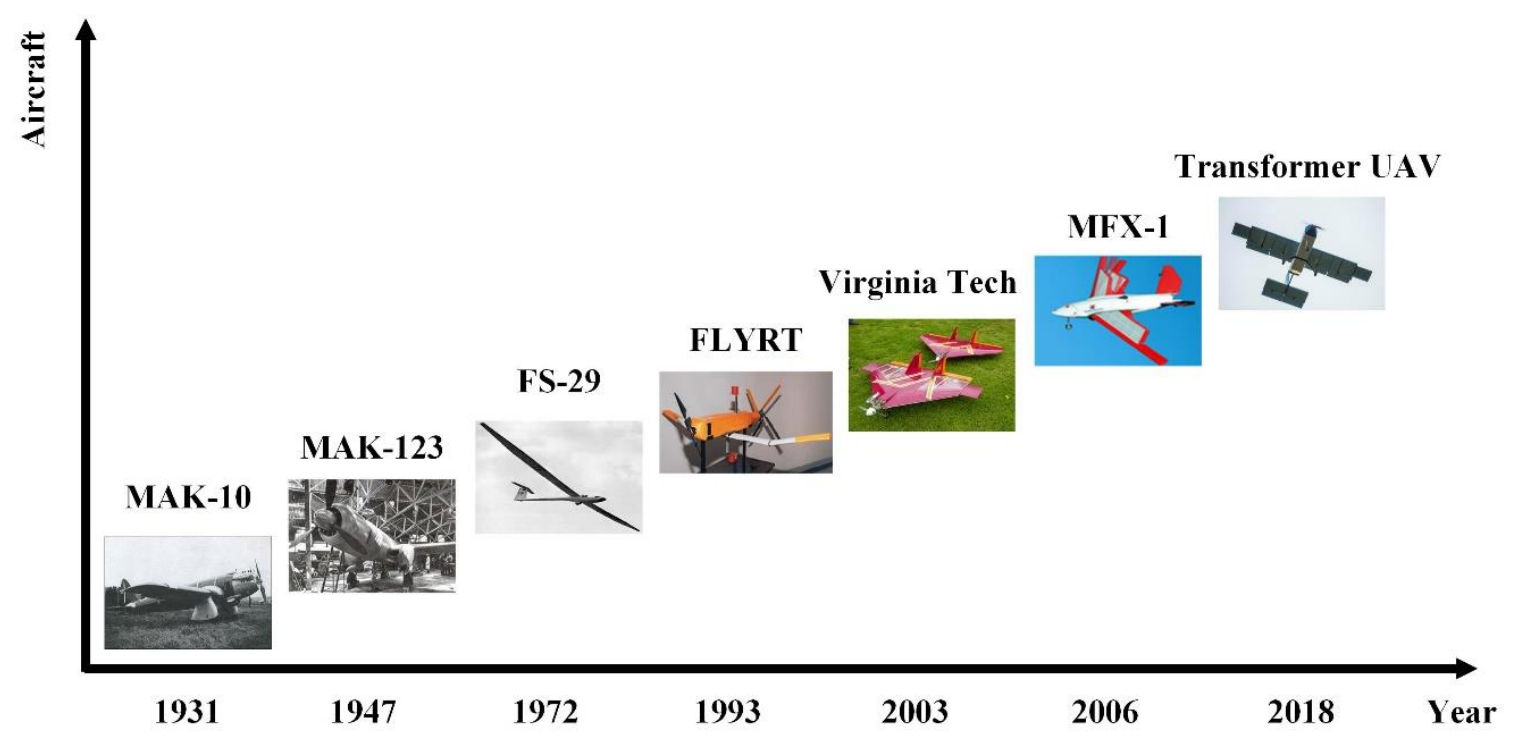

Figure 3. Aircraft equipped with span morphing wings. 


\subsubsection{Aeroelastic stability}

Huang et al. [42] presented an aeroelastic formulation with the inclusion of rigid-body motion and a flutter analysis. Quasi-static modeling was used to develop an aeroelastic equation for a span morphing wing, involving the rigid-body motion by combining unsteady strip aerodynamic theory with Euler-Bernoulli beam theory. The wing was modeled as a three-segment Euler-Bernoulli beam. The results showed that as the span increases the flutter mechanism varies from a bendingtorsional flutter to body-freedom flutter, where the rigid body motion coupled with the wing bending motion [43-45]. In addition, the flutter speed decreased as the span increased. Similarly, Huang and Qiu [46] developed a novel first-order state-space aeroelastic model to study the transient aeroelastic and flutter characteristics of a variable span wing during morphing. EulerBernoulli beam theory with time-dependent boundary conditions was used to establish a timevarying structural model of the wing. The reduced-order unsteady vortex-lattice method (UVLM) was used to calculate the aerodynamic forces. The effect of morphing speed and wingspan on the aeroelastic behavior was investigated. The results showed that the critical flutter speed is very sensitive to the span. During span extension, the flutter speed increased with increasing morphing rate and decreased during the retraction process. Moreover, the transient aeroelastic response analysis showed that morphing technology enhances the flight quality by flutter control. Gamboa et al. [47] conducted a numerical aeroelastic analysis of a variable span morphing wing on a small UAV. The study aimed to estimate the flutter critical speed as well as determine the mode shapes and frequencies of natural vibration. The model was developed using ANSYS Structural APDL. Three-dimensional lifting surface strip theory, together with the unsteady linearized potential theory, were used to compute the flutter critical speed. The results showed that the loss of rigidity in the overlapping section had a negative effect on the critical flutter speed. However, the flutter analysis highlighted the safe operation of the variable span morphing wing within the intended speed envelope, since the critical flutter condition is well above the maximum flight speed. In addition, Murugan et al. [48] investigated the aeroelastic stability of a span morphing wing by deriving an analytical aeroelastic model. Parametric variations introduced by a span morphing wing were considered when deriving the structural and aeroelastic models. Thin airfoil theory and CFD were used for the dynamic aeroelastic stability analysis. The results from the CFD analysis showed that the lift increased nonlinearly both during and after morphing. The flutter analysis results showed a significant reduction in flutter velocity during the morphing process, due to changes in flow after the morphing period and also as a result of elastic, inertial and aerodynamic variations.

\subsubsection{Aeroelastic control}

Ajaj and Friswell [40] developed a time-domain aeroelastic model to study the behavior of rectangular uniform, cantilever compliant span morphing wings using the Rayleigh-Ritz method. The aerodynamic loads on the wing were estimated using Theodorsen's unsteady aerodynamic theory. Theodorsen's unsteady aerodynamics can be expressed as: 


$$
\begin{gathered}
L^{\prime}=\pi \rho \frac{c^{2}}{4}\left[-\ddot{w}+V \dot{\theta}-\hat{a} \frac{c}{2} \ddot{\theta}\right]+2 \pi \rho V \frac{c}{2} C(k) \times\left[-\dot{w}+V \theta+\frac{c}{2}\left(\frac{1}{2}-\hat{a}\right) \dot{\theta}\right] \\
M_{e a}^{\prime}=L^{\prime}\left[\frac{c}{4}+\frac{\hat{a} c}{2}\right]+\pi \rho \frac{c^{3}}{8}\left[\frac{\ddot{w}}{2}-V \dot{\theta}-\frac{c}{2}\left(\frac{1}{8}-\frac{\hat{a}}{2}\right) \ddot{\theta}\right]
\end{gathered}
$$

where $L^{\prime}$ is lift per unit span, $M_{e a}^{\prime}$ is unsteady pitching moment around the elastic axis per unit span, $c$ is the chord of the wing at any location, $\hat{a}$ is the normalized pitch axis location with respect to half the chord, $C(k)$ is the frequency dependent Theodorsen's function that accounts for attenuation of lift amplitude and phase lag in lift response due to sinusoidal motion and $w$ and $\theta$ are the plunge displacements and pitch displacements at any spanwise locations respectively. The influence of actuation rate, mass per unit span and the bending and torsional rigidity on the flutter of span morphing wings were investigated. Finally, comparisons between two different span morphing wings concepts (Zigzag wingbox [49] and GNATSpar wing [50] shown in Figure 4) were performed. The results showed that the Zigzag wingbox concept was more promising than the GNATSpar wing for flutter suppression. Moreover, they concluded that even though flutter suppression can be achieved by span morphing, it is very much dependent on the morphing mechanism employed.

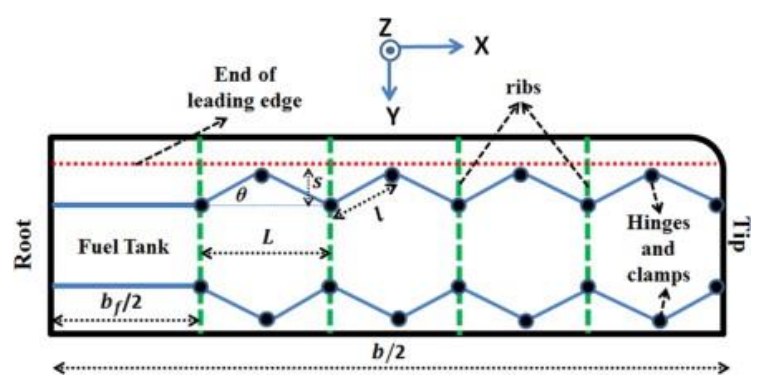

a. The Zigzag wingbox [49].

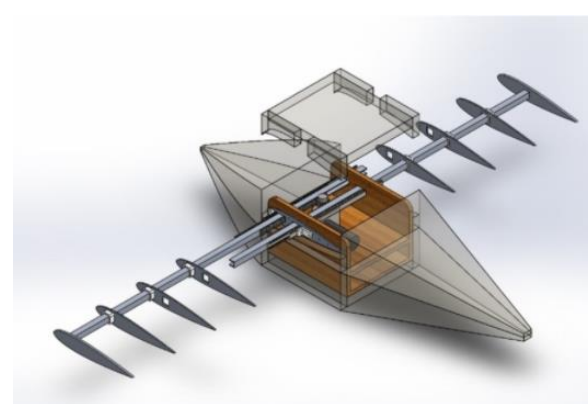

b. The GNATSpar wing [50].

Figure 4. Span morphing concepts considered in [40].

Furthermore, Ajaj et al. [41] investigated the aeroelastic behavior of multi-segment (threesegments), telescopic span morphing wings, by simplifying the wing as a linear cantilever EulerBernoulli beam. The Rayleigh-Ritz method was used to derive the shape functions to model the spanwise-out-of-plane bending and the torsion response. The estimation of aerodynamic loading was conducted using Theodorsen's unsteady aerodynamic theory. The effect of the extending segment and the overlapping segment on the aeroelastic behavior of the wing was investigated. The results showed that the extending segment has a significant effect on the aeroelastic behavior of the wing. Finally, the feasibility of span morphing for flutter suppression was investigated. Similarly, Li and Jinn [51] used numerical techniques to study the dynamic behavior and stability of a variable span wing subject to supersonic aerodynamic loads. The wing was considered to be an axially moving cantilever plate and the equations of motion were derived using Kane's method and piston theory. A morphing strategy was proposed to suppress the flutter that occured beyond the critical span length, by assuming that the span length varies periodically around a mean value. 
Flutter stability was verified by Floquet theory. Moreover, transient stability during morphing was analyzed. The results showed that the critical speed for flutter decreased at larger span lengths and increased with growing deploying rates due to the increased rigidity of the wing. They concluded that varying the span length periodically with proper amplitude could enhance the flight quality of the morphing vehicle.

\subsubsection{Observations}

There seems to be a balance between the studies that addressed aeroelastic stability and aeroelastic control themes. For both themes, the majority of the papers are either analytical and/or numerical and there is lack of experimental studies. The studies under both the themes used linear isotropic beam elements for structural analysis of general and UAV wings combined with aerodynamic loads from either CFD analysis or theoretical unsteady aerodynamic theories under subsonic conditions. Only one study, under the control theme, used linear plate formulation combined with piston theory for supersonic condition. None of the studies addressed the flight dynamics aspects associated with span morphing. Furthermore, it is highly likely that as the wing span increases, the effect of geometrical and aerodynamic nonlinearities become significant. None of the papers in literature has accounted for such nonlinearities. Another aspect of concern is when a failure happens in the span morphing mechanism, since the stiffness of the wing would change to some extent, and therefore might be prone to instability. In terms of the safety, this could be very dangerous, especially if a catastrophic failure occurs in the system. Table 1 summaries the studies on the aeroelasticity of span morphing wings.

\subsubsection{Chord}

On conventional fixed-wing aircraft, chord change is usually achieved using leading/trailing edge-flaps which are actuated by screw systems. Chord morphing can replace or augment the performance of conventional high lift devices. Increasing the chord increases the wing area and consequently increases the lift [52]. It is likely that the Bakshaev LIG-7 designed by the USSR in 1937 was the first aircraft capable of increasing its chord. Chord extension on this aircraft was achieved during the take-off and landing by extending six chord wing sections from the fuselage to $2 / 3$ of the wingspan [3].

Chord morphing is not popular on fixed-wing aircraft due to the presence of fuel tanks, spar and other components which present structural complexity. It appears that there is a lack of aeroelastic studies that involves chord morphing on fixed-wing aircraft in the last decade. In contrast, chord morphing has been utilized significantly for rotary wing applications [5]. This is mainly because the blades of rotary wings have a single D-spar and a honeycomb filler; hence, it is much easier to add chord morphing on rotary wings. For rotary wing aircraft, chord morphing allows an increase in the altitude and maximum speed whilst reducing the required power from the main rotor near envelope boundaries [53-57]. It has been observed that the frequency and amount of actuation are the most important factors affecting the performance of the system [54- 
57]. Figure 5 shows an experimental prototype of chord section used for a morphing rotor blade developed by Barbarino et al.[55]. The concept consist of a cellular structure which allows chord morphing using variation in the centrifugal force caused by change in rotor RPM.

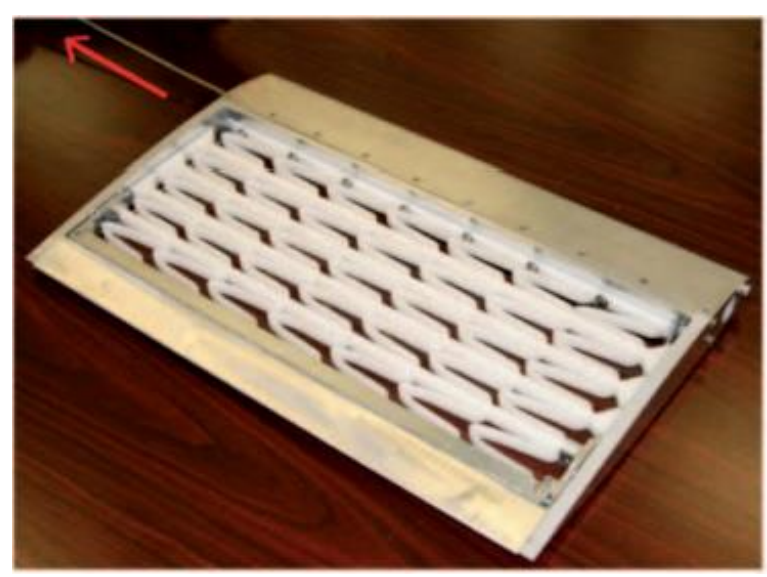

(a) Before chord extension.

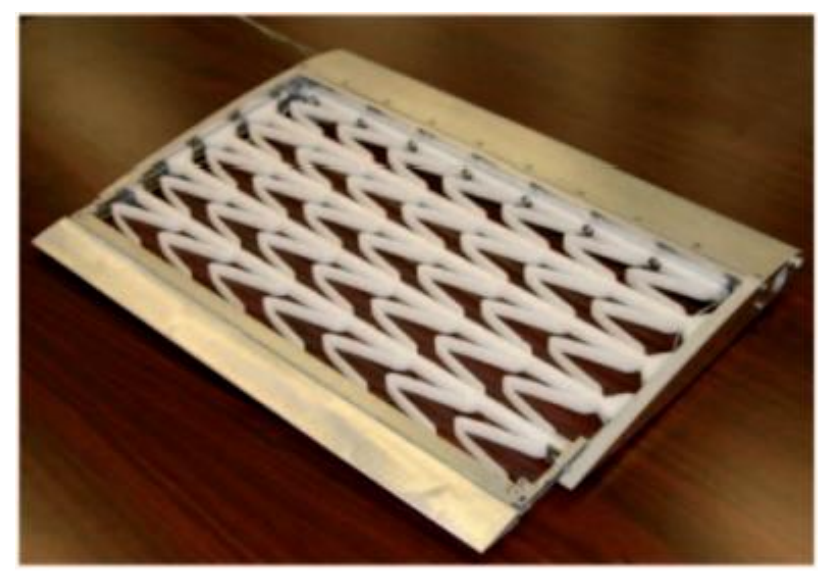

(b) After chord extension.

Figure 5. Chord morphing prototype for a helicopter rotor blade [55].

\subsubsection{Observations}

As stressed earlier, this paper focuses on fixed-wing aircraft applications, therefore studies on chord morphing for rotary wings are highlighted in Table 2 for the sake of completeness, but are not discussed thoroughly. All studies cited here aimed to reduce the power requirement in the main rotor and didn't contribute to any of the aeroelastic themes. Therefore, the aeroelastic investigation of the blade is something that needs to be studied in detail. The majority of the studies were numerical and they used beam model for structural modelling. The aerodynamic forces were mainly calculated using unsteady aerodynamic theories combined with air tables or CFD. One of the studies [55] coupled numerical simulations with experiments to investigate the functionality of the chord morphing prototype for a helicopter blade. Also, in all studies in the literature, chord extension was analyzed in forward flight, while the aircraft might face different maneuvers and environmental conditions. Moreover, the blade was considered to be isotropic, while blades are normally made from composite materials with various types of elastic couplings. Such couplings can be very important and must be modelled and considered. Advanced helicopter blades also have tip devices to reduce noise and vibration levels. Therefore, it would be interesting to establish what the effect of chord morphing would be on the stability, noise, and vibration of rotating blades. 


\subsubsection{Sweep}

Sweep morphing extends the operational margin of an aircraft by allowing it to adapt its wing geometry for low speed (for takeoff and landing) and high speed (fast cruise or supersonic capability) flight phases. Sweep morphing changes the aspect ratio, and wing area, hence alters the aerodynamic forces. The aerodynamic center and the center of gravity changes with sweep angle, which affects the longitudinal stability of the airplane. The sweep angle also affects the lateral stability and increases the dihedral effect [58-60]. In addition, the lift curve slope decreases as sweep increases. Wing sweep delays the drag rise at Mach numbers close to unity [5]. In fact, sweep morphing has been implemented on real-life fixed-wing aircraft more than any other morphing degree of freedom. The first aircraft equipped with sweep morphing was the Bell X-5, which was flown in 1951. It was adapted from the Messerschmitt P-1101 [61] and used a jackscrew assembly for the actuation. The sweep mechanism for this aircraft was ineffective and led to uncontrollable spins at stall speed. The wing was swept and translated forward simultaneously to control the position of the aerodynamic center [60]. Sweep morphing wings became viable in mid1950s when the NASA Langley Research Center developed a system with pivots outboard of the fuselage [62]. Many military aircraft in the 1960s and 1970s used a sweep morphing mechanism, including the F-111, the Northrop Grumman F-14, the Tupolev Tu-160 Blackjack, the Su-24, the Sukhoi Su-22, the Mikoyan Mig-23, and the Panavia Tornado [5]. Due to their significant impact on the center of gravity, aerodynamic center, stall behavior, and bending-torsion coupling, it is clearly vital to study the aeroelasticity of sweep morphing wings. Figure 6 shows the F-111 Aardvark aircraft at different sweep angles.

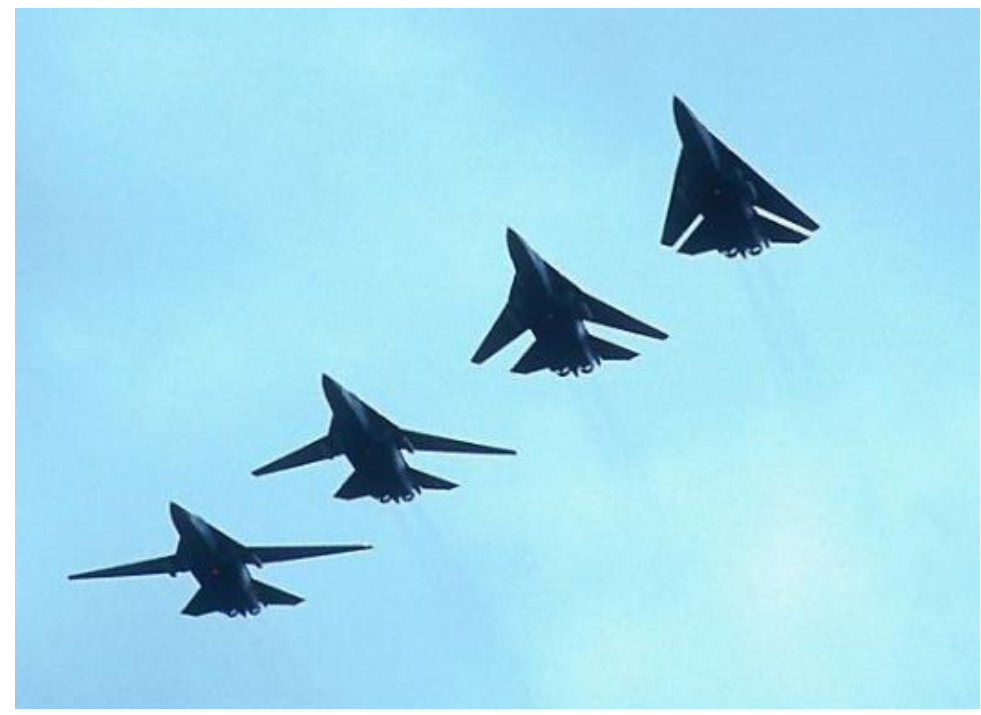

Figure 6. F-111 Aardvark aircraft flying at different sweep angles.

Similar to chord morphing, very little research has been done on the aeroelasticity of sweep morphing during the last decade. The most reasonable justification is that morphing applications are focusing more on small-scale UAVs that usually fly at low-subsonic speeds where sweep 
morphing doesn't provide major benefits. For small-scale UAVs, sweep morphing has been used to increase agility during strike missions and for flight control through asymmetric morphing.

\subsubsection{Aeroelastic stability}

Sabri and Meguid [63] conducted a flutter analysis of a previously developed sweep morphing wing $[64,65]$ for different morphing configurations at low speed. The unsteady aerodynamic forces and moments were estimated using a 2D strip theory model and the structural dynamics of the wing were obtained using the lumped mass method. The PK method was used to predict the flutter boundary. The results showed that the designed morphing wing increased the critical flutter velocity. Moreover, model predictions indicated that the morphing configurations increased the aeroelastic stability of the UAV. In addition, Hui et al. [66] designed a bio-inspired morphing discrete wing that can morph into different swept wing configurations. The wing was designed with bionic feathers that were inspired from a pigeon's wing structure aimed to improve the aerodynamic performance of a UAV. They considered two morphing states: fully extended and fully folded symmetrical morphing states. The morphing actuation system consisted of a driving pulley, a driven pulley, an elastic belt, and a servo motor mounted at the wing root of the half-span rectangular wing. For the aerodynamic analysis an open-source code, CFL3D was used. Windtunnel experiments were carried out to investigate the aerodynamic performance of the morphing wing. The results showed that the developed morphing UAV always maintain an optimal lift-todrag ratio at three different Reynolds numbers utilizing the symmetrical wing morphing. A smallamplitude fluttering phenomenon was observed at Re of 187000 in both the fully folded and fully extended cases.

\subsubsection{Observations}

All the studies belong to the aeroelastic stability theme. Both numerical analysis and experimental testing were performed. The isotropic, Euler-Bernoulli formulation was used for structural analysis whilst unsteady Theodorsen's theory and CFD were used for aerodynamic analysis. The experimental aeroelastic studies were limited to wind-tunnel testing only. All the studies associated with the aeroelasticity of sweep morphing focused on small-scale UAVs flying at low subsonic speeds. Table 3 gives a summary of studies on the aeroelasticity of sweep morphing wings.

\subsection{Out-of-plane Morphing}

Out-of-plane morphing includes twist morphing and dihedral/gull/ folding wingtips/spanwise bending.

\subsubsection{Twist}

Twist morphing, considered the oldest form of morphing, was implemented on the Wright Brothers Flier for roll control. For almost 80 years, twist morphing was avoided, due to various aeroelastic problems, however recently it has received attention, due to advances in aerospace materials. Changing the twist distribution of a wing allows an improved flight performance and enhanced control authority. Aircraft designers have focused on using the structural flexibility 
favorably to avoid aeroelastic instabilities. Unlike variable sweep and span, twist morphing can have a significant impact on the aerodynamic characteristics of the wing, without large platform modifications. Moreover, twist morphing can increase the lift coefficient, alleviate gust and maneuver loads and reduce drag significantly. In addition, twist is a more robust strategy for roll control than ailerons [67]. However, it has been shown that the twist of the structure also affects the dynamics of the wing or blade [68]. Various actuation methods and systems have been studied to achieve twist morphing, such as shape memory alloys (SMA), piezoelectric stacks, and active aeroelastic structures [5]. Barbarino et al. [5] concluded that twist morphing has been mainly applied to fixed-wing aircraft, especially in fighters. Figure 7 shows a composite cellular material morphing wing capable of twisting developed by Benjamin et al. [69].

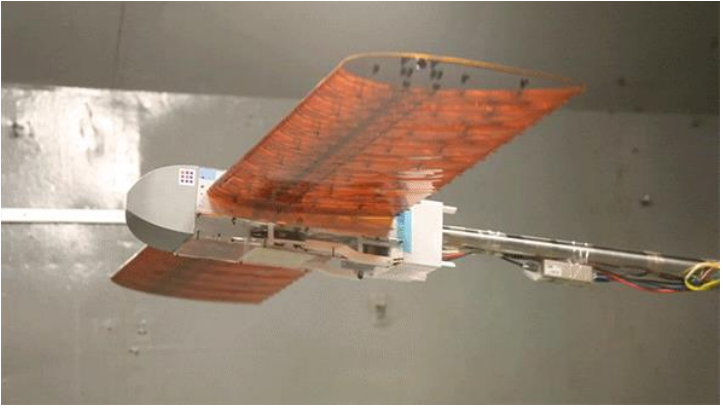

(a) At zero tip twist.

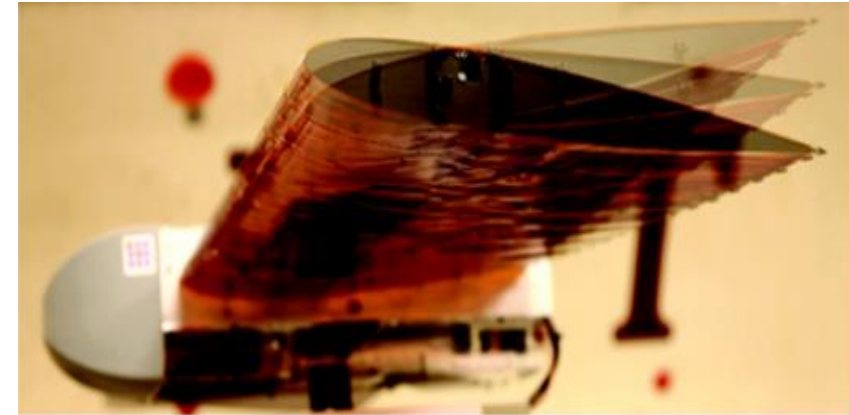

(b) At $\pm 10^{\circ}$ tip twist.

Figure 7. The composite cellular material morphing wing [69].

\subsubsection{Aeroelastic stability}

In the last decade, a reasonable number of papers studied the aeroelasticity of twist morphing on fixed-wing aircraft. For example, Cramer et al. [70] introduced a lattice-based, ultralight, and conformable heterogeneous aeroelastic structure, which allowed for aeroelastic shape deformation when subjected to external loading. They studied passive twist morphing induced by aerodynamic loads and active twist morphing using a torque rod actuation mechanism. The structure consisted of a cuboctahedral lattice based on an octahedral unit cell manufactured using polyetherimide (PEI) material. The substructure, using octahedral unit cells, was modeled using Rhino 3D CAD software. The pressure distribution over the airfoil was determined using XFOIL. The aerodynamic loads were applied on the structural using ABAQUS software. They conducted experimental study where they tested the wing in a subsonic wind-tunnel at the NASA Langley Research Center. The wind-tunnel tests showed that the lift-to-drag ratio of the heterogeneous structure increased when compared to a homogeneous baseline structure. The global aeroelastic bending and torsion stiffness were reduced by $46 \%$ and $43 \%$ respectively. Pecora et al. [67] numerically investigated the benefits of roll control of a high aspect ratio wings using twist morphing. The sailplane G103-B was used as the reference aircraft. Finite element (FE) analysis, using MSC.Nastran, was used to develop the structural and aeroelastic models. The vortex lattice method (VLM) was used for aerodynamic modeling. The twist morphing wing was compared to a wing with conventional ailerons. The results showed that the asymptotic roll rate produced by twist morphing is 1.6 times larger than the rate produced by a conventional aileron for linear and quadratic twist distributions along the span. The aeroelastic stability analysis showed that twist morphing is a more robust strategy for roll control than ailerons, in terms of the control reversal 
speed. Similarly, Sleesongsom and Bureerat [71] investigated the aeroelastic and mechanical behavior of a twist morphing wing actuated by external forces. An aeroelastic model of the wing structure was derived. An unswept rectangular wingbox was considered for the demonstration. The aircraft design parameters, buckling factor, lift effectiveness (the ratio of total lift force on a flexible wing to that of its rigid counterpart), divergence, flutter, and stress were computed by applying various actuator moments on the wing. The aeroelastic modeling was carried out using the finite element method (FEM) and the aerodynamic loads were estimated using the Vortex Ring Method. The results showed that the torque for the actuation had a significant impact on the mechanical and aeroelastic behavior of the wing. The lift effectiveness of the unloaded wing increased with a positive moment and decreased with a negative moment. The flutter speed also exhibited the same trend as lift effectiveness. The divergence speed dropped at a higher values of torque and peaked at lower external forces. In addition, Ajaj et al. [72, 73] developed the Adaptive Torsion Wing (ATW) concept to achieve aeroelastic twist by varying the torsional stiffness of a two-spar wingbox. The ATW concept changes the area enclosed between the front and rear span of a two-spar wingbox to modify the torsional stiffness $[74,75]$. A multi-disciplinary optimization suite consisting of a Genetic Algorithm (GA) optimizer coupled with a high-end low-fidelity aerostructural $[76,77]$ was used in this study. The aero-structural model comprised of the Tornado VLM and a FE beam model. They performed quasi-steady aeroelastic studies and that large tip twists can be achieved at large dynamic pressures. Ajaj et al. [78] conducted dynamic aeroelastic studies on the ATW. The aeroelastic model consisted of Theodorsen's unsteady aerodynamics coupled with an Euler-Bernoulli beam model. They estimated the power requirement for shifting the spar webs.. The results showed that shifting the front web was more effective as it induced a larger twist/pitch angle, but with larger actuation requirements. The combined shift of the front and rear web can provide the aeroelastic twist required without exceeding the flutter and divergence boundaries.

\subsubsection{Aeroelastic control}

Silva et al. [79] used a flexural-torsional testbed called a pitch and plunge apparatus (PAPA) for the acceleration reduction in the section of a wing. This was achieved by passive and active model-based control. The passive control system used a shape memory wire in the torsional axis to increase the torsional stiffness. The increased torsional stiffness was achieved by increasing the temperature of the wire through the Joule effect. Active control was achieved by the actuation of servomechanism, and consisted of a stability-augmented system with gain scheduling and output feedback via linear-quadratic regulator theory. The objective of the active control system was to reduce the acceleration of the system in the flutter regime and to maintain stability. To complete this objective, a stability augmented system (SAS) was developed. The aerodynamic loads were estimated for a 2D typical section using Wagner's function-based unsteady time-domain formulation. The results showed that the aeroelastic boundaries were improved by SMA based passive control by significantly changing the torsional stiffness of the system when the SMA wire reached the martensitic transformation temperature. Comparisons between the SAS-based active control and the SMA based passive control showed that the latter was more promising since it didn't change the flow characteristics, thus it didn't the drag and was less intrusive. In addition, Guo et al. [80] studied load alleviation and the gust response of a 200 seater aircraft equipped with a passive twist wingtip (PTWT). FEM was used for structural analysis whilst doublet lattice method (DLM) was used aerodynamic analysis. The dynamic response analysis to discrete (one- 
cosine) gusts was also performed. The results showed that the PTWT reduced the wing root bending moment by $14 \%$ and gust-induced wingtip deflection by $21 \%$ in the most critical flight phases, This highlighted the effectiveness of PTWT in gust alleviation. Furthermore, they concluded that PTWT did not have a significant influence on heave motion and normal velocity. Finally, the PTWT reduced the rolling control effectiveness via reducing the rolling moment by $20.5 \%$.

\subsubsection{Observations}

The studies on the aeroelasticity of twist morphing belong to both themes with the majority of the studies dedicated for aeroelastic stability. Most of the studies were numerical simulations of UAVs, general wings, or HALE aircraft. FE software were used for structural analysis and the DLM, VLM, XFOIL or unsteady aerodynamics were used for aerodynamic prediction under subsonic speeds. It should be noted that under the aeroelastic control theme, some studies [79] performed both experimental and numerical analysis. Although some of the studies achieved large twist angles, the effect of aerodynamic nonlinearities was neglected. Failure modes associated with some of the passive concepts (such as the PTWT [80]) and their impacts on the aeroelastic behavior/stability were not addressed. Table 4 gives a summary of studies on the aeroelasticity of twist morphing wings.

\subsubsection{Dihedral/Gull/Folding Wingtips/Spanwise bending}

Dihedral morphing, which includes dihedral, gull, folding wingtips and spanwise bending, has been used for a number of purposes such as drag reduction (through vorticity distribution), improved stall characteristics, replacing/augmenting conventional control surfaces, controlling wingspan, aircraft storage in confined spaces, and enhancing agility and maneuverability. One of the first applications of variable dihedral wings was the IS-1 fighter, designed by NikitinShevchenko in 1932, capable of out-of-plane morphing from a biplane to a monoplane to operate at high speed [5]. Similarly, folding wings have been used on naval aircraft such as the de Havilland Sea Vixen and Boeing F/A18 fighters to allow storage in confined spaces on aircraft carriers. Recently, the Boeing B777x aircraft has adopted folding wingtips to achieve a larger wingspan during flight for enhanced flight performance. The folding wingtip capability allows the B777x to access standard $65 \mathrm{~m}$ airport gates. Similarly, Airbus envisions folding wingtips as a promising technology for drag reduction by enabling larger wingspan and for loads alleviation through using a flared-hinge [81]. The review by Barbarino et al. [5] in 2011 showed that dihedral morphing has been mainly implemented on UAVs. However recently, folding wingtips have been utilized on large transport aircraft for storage and loads alleviation purposes. Wilson et al. [81] presented a summary of published aeroelastic studies on hinged wingtips up to 2016.

\subsubsection{Aeroelastic stability}

$\mathrm{Ni}$ et al. [82] presented a time-varying aeroelastic state-space equation to study the transient aeroelastic behavior of a folding wing during morphing. MSC.Nastran was used for structural modelling. The wing was assumed to be made from aluminum plates. The DLM was used to obtain the aerodynamic forces. The Runge-Kutta numerical integration technique was used to solve the equations of motion and predict the transient aeroelastic response. The impact of flow velocity, aerodynamic forces and morphing velocity/rate on the aeroelastic performance were studied. The 
results showed that the aerodynamic forces play a positive role in the morphing motion. The reaction moment decreased with increasing the flow velocity and decreasing morphing velocity. They concluded that neither morphing velocity/rate nor the flow velocity had a significant effect on the reaction moment. On the other hand, $\mathrm{Li}$ et al. [83] derived the aeroelastic equations for a folding wing with structural nonlinearity. The nonlinear free-play structural dynamic equation was obtained by free interface component mode synthesis in which the nonlinear internal force was considered and continuity at the interfaces was modified. The unsteady aerodynamic rational function approximation and the Runge-Kutta method were used to derive the nonlinear aeroelastic equations. The DLM was used to predict the aerodynamic forces. For the folding configuration, the aerodynamic model can be formulated by DLM as [84]:

$$
f=q_{\propto} A(\omega) Z
$$

where $q_{\propto}$ is dynamic pressure, $\omega$ is oscillating frequency, $A(\omega)$ is unsteady AIC matrix, $f$ and $Z$ are the force vector and displacement vector for aerodynamic panels respectively. The natural frequency and the flutter boundary estimated using the derived equation were compared with their corresponding values from MSC.Nastran. There was good agreement between the results with an error less than $10 \%$. Hu et al. [85] investigated the aeroelastic characteristics of a folding wing during morphing. The flexible multi-body dynamics approach was used to model the folding wing. The aerodynamic influence coefficient (AIC) matrices were obtained at different folding angles using the DLM. The structural model was built using a flexible multi-body dynamics approach incorporating Craig-Bampton modes. The influence of morphing parameters, morphing rate, and morphing mode (folding and unfolding) on the dynamic aeroelastic stability of the folding wing was studied. The results showed that the dynamic aeroelastic stability of the folding wing was different from the quasi-steady aeroelastic stability. At folding angles slightly greater than $33^{\circ}$, the dynamic aeroelastic stability changed from stable to unstable. The angle at which the dynamic aeroelastic stability flipped was highly sensitive to the folding rate. Zhang et al. [86] proposed an aeroelastic analysis approach to investigate the aeroelastic stability of a folding wing. The structural dynamic equation of the folding wing was derived using a fixed component mode analysis. The DLM was used for the unsteady aerodynamic model. The aeroelastic model was achieved by the integration of component mode analysis with the DLM. The Gramian matrix in control theory was used to investigate the aeroelastic stability of the folding wing. The proposed method was verified by comparing it with traditional flutter eigenvalue analysis. The flutter analysis was carried out for a wide range of folding angles, which was modeled using MSC.Nastran. The results showed that the flutter velocity was very sensitive to the folding angle since it had a significant effect on both the aerodynamic and structural characteristics. As the folding angle increased, there was a transition between unstable modes. Higher model structural damping improved the flutter boundary to some extent. The Gramian matrix allowed the determination of the unstable modes with the largest contribution to the velocity and flutter mechanism. Similarly, Verstraete et al. [87] developed a methodology to investigate the unsteady nonlinear aeroelastic behavior of a folding wing concept in different flight configurations. The methodology was based on the co-simulation scheme in which the dynamic system is split into structural and aerodynamic models. The aerodynamic model was based on the UVLM and the structural model was based on an FEM. The fourth-order predictor-corrector method developed by Hamming [88] was used to integrate the aerodynamic and structural equations. The results 
showed that while changing from one stable configuration to another, morphing aerial vehicles could experience flutter and this can be avoided by varying the airspeed during the morphing process. Moreover, a decrease in the flutter speed was observed when the dihedral angle increased until it reached an angle of $30^{\circ}$.

Zhao et al. [89] developed a parameterized aeroelastic model to investigate the flutter characteristics of a folding wing with different configurations. A simple aeroelastic model was developed by coupling a parameterized structural model (established using substructure synthesis) with DLM. MSC.Nastran was used to verify the accuracy and robustness of the developed aeroelastic model. The flutter characteristics of the folding wing were predicted using the developed model. The results showed that due to the pronounced effects on the aerodynamic and structural characteristics, the critical flutter speed of the folding wing was very sensitive to the folding angle. The transition between unstable modes could occur as the folding angle increased. Moreover, Zhao and $\mathrm{Hu}$ [90] developed a set of differential algebraic structural equations using a floating frame approach that governed the time evolution of the folding wing during the morphing process. The transient responses of the wing during the morphing process was computed using established equations. By integrating the developed equations with CFD, the transient aeroelastic analysis of the morphing wing was investigated. The developed equations can be applied to both the fast and slow varying processes of wing folding. The transient response of a flexible wingwas compared with the rigid wing. The results showed that without considering the gravity effect the transient response of the flexible system was oscillating about the rigid-body motion trajectories. On the other hand, a larger transient response was observed when gravity effects were considered. Liska and Dowell [91] developed effective theoretical and computational methods to find the flutter solutions of a folding-wing configuration through coupled structural and aerodynamic models. The flutter and divergence instabilities were identified from the developed model. The frequency and damping were determined at different fold angles and freestream velocities using an exact method that was free from dynamic approximations and spatial discretization. Linear elastic beam theory was used to describe the dynamic behavior of the wing. Three different aerodynamic models (based on strip theory) were considered: steady, quasi-steady and unsteady linear aerodynamic models. The results showed that for a much smaller fold angle, the steady and quasi-steady models caused a change in the flutter model compared with the unsteady model. For the unsteady model, an increase in the fold angle lowered the flutter speed initially, yet flutter did not monotonically decrease. Matthew et al. [92] investigated the aeroelastic characteristics of a folding wing that enabled wing area changes of up to $200 \%$. The sensitivity of natural frequencies and flutter instabilities to actuator stiffness, fold angle, and vehicle weight were investigated using the FE approach. DLM was used for aerodynamic modeling. The results showed strong interrelationships between hinge stiffness, weight of the morphing vehicle, and fold angle. The modal analysis showed that the hinge stiffness had a significant influence on the bending modes. The unfolded configuration bending modes became similar to the traditional wings when the hinge stiffness was increased above the structural stiffness. For higher spring stiffness at high fold angles, the bending modes were primary functions of the structural stiffness. The body freedom flutter may be an influencing factor when the vehicle approached its empty weight. Body freedom flutter became the dominant flutter mode at 90 degrees' fold angle for all configurations. At higher 
stiffness, as the wing fold angle increased past 90 degrees, the flutter mode changed to inner wing torsion. Attar et al. [93] computationally modeled a folding wing structure using a 3D vortex lattice aerodynamic model with a planar wake assumption and an exact tangent flow boundary condition. A geometrically-nonlinear structural dynamics theory based on von Karman strains was used. A discrete Ritz-basis derived from FE analysis and component mode synthesis was used to discretize the structural dynamic equations of motion in space. The computational results were compared with the results from wind-tunnel experiments designed and tested at Duke University for three folding configurations. The computational results showed that for each folding configuration, the limit cycle oscillations were found at flow velocities greater than the linear flutter velocity and this result was in agreement with the experiment. Over the range of velocities tested, the theoretical and experimental limit cycle oscillation curves for the inboard wing showed limited nonlinear stiffening with flow velocity. Three different folding angles were considered for the outboard wing: 0, 30 and 60 degrees. For 0 and 30 degrees folding angles, the theoretical model predicted a similar limit cycle tip displacement for the outboard wing and at a 60-degrees angle significantly smaller limit cycle amplitudes were observed. Wang et al. [94] developed an aeroelastic model for the prediction of the flutter speed and frequency for a folding wing with an arbitrary number of wing segments and a simplified geometry. The strip-theory unsteady aerodynamic model was coupled with beam model. Three experimental models were constructed to study two-segment, three-segment, and four-segment folding wings. The wing segments were connected using torsional springs manufactured from sheet steel. Wind-tunnel testing was conducted at Duke University and flutter tests were conducted for different fold angles. The results showed that for most configurations, the theoretically predicted flutter speeds were within $10 \%$ of the experimentally measured values. Moreover, there was a $30 \%$ increase in the flutter speed upon increasing the folding angle.

In addition, Cooper et al. [95] proposed a wingtip for Regional Jet aircraft. The concept was based on a chiral type internal structure, enabling controlled cant angle orientation, camber and twist through the flight envelop. A turbofan aircraft configuration model was considered as the baseline aircraft. The aerodynamic analysis was performed using VCFlite3D CFD code and DLM. The structural analysis was carried out by FE analysis using Nastran. The study showed that the chiral structure can facilitate the required shape changes in camber, twist, and cant. Moreover, the wingtip device could provide $2 \%$ fuel saving. A similar reduction in weight due to passive gust loads alleviation was also possible with a slight change of configuration. Mardanpour and Hodges [96] modeled the wing of the HALE aircraft with three beams using lockable hinge connections. The wing was morphed to a " $Z$ " configuration for maximum energy absorption. To analyze aeroelastic trim and stability, a computer program, NATASHA, based on a finite-state induced flow model and geometrically exact, fully intrinsic beam equations was used. The results of the stability analysis showed that the aircraft exhibited aeroelastic stability. There were instabilities in the flight dynamic modes with very small non-oscillatory eigenvalues. Jung and Kim [97] conducted a flutter analysis of a folding wing structure using plate element models. Two different plates: aluminum, and composite plate were considered. The effect of fold angle and hinge stiffness were investigated. FEM, using first-order shear deformation theory, was used for structural analysis and DLM was used for aerodynamic analysis. The result showed that the flutter boundaries were sensitive to the fold angles. For some fold angles, the dynamic pressure suddenly 
decreased or increased when the flutter mode altered. In addition, the hinge stiffness affected flutter stability behavior significantly. de Breuker et al. [98] presented a nonlinear aeroelastic model for a morphing winglet that achieve morphing by three discrete modes of morphing deformations: folding, shearing and twisting. The aeroelastic model consisted of Weissinger's method based high-subsonic aerodynamic model with Prandlt-Glauret correction and a corotational beam element model that accounted for geometric nonlinearities. The aforementioned code was embedded on a gradient-based optimization routine to optimize the winglet which was retrofitted to a regional airliner. The aim of the optimizer was to reduce the drag over entire flight of the airliner. The results were compared with an optimized fixed winglet. The study showed the energy consumption of morphing winglet was reduced by a factor of two when compared with the fixed winglet. The morphing winglet could reduce the drag and limit the root bending moment by folding the winglet downwards and creating a washout angle over the winglet.

\subsubsection{Aeroelastic control}

Liausun et al. [99] conducted a preliminary study to determine the aeroelastic behavior and load control of four different morphing winglet concepts: a flapping winglet, a winglet capable of rotating around an axis along its span, a winglet whose deformation in torsion was controllable, and a winglet equipped with a trailing edge flap. They developed fast and accurate aeroelastic models that account for structural dynamics, aerodynamics, and flight mechanics. The models were developed from the rational function approximation of the Roger's formulation based aerodynamic forces and structural reduction. The developed models were validated using highfidelity fluid-structure (CFD-CSM) coupled simulations. The results showed that the winglet equipped with a trailing edge was the most suitable concept in terms of load control, especially when used in conjunction with the aileron. This concept yielded a significant efficiency but had a weaker impact on drag. Fonte et al. [100] investigated the load alleviation of an aircraft wing with active morphing winglets in maneuvering conditions through nonlinear simulations. The active winglet was equipped with two independent control surfaces with variable camber and differential settings capability. The control surface on the winglets provided an MLA capability. The mechanical system was capable of facing different flight static and dynamic situations by proper control of the movable control tabs on the winglets. The load reduction on the wing and winglets using the control tabs was investigated through a static aeroelastic analysis, using a feedforward MLA controller. To evaluate the ability to cope with the expected morphing aero-shapes and complete system performance, an electro-mechanical Matlab/Simulink model of the actuation architecture was used. Symmetric and asymmetric maneuvers achieved by the sudden deflection of the control surfaces were evaluated using the developed aeroelastic model combined with a nonlinear simulator. The aerodynamic computations were performed by DLM. The results showed that the proposed mechanical system was capable of wing load alleviation in different flight conditions without compromising the aerodynamic efficiency. The MLA controller reduced the structural loads even though it resulted in a reduction in the ailerons' roll effectiveness. Noviello et al. [101] investigated the influence of the combined use of morphing winglets and adaptive flap tabs on the aeroelastic stability of a regional aircraft. The combined use of morphing winglets and adaptive flap tabs improved the aerodynamic performance in climb and cruise conditions by $6 \%$. The flutter and divergence characteristics of the wing equipped with winglets and adaptive flap tabs were assessed. The static and dynamic aeroelastic stability were investigated by a multiparametric flutter analysis in compliance with CS-25 airworthiness requirements. The proposed 
kinematic systems were characterized by movable surfaces and integrated with an ElectroMechanical Actuation (EMA) based actuation system. For that purpose, the sensitivity analysis was performed using MSC.Nastran based computations. This was accomplished by considering the variations of inertial properties and the stiffness of the referred architecture. The SANDY 4.0 code was used to solve the aeroelastic stability equations and to generate the aero-structural model. The results showed that the crucial flutter modes could be resolved using a mass balancing procedure and were independent of the actuation line stiffness. A second trade-off flutter analysis was conducted by considering the effect of morphing winglet tabs. The flutter modes arise in all the stiffness and inertial configurations below the safe speed of $200 \mathrm{~m} / \mathrm{s}$. They concluded that proper mass-balancing was required to avoid the flutter instability caused by a combined use of winglets and morphing flaps.

Wilson et al. [81] studied the aeroelastic behavior of zero stiffness (or free hinge) flared hinge folding wingtips on a short-range aircraft. They concluded that this approach can effectively alleviate gust and maneuver loads with an opportunity for weight saving. However, the zero stiffness hinge could cause flutter that can be stabilized by tip masses. The choice of hinge flare and hinge location had a small effect on the bending moment at the wing root. Similarly, Wilson et al. [102] proposed an aircraft comprising a wing with a wingtip device mounted about a hinge at the tip. The wingtip operated as a device for load alleviation during flight by switching between the flight and load alleviating configurations. The aircraft comprised a restraining assembly which could help the wingtip device to adopt the load alleviation configuration by operating between a restraining mode and the releasing mode. In the restraining mode, the wingtip device used a restraining force to fix it in the flight configuration such as power-off brakes. In the releasing mode, the wing tip device could adapt the load alleviation configuration by releasing the restraining force on the wingtip. The study claimed that when the restraining assembly adopted the releasing mode, the onset of the flutter could be delayed. Finally, it was observed that at load alleviation configuration, the lift on the wing in the vicinity of the tip and beyond tip device was reduced during the gust causing a significant reduction in the root bending moment. Cheung et al. [103] investigated the gust load alleviation capability of a hinged folding wingtip device experimentally through static and dynamic tests in a low-speed wind-tunnel. A numerical FEM study using MSC.Nastran was conducted to compare the resulting predictions with wind-tunnel results. The aeroelastic loads were predicted using the DLM within MSC.Nastran. The results showed that gust load alleviation can be achieved by a folding wingtip with a nonzero flare angle. The alleviation of gust loads varied with the lifting condition and the hinge spring stiffness. A 56\% reduction in peak loading was achieved. The steady aerodynamic tests showed that the folding wingtip provided static aerodynamic stability for both the free-hinge and stiff-hinge arrangements. Cheung et al. [104] further investigated gust load alleviation of a flexible high aspect ratio wing with a folding wingtip using a low-speed wind-tunnel equipped with a vertical gust generator through a range of 1-cosine gust inputs. The orientation of the folding hinge axis of the folding tip was 10 degrees from the flow direction. They studied the overall gust load alleviation along with the effect of a non-zero hinge angle and the usage of a wingtip tab. The results showed that using a folding wingtip design reduced the wing-root bending moment by $6 \%$ relative to the lockedhinge for shorter gust lengths and by $11 \%$ during longer gust lengths. Moreover, the wingtip tab 
could control the folding tip orientation effectively in steady aerodynamic conditions and this control surface was able to achieve a further reduction in the peak wing-root bending moment through active control during gust encounters.

Moreover, Castrichini et al. [105] investigated the effect of a folding wingtip as a device to reduce dynamic gust loads. The study was carried out in-flight conditions, with the introduction of a passive nonlinear hinge spring on the folding wingtip for 1-cosine gusts. The nonlinear passive hinge spring allowed the wingtip deflection only at larger load cases. Aeroelastic modeling was carried out on a representative civil jet aircraft using a multi-body simulation code to investigate the effect of such a hinged wingtip on the dynamic load behavior. Aerodynamic modeling was carried out using the DLM and the aeroelastic analysis was carried out using a commercial multibody code LMS Virtual Lab Motion. The results showed that the load alleviation capabilities were influenced by the hinge moment threshold to release the wingtip by the hinge damping value. Low hinge damping with a low threshold hinge moment allowed a rapid deflection of the folding device due to trim loads and positive gust. This caused an increment in the wing root bending moment. Moreover, the increase in the hinge moment threshold of the nonlinear device resulted in higher wing root bending moments and delayed the wingtip rotation. Castrichini et al. [106] also studied the effect of exploiting a passive nonlinear stiffness hinge spring integrated folding wingtips on dynamic gust load reduction in flight. The dynamic gust responses for different hinge device designs was studied using a representative civil jet aircraft aeroelastic model and a singledegree-of-freedom model. The structural model consisted of a rigid stick structural model with lumped masses. Aerodynamic modeling was performed using the DLM. The results obtained were compared with the baseline model without wingtips. The results showed that the nonlinear spring device improved the load alleviation capability compared to a linear device. Also, the nonlinear spring device reduced the incremental wing root bending moments to lower levels relative to the baseline model. It was proven that for a large enough range of deflection angles, significant load alleviation is possible when the system exhibited a low overall stiffness around the trim equilibrium point. The reduction in gust effects that was observed during higher and faster wingtip deflections were a result of the negative stiffness contribution. Furthermore, Castrichini et al. [107] used a folding wingtip in flight as a device to reduce the static and dynamic loads. The investigation was carried out using a civil jet aircraft aeroelastic model, in which the wingtip device was connected to the wing with an elastic hinge. The effect of stiffness, wingtip weight, damping and hinge orientation on the static and dynamic (discrete gust and continuous turbulence) response were studied. The model used to investigate the aeroelastic behavior was the modified Future Fast Aeroelastic Simulation Technologies (FFAST) model of a representative civil jet aircraft. The structure was modeled using a stick model with lumped masses. Aerodynamic modeling was carried out using the DLM. The PK and PKNL methods were used to conduct the flutter analysis. The results from the static analysis showed that the hinge orientation had a significant influence on the response of the model. For the stream-wise hinge case, no-load alleviation effect was observed. At lower wingtip masses and hinge spring stiffness, the greater the hinge angle with respect to the free stream direction, the greater the load alleviation capability, due to a nose down twist of the wingtip. The results showed that a low wingtip mass at hinge angle of $25^{\circ}$ was beneficial for aeroelastic stability, both for fixed and flexible hinges. It was observed that an increase in span of $25 \%$, using the folding wingtip, caused almost no increase in load for the cases considered. In addition, Castrichini et al. [108] investigated the interaction between the aircraft 
flight dynamics and the aeroelastic effect of wingtip and the semi-aeroelastic hinge (SAH). The integrated model of flight dynamics and aeroelasticity in this study was built upon the simplified version of the formulation proposed by Saltari et al. [109]. The DLM was used to model unsteady aerodynamic effects. The results showed that regardless of the $25 \%$ increment in span, the freehinge aircraft had the same dynamic response and handling qualities as the baseline model with no wingtip extension. Therefore, the SAH could be used to alleviate the roll damping increment induced by a longer span and as a load reduction device. Thus enhanced aileron authority could be achieved with a resulting weight reduction with respect to the fixed-hinge aircraft. Wilson et al. [110] developed the AlbatrossONE, a SAH small-scale demonstrator aircraft, and conducted extensive wind-tunnel and flight tests. The AlbatrossONE is a scaled-down short-range aircraft with a fuselage based on Airbus A321 as shown in Figure 8a. Five wingtip configurations with three span lengths were considered: one with no wingtips (2.6 m span), two with locked wingtips (3.2 and $3.7 \mathrm{~m} \mathrm{span}$ ), and two with the wingtips free to rotate about their hinges $(3.2$ and $3.7 \mathrm{~m}$ span). The wing skin was constructed using CFRP stiffened with Rohacell foam. The spar was made of plywood wrapped in CFRP. The mid and outer wings are constructed using titanium by additive manufacturing technique and that was detachable from the inner wing. The wing hinges were also constructed using titanium. Two electric ducted fan motors were used to power the aircraft with a maximum cruised speed of $40 \mathrm{~m} / \mathrm{s}$. The aircraft was equipped with strain gauges and the accelerometers for the flight-testing. The flight tests showed that the wingtips were both statically and dynamically stable. Moreover, the load alleviation capability of wingtips was confirmed from strain gauge measurements. In addition, the near linear variation of flapping frequency of wingtip with airspeed was confirmed by wind-tunnel tests. Figure $8 \mathrm{~b}$ shows the SAH wing installed in wind tunnel.

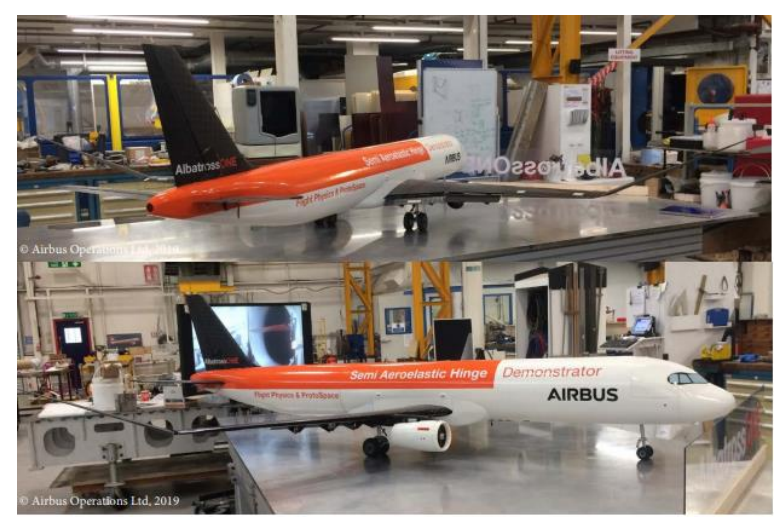

(a) The AlbatrossONE.

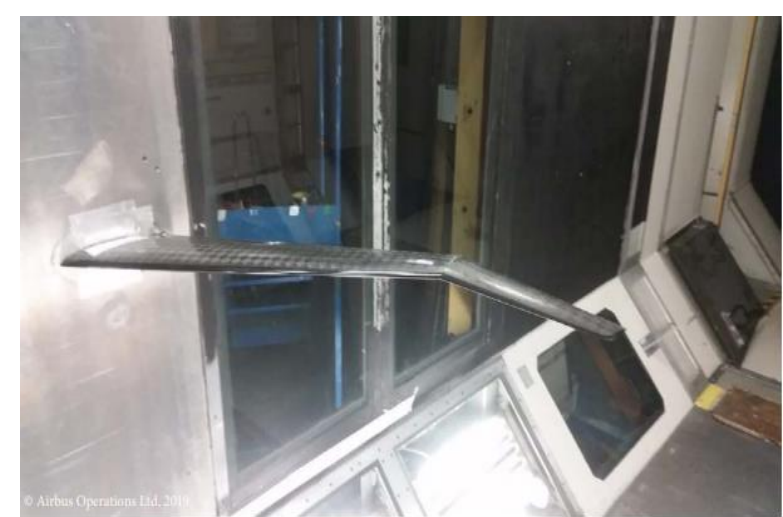

(b) The SAH wing installed in wind tunnel.

Figure 8. SAH demonstrator, AlbatrossONE [110].

\subsubsection{Observations}

The majority of studies on the aeroelasticity of dihedral morphing wing belong to the aeroelastic stability theme. Most of the works in both the themes are numerical analysis with a limited number of experiments including a flight testing under aeroelastic control theme [110]. The FE was widely used for structural analysis in both themes. Under the aeroelastic stability theme, there is a limited 
number of studies that considered the nonlinear formulations [93, 96] for structural modeling. The DLM, unsteady aerodynamic theories, VLM, and CFD were used to estimate the aerodynamic loads. For both themes, most of the studies considered subsonic flight for civil aircraft with or without a gust. Moreover, the effect of wingtip jamming or failure on the aeroelasticity of the wing has not been addressed. The coupling between aeroelasticity and flight dynamics associated with morphing was only addressed by a limited number of studies [108, 109]. Table 5 provides a summary of the recent literature on the aeroelasticity of morphing dihedral/gull/folding wingtips/spanwise bending wings.

\subsection{Airfoil Morphing}

This section includes thickness-to-chord variations and camber changes. The majority of work on the aeroelasticity of airfoil morphing has focused on camber morphing with very limited effort dedicated to thickness to chord morphing. In fact, the research effort that addressed aeroelasticity of airfoil morphing is much larger than the those associated with out-of-plane and planform morphing [5].

\subsubsection{Thickness-to-Chord Ratio}

Significant drag reduction can be achieved by varying the thickness-to-chord ratio of the wing to delay flow transition and control flow separation. This can be done by shifting the transition point near the trailing edge [111].

\subsubsection{Aeroelastic stability}

Courchesne et al. [111] investigated the aeroelastic characteristics of a morphing wing equipped with SMAs. The wing had a laminar airfoil shape and the upper surface was made of a Carbon-Kevlar composite material flexible skin. The electronically controlled Shape Memory Actuators were used to morph the upper surface of the wing causing a variation in the airfoil thickness. This caused the flow transition point to move closer to the trailing edge. The aeroelastic analysis was carried out using MSC.Nastran for structural analysis and DLM was used for aerodynamic predictions. The aeroelastic study aimed to determine the condition at which the wing was stable in terms of flutter. The results showed that the flutter occurred at a Mach number equal to 0.55 . Grigorie et al. [112] took the morphing concept proposed by Courchesne et al. [111] a step further and developed an integrated controller consisting of bi-positional controller (on-off) and a proportional-integral controller was developed. The controller was validated using numerical simulations, bench testing and wind-tunnel testing. An aeroelastic study was conducted to determine the flutter conditions to be avoided during the wind-tunnel testing for validation purposes. MSC.Nastran was used to build a 3D numerical model of the upper flexible skin of the morphing wing. Doublet lattice panel theory was used for aerodynamic modeling and the V-g method was used to estimate flutter speed. The study showed that aeroelastic instabilities for the morphing configurations considered appeared at Mach number 0.55, which was higher than the wind-tunnel Mach number limit speed of 0.3. Once flutter was cleared, the wind-tunnel validation tests were conducted and they showed that the performance of the actuator controller significantly 
enhanced the wing aerodynamic performance. Figure 9 shows a variable thickness airfoil with flexible skin [113].

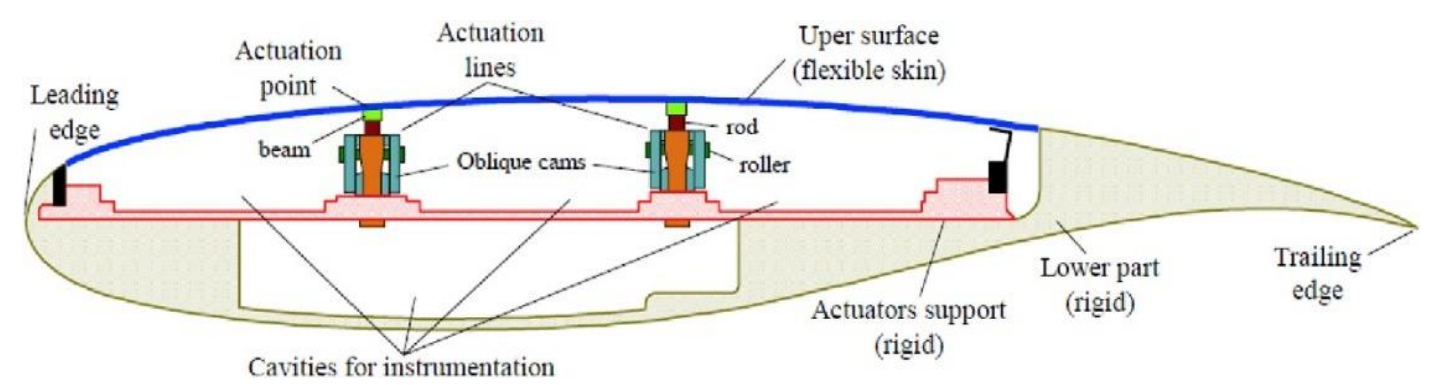

Figure 9. Cross-section of thickness morphing wing model [113].

Rhodes and Santer [114] presented a thickness morphing airfoil with a deployable shock control bump for transonic shock control aiming to reduce the drag. Controlled loads were used to model structural morphing. A commercial FE software, Samcef was used for structural analysis, and OpenFOAM CFD code was used for aerodynamic analysis. Static aeroelasticity was included in this work as a weak coupling between the structural and aerodynamic models. The results showed that a drag reduction of $4.2 \%$ was observed by deployed bump. There was a very small contribution of static aeroelastic characteristics to the structure. A small increase in bump height was observed during static aeroelastic analysis and which didn't affect the shock control capabilities. In addition, Jinks et al. [115] investigated the response of flexible active plates suitable for shock control bumps using supersonic wind-tunnel. High-speed Schlieren Imaging was used to capture the shock structure over the plates. Two captive linear actuators (Haydon-Kerk 25443 actuators) were used to actuate the plate during the tests which can provide a maximum displacement of $18 \mathrm{~mm}$. Schlieren Images showed a change in the shock structure as it passed over the flexible plate. For the actuated plate, it was possible to control the position of the shock. From the experiment, the effects of large-scale destructive panel flutter were not observed. However, due to small variations in free stream pressure, small oscillations were observed.

\subsubsection{Observations}

All studies on the aeroelasticity of thickness-to-chord ratio belong to the aeroelastic stability theme. The effect of thickness changes in the airfoil during the flight on the aeroelasticity of wings was analyzed both numerically $[111,112,114]$ and experimentally $[112,115]$. However, most of the studies did not consider its effect on the flight dynamics. The structure of the wing was modelled using FE software without considering large deformation nonlinearities, and they are mostly isotropic. The aerodynamic loads were simulated using the DLM for subsonic speeds and CFD [114] for transonic speeds. The aeroelasticity of wings equipped with thickness morphing mechanisms mostly considered the level flight condition, while it is necessary to check the impact of flight maneuvers on the efficiency of this morphing. The majority of the studies ignored the impact of skin flexibility on the aeroelastic behavior of the wing except one study [111]. Finally, it must be highlighted that the number of studies concerning the aeroelasticity of flying vehicles 
using thickness morphing is very limited. Table 6 provides a summary of the aeroelasticity of thickness-to-chord morphing wings.

\subsubsection{Camber}

On fixed-wing aircraft, camber variation has been used to control roll, pitch, and yaw for over 100 years [116]. Moreover, camber change has been used to generate high-lift coefficients during takeoff and landing [117]. Camber morphing is one of the most popular morphing degrees of freedom probably due to its simplicity and effectiveness. It has been utilized for a range of applications such as adjusting the upper surface profile to delay shockwaves to increase flight performance in the transonic regime [118]. Similarly, camber morphing wings have been used for gust and maneuver load alleviation allowing a significant reduction in structural weight, leading to reduced fuel burn [119]. Other applications include active flutter suppression. It should be highlighted that most camber morphing applications have focused on UAVs. In literature, the aeroelasticity of camber morphing wings has attracted the greatest attention mainly because it can be achieved with less complicated mechanisms and it requires relatively smaller actuation forces. In general, camber morphing has a significant impact on the aerodynamic forces, but less impact on the inertia and elastic forces when compared to other morphing degrees of freedom. Figure 10 shows a recently developed polymorphing wing capable of camber and chord morphing [120].

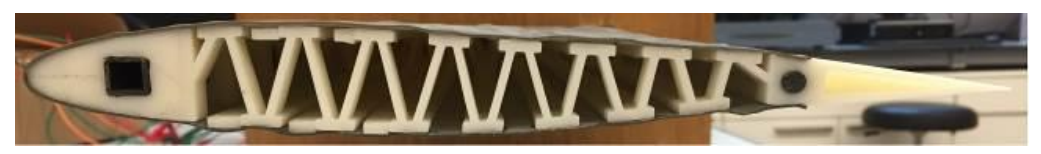

(a) Pre-morphing.

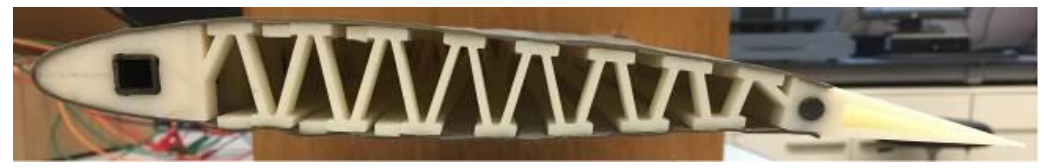

(b) $20^{\circ}$ down.

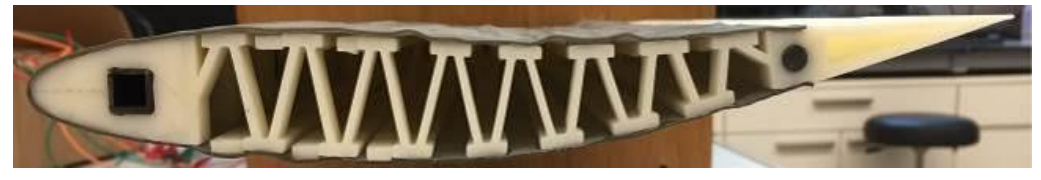

(c) $20^{\circ}$ up.

Figure 10. The polymorphing wing [120].

Another example of camber morphing concept is the Fishbone Active Camber (FishBAC) developed by Woods and Friswell [121]. Figure 11 shows the FishBAC wind tunnel model [122]. 


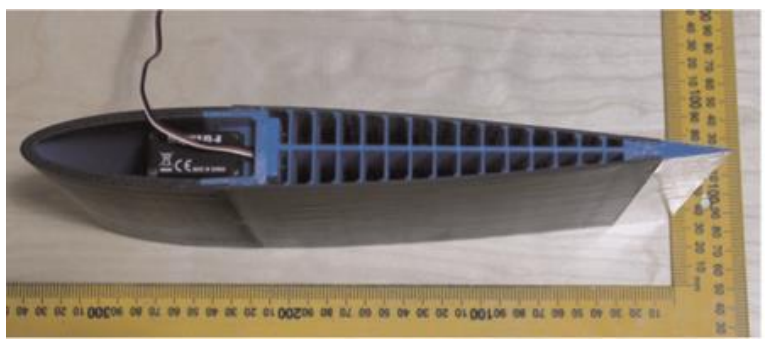

(a) Before morphing.

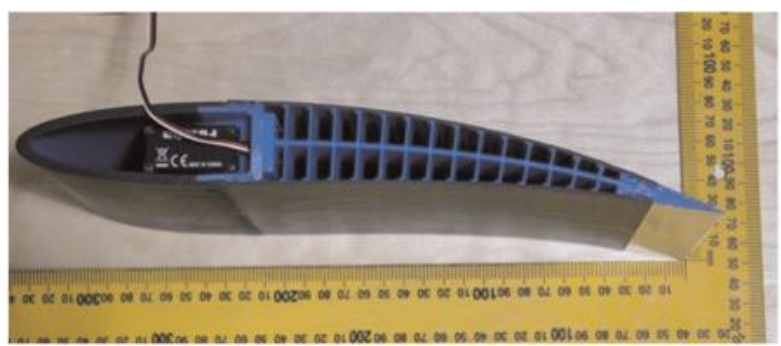

(b) After morphing.

Figure 11. FishBAC camber morphing concept [122].

\subsubsection{Aeroelastic stability}

Molinari et al. [123] introduced a camber morphing wing concept to replace conventional ailerons. The concept is actuated using piezoelectric actuators. Numerical optimization was carried out to achieve a shape that was aerodynamically efficient and could withstand the aeroelastic loads. Coupled 3D aero-structural simulations, using FEM and 3D panel method, were carried out to investigate the static and dynamic aeroelastic behavior. The aeroelasticity of wing was evaluated at three flight conditions. The aeroelastic analysis showed the operational ability of the morphing wing without the occurrence of flutter. Henry et al. [124] studied the optimal structural parameters of the skin and piezoelectric actuators for a compliant morphing wing to increase the system performance. The study aimed to optimize the design parameters to achieve the maximum rolling moment and flutter speed while minimizing wing weight. The study showed that the performance of the baseline was increased significantly as a result of width and thickness distribution optimization of bi-morph piezoelectric actuators. The rolling moment was increased by $27.67 \%$ with a $4.31 \%$ mass penalty. Moreover, the flight speed could be increased by $83.4 \%$ whilst maintaining sufficient roll control. Tsushima et al. [125] conducted a static nonlinear aeroelastic study on a composite morphing wing with a corrugated structure to achieve camber morphing. They developed an aeroelastic framework consisting of FEM for structural modeling and the UVLM for aerodynamic predictions. The developed code could be used to investigate the aeroelastic characteristics of both isotropic and orthotropic materials. Static aeroelastic analysis was undertaken on a tapered wing using the proposed analysis framework. The wing considered was the base wing of the JAXA Technology Reference Aircraft (TRA) 2012A. Modification to the base wing was done. The analysis was carried out by considering two different materials: Aluminum Alloy and Nylon. The performance of the wing with a corrugated camber morphing flap was compared to the wing with a hinged flap. The results showed that the wing made of aluminum alloy gave increased lift resulting in larger vertical deflection for both the corrugated structure and hinged flap at tested conditions when compared wing without flap deflection. For the wing structure with nylon, along with the vertical deflections, twisting of the corrugated structure was observed under tested conditions. Arena et al. [126] studied the numerical and experimental validation of a morphing aileron model based on a servo-actuator as a part of the CRIAQ-MDO505 project. The investigation focused on the functionality, wind-tunnel tests, and ground vibration of the model. The action of the actuators was integrated within the numerical model of the aileron. Wind-tunnel experiments were carried out to investigate the compliance of the device. Structural modeling was performed using MSC.Nastran and the unsteady AIC were 
obtained using the DLM. Aeroelastic stability analysis was performed in accordance with EASA CS-25 airworthiness requirements. The functionality tests showed that flap actuation to the desired morphed shape was reproducible. The preliminary results showed that the actual structural configuration of the aileron is stable if assembled on a typical regional aircraft wing. There was no critical flutter instability in the flight envelope during the aeroelastic analysis based on symmetric and anti-symmetric modes with a spectral bandwidth of 0-60 Hz. Arena et al. [127] also investigated the aero-servo-elastic impact on the morphing wing trailing edge (Active Trailing Edge-ATE) of a CS-25 category aircraft as part of the SARISTU project. The stiffness and inertial distributions of the stick-beam mockup of the complete structure were estimated using MSC.Nastran. The unsteady aerodynamic coefficients were estimated using DLM. The flutter analysis was carried out using SANDY 3.0 to verify the safety requirements. Finally, a dynamic stability assessment was performed to support Fault and Hazard Analysis (FHA). The results showed that the ATED (Active Trailing Edge Device) did not induce any kind of flutter instability. Working on the same project, Pecora et al. [128] conducted an aeroelastic analysis of a novel smart structure to achieve the controlled modification of the trailing edge shape. A full-size CS25 category aircraft wing was used in this study. The effect of variations in the stiffness of the trailing edge actuators on the aeroelastic behavior was simulated by implementing the rational approaches. MSC.Nastran was adopted for structural modeling and DLM was used to estimate the AIC. The SANDY 3.0 code was used to couple the aero-structural model and to solve the aeroelastic stability equations. The results showed that for the most practical combination of inertial distributions and trailing-edge stiffness, flutter was avoided when the actuation chain provides sufficient stiffness. Moreover, the proper balancing of the trailing edge could avoid flutter instability within the flight envelope. Rea et al. [129] conducted an aeroelastic stability analysis of a wind-tunnel model equipped with a full-scale morphing aileron driven by load-bearing electromechanical actuators. The aim of their study was to prove that the concept is free from flutter up to 1.2 times the maximum expected flow speed $(85 \mathrm{~m} / \mathrm{s})$ during planned wind-tunnel tests. The aeroelastic models/tools developed by Arena et al. [127] were used. They investigated flutter speed trends versus the stiffness of the external linear actuator. They concluded that the concept was free from any dynamic instability up to 1.2 times the maximum airflow speed expected during testing. They observed that at higher speeds the sources of aeroelastic instability was a typical ternary mechanism characterized by the combination of the aileron harmonic mode and aileron tab mode and sustained by the bending mode.

Keidel et al. [130] introduced a novel structure-actuation camber morphing concept for a flying wing. The concept used an internal structure actuated by electromechanical actuators. The aerodynamic coefficients were estimated using a 3D panel method, coupled with a nonlinear extended lifting line technique. The structural analysis was conducted using MSC.Nastran. The morphing capabilities and the wing up bending test were carried out experimentally and the deflection of the actuators was measured using a digital image correlation (DIC) system. Windtunnel testing was performed to predict the aerodynamic and aeroelastic behavior of the morphing wing and the results were compared to the numerical results. The results showed that the design has a flutter speed that satisfied the buckling constraint and had a static stability margin of 0.29 and 0.27 at loiter speed $(15 \mathrm{~m} / \mathrm{s})$ and cruise speed $(30 \mathrm{~m} / \mathrm{s})$ respectively [131]. Precup et al. [132] developed an aeroelastic wing model for low-speed wind-tunnel tests at the University of Washington as a part of the SSCI DIRECT project. The model was based on the real-time continuous camber and twist shaping concepts. The model had twelve independently controlled 
trailing edge control surfaces. This work followed the development of a smaller earlier VCCTEF (Variable Camber Continuous Trailing Edge Flap) [133] aeroelastic model. For the previous work, the setting of the angles of the individual trailing edge segments was performed manually. For the new model, a VCCTEF flap actuator was developed and housed inside the outer mold line of the wing. An analytical model was developed to investigate the structural dynamics and aeroelastic characteristics of the new model and validated by modal tests and static loads. The wing was fabricated using fiberglass and a foam core. A VICON Nexus 3D motion tracking system was used to track the position of markers on the wing during wind-tunnel testing. A Nastran model was developed to compare with the experiments. The prediction of lift coefficient from the Nastran aeroelastic trim solution was in good agreement with the wind-tunnel results and Nastran captured the linear behavior in the lift versus angle of attack plot very well. The flutter speed of the system was much higher than the maximum speed planned for the tests. Fasel et al. [134] presented the numerical modeling and optimization of a camber morphing Airborne Wind Energy (AWE) aircraft. The work focused on modeling the reduced-order coupled flight dynamics and aeroelasticity of the aircraft using Matlab Simulink. A numerical optimization framework was used to maximize the average annual power production of the system. The numerical simulation used was a two-way fluid-structure interaction (FSI) simulation. MSC.Nastran was used for the structural analysis and a potential-flow based 3D panel method was used for the aerodynamic analysis. The results showed that the use of reduction technique dramatically improved the computational efficiency of the simulation. The performance of the AWE system, in terms of annual power production, was evaluated. The results showed that the proposed multidisciplinary optimization approach offers the potential to improve power production by $52 \%$ by exploiting the interdisciplinary interactions. Furthermore, Fasel et al. [135] conducted a computational investigation on a camber morphing wing on an AWE aircraft, using a reduced-order coupled aeroelastic and flight dynamics model. Structural modeling was carried out using MSC.Nastran and the aerodynamic modeling was carried out using the 3D panel method. The stringers and actuators of the wing were modeled using beam and rod elements and the corrugated skin was modeled using plate elements. The mesh of the wing was generated using Matlab and the mass and stiffness matrices were obtained using Nastran. The computation model was used to simulate the operation of a camber-morphing AWE system following circular trajectories. The results highlighted the potential of the proposed model to evaluate the performance of the AWE system. The developed model was suitable for aeroservoelastic optimization and it allowed the concurrent analysis and identification of the ideal structural, aerodynamic and controls-design parameters of the morphing wing. The camber morphing concept was applied over the whole span of the wing which allowed the control of the spanwise lift distribution for different flight conditions to maximize the power production. Ai et al. [136] presented the design and manufacturing of a morphing trailing edge flap using spatially variable stiffness materials. They developed a design optimization methodology to identify the required material stiffness variations of the 3D printed honeycomb core structure with and without the consideration of two-dimensional static aeroelastic effects. The optimization was carried out using a GA optimizer in Matlab. The aerodynamic loads were estimated using XFOIL. The structural analysis was performed using Abaqus. Different airfoil morphing profiles [137] were chosen for the optimization study. The optimization model provided the stiffness variations in the morphing core for different morphing profiles. The results showed that the aeroelastic effects significantly affected the structural design. For the most curved airfoil profile, the aerodynamic loads significantly affected the optimization results. This showed 
that a stiffer core is required to withstand the pressure loads leading to an increase in actuation energy.

$\mathrm{Su}$ [138] developed an aeroelastic formulation to analyze aeroelastic behavior of arbitrary camber deforming flexible airfoils. Orthogonal Legendre polynomials, with traditional rigid body pitching and plunging motions, were used to describe the camberwise bending deformations of flexible airfoils. Hamilton's principle was used to derive the aeroelastic equations of motion. A $2 \mathrm{D}$ finite-state unsteady aerodynamic solver was used. The aerodynamic formulation assumed incompressible and inviscid flow and ignored stall effects. The effect of camber flexibility on the static and dynamic aeroelastic characteristics was assessed. The aeroelastic analysis showed that the flexibility exhibited torsional divergence and significantly reduced the flutter boundary. Murugan et al. [139] investigated the characteristics of the FishBAC concept (shown in Figure 12) based camber morphing airfoil using two-level hierarchical modeling and optimization. At lower level hierarchy, a structural analysis was performed with a 2D airfoil. The FSI using a 2D panel method and the homogenized beam model was studied. At higher-level hierarchy the aeroelastic analysis was performed. A FEM was developed for the camber morphing composite skin with representative boundary conditions. A variable stiffness skin was modeled to minimize the out-ofplane deformation by varying the fiber angle along the chord. The optimal curvilinear fiber paths of the composite skin were performed using a multi-objective optimization framework at the second level of hierarchy, based on a GA optimizer to obtain Pareto-optimal solutions. The FSI study showed a strong coupling between the actuation moment, aerodynamic pressure loading, and deformation in the spine of the airfoil. The analysis on the skin showed a significant reduction in the out of plane deformation of skin and elastic strain energy, simultaneously. It was proved that the actuation energy can be minimized using curvilinear fiber while simultaneously minimizing the skin deflection due to aerodynamic loads.

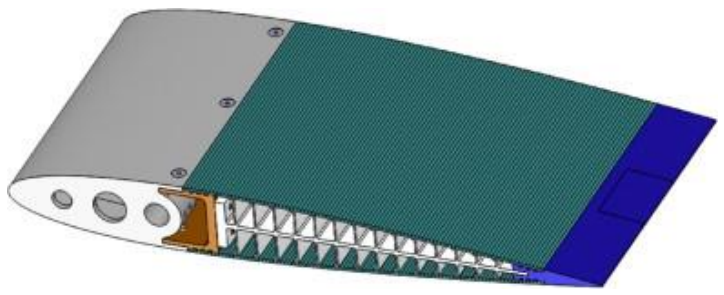

(a) FishBAC with internal structure and flexible skin.

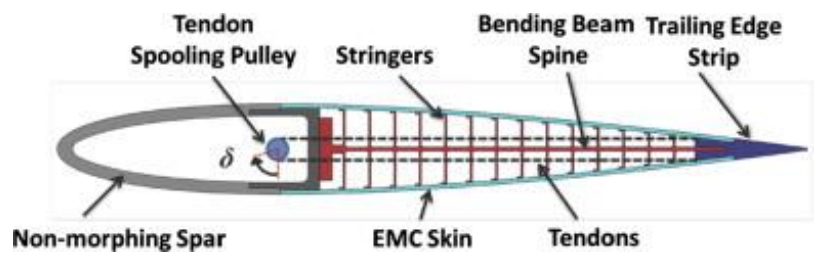

(b) FishBAC compliant structure.

Figure 12. Variable camber airfoil employing FishBAC concept [139].

Li et al. $[140,141]$ conducted a nonlinear aeroelastic study of a camber morphing composite wing. The wing had a morphing trailing edge actuated by curved beams. The wing was modeled using the FE code MSC.Patran/Nastran software and an experimental wing model was constructed. Impact test was carried out on the experimental model and the results were used to validate the FE models. A nonlinear aeroelastic equation was developed to investigate the effect of freeplay nonlinearity between discs attached to wing skins and curved beams. The AIC were estimated using the DLM [140] and Roger's approximation [140, 141]. The DMAP language based on 
MSC.Nastran was used to generate the stiffness matrices, damping, and generalized structural mass. A Matlab code was developed to solve the aeroelastic equations. The effect of morphing stiffness on the critical flutter speed was studied. The results showed that the aeroelastic responses of nonlinear systems increased the divergence speed when the velocity was higher than the critical flutter speed and reduced the divergence speed at low velocity. Limit cycle oscillation and supercritical Hopf bifurcation were detected as well [140]. In addition, they concluded that freeplay nonlinearity could reduce the critical flutter speed resulting in supercritical Hopf bifurcation [141]. Murua et al. [142] conducted a numerical study to investigate the effect of the chordwise flexibility on the dynamic stability of compliant airfoils. The time-varying camber deformations were studied using a classical aeroelastic model. Unsteady thin airfoil theory was used to obtain the aerodynamic forces and the FEM was used for the corresponding compliant airfoil stiffness and inertia. The flutter speed was computed using the V-g and state-space stability methods. The study considered three physical degrees of freedom: one elastic (camber deformation) and two rigid bodies (plunge and pitch motions). The results showed that the camber mode alone caused flutter at a constant reduced frequency due to the lock-in phenomenon between camber motion and the shed wake. For the rigid body cases, there was a significant dip in the flutter boundary of the compliant airfoil. Seber and Sakarya [143] conducted a nonlinear FE modeling and static aeroelastic analysis of an adaptive camber wing using MSC.Patran and MD.Nastran. The wing consisted of cutout ribs, guide-slide assemblies at the trailing edge section, pushrods, and servo-actuators. During morphing, the guide-slide assemblies allowed the trailing edge part of the cutout rib by means of pushrods. A previously designed hingeless control surface was integrated into the wing in FE analysis. The higher-order panel code PAN AIR was used to calculate the steady-state aerodynamic loads and an in-house code SAMOA was used to account for aeroelastic coupling. An iterative process with linearized influence coefficients was used to calculate the actuation force magnitude during morphing. The results showed that the induced drag and root bending moment can be reduced by elliptical and linear washouts that are created by spanwise camber variations. The static aeroelastic analysis indicated that at the majority of the guide-slide assemblies, the magnitude of actuation force increased to overcome the aerodynamic loading and maintain the section camber. At the outboard guide-slide assembly, the aerodynamic loads acted favorably and reduced the magnitude of actuation force due to the largest washout. Bilgen et al. [144] presented a variable camber morphing airfoil actuated by a Piezoceramic actuator known as the Macro-Fiber Composite (MFC). The airfoil consisted of a pair of optimized pinned boundary conditions, two cascading active surfaces and optimized locations of the geometric features. The pinned boundary conditions allowed for the smooth and variable deformation of the camber line. A single substrate that wraps around the airfoil shape was used to achieve the continuity in the airfoil. This work focused on the theoretical static-aeroelastic response characterization. The boundary conditions and the geometric parameters of the airfoil were optimized using a parametric FSI study. XFOIL was used to obtain the aerodynamic coefficients and the pressure distribution over the airfoil and ANSYS (FEM) were used to compute the structural deformations. The proposed airfoil achieved a higher lift coefficient and slightly lower lift-to-drag ratio when compared to the baseline variable camber airfoil (with solid-state internal hinges and 9.0\% chord thickness). Bilgen et al. [145] also presented a 2D theoretical staticaeroelastic model and optimization of a previously designed [146] variable camber morphing airfoil actuated via surface-bonded piezoceramic materials. The morphing of the airfoil was achieved by employing two cascading bimorph actuators (MFCs) in the top and bottom surfaces 
of the airfoil which was pinned at the trailing edge. A GA optimization technique was used to determine the structural parameters (mainly the substrate features) of the airfoil. A carbon nanotube-reinforced composite was assumed as the substrate. Aeroelastic modeling was carried out using XFOIL and ANSYS. A Matlab code was used to solve the FSI interaction problem by iterating between the XFOIL and ANSYS. The results presented in this study covered a velocity range of $10-30 \mathrm{~m} / \mathrm{s}$ and Reynolds numbers over the range 118000-353000. At low velocity, the flow-induced deformations were small due to low dynamic pressure and at high velocity the flowinduced deformations were more noticeable.

Previtali and Ermanni [147] designed a camber morphing wing made of composite materials using a previously designed compliant rib [148]. The wing consisted of eleven compliant ribs and five actuation stations. The actuation stations were placed between two ribs and a single rib was placed near the constraint. A linear actuator was used to actuate the wing structure. Both the 2D and 3D aerodynamic properties and 3D structural behavior were presented. For the 2D aerodynamic analysis, XFOIL was used and the data were processed using Matlab. The 3D aerodynamic simulations were based on the nonlinear extended lifting line theory (ELLT). The structural analysis was carried out using nonlinear FEM simulations in MSC.Nastran. The quasistatic aeroelastic calculation was carried out by considering a change in pressure coefficient, absolute displacement, lift coefficient and drag coefficient as parameters. The calculation was performed at $5^{\circ}$ angle of attack and a speed of $30 \mathrm{~m} / \mathrm{s}$. The results showed that the aerodynamic performance could be improved with low actuation forces and a limited rolling moment can be obtained. The aeroelastic analysis of the variation of parameters was small for the speeds considered. Varello and Lamberti [149] studied the static aeroelastic response of a straight wing with highly-deformable airfoil cross-section via the coupled Carrera Unified Formulation-XFLR5 (CUFXFLR5) approach. Refined structural one-dimensional models were developed based on the Carrera Unified Formulation (CUF). The 3D panel method was used for the aerodynamic analysis, and the wing was modeled as a clamped beam using FEM. The variations of the equilibrium aeroelastic response and wing aerodynamic parameters in terms of in-plane cross-section deformations and displacements were assessed. The results showed that when the wing has significant flexibility, the variation in the aerodynamic loading has a significant influence on the in-plane cross-section deformation. The in-plane distortion effect is higher at higher free stream velocity. Berci et al. [150] conducted a preliminary multidisciplinary design and optimization of a wing with deformable airfoil suitable for a small UAV using a multi-fidelity model-based strategy. Using a coupled aeroelastic formulation, both the shape of the airfoil and the passively adaptive structure were optimized for the best aerodynamic performance under aero-structural constraints. To calculate all the constraints, a linear semi-analytical model was utilized. To obtain the highfidelity counterparts, a nonlinear numerical model was used in which static aerodynamic load and drag of the flexible airfoil were estimated using XFOIL. Then using a tuning technique, the lowfidelity responses were corrected with few high-fidelity responses. A gradient-based GA and pattern-search algorithm were employed to solve the optimization problem. The results showed that there were clear advantages of the flexible airfoil in terms of the aerodynamic performance with respect to a chordwise rigid wing without significant degradation in aeroelastic stability. Moreover, improved gust response alleviation and wing weight reduction were also obtained. Perara and Guo [151] investigated the dynamic and aeroservoelastic behavior of a seamless aeroelastic wing (SAW) for a small UAV. A torque tube actuation mechanism (TTAM) and a sliding trailing edge of the wing skins were the two innovative features of the SAW control section. 
These two features allowed the wing to exhibit local camber changes and twist into a favorable shape. A full scale swept-back rectangular wing model was developed. An experimental model of the wing was developed for the demonstration. The FEM modeling and the structural and aeroelastic analysis of SAW were carried out using MSC.Patran/Nastran. The effective stiffness of the actuation system was evaluated using vibration analysis. Moreover, the deflection analysis was carried out to investigate the structural integrity. The results showed that a large sweep angle reduced the aeroelastic stability, due to coupling between wing bending and torsion. The results of the dynamic response analysis showed that the actuation system integrated with the SAW skin structure was stable under transient loads. The deflection analysis showed that the stress level was relatively low, even at $4.2 \mathrm{~g}$ ultimate load factor for the two-layer glass/epoxy laminate skin. Mao et al. [152] developed an efficient and feasible method to study the static aeroelastic characteristics of a morphing trailing edge. The aerodynamic forces were calculated using a geometrically-exact VLM which gives equal importance to both efficiency and accuracy. Firstly, a typical model of an active morphing trailing edge driven by a piezoelectric patch was chosen and built. Then, the static aeroelastic analysis of the morphing trailing edge was carried out. Finally, the results were compared with those offered by a traditional wing with a rigid trailing edge using the traditional linear VLM. By geometrically exact VLM the thin-airfoil camber line is divided into $n$ equally distributed subpanels and the $n$ vortex points were placed at quarter-point of each panel. The total lift and moment for a camber morphing wing with a torsion spring installed were expressed as:

$$
\begin{gathered}
L=\sum_{i=1}^{n} q_{\propto} S C_{p i} \cos \varphi_{i} \Delta s_{i} \\
M=\sum_{i=1}^{n} q_{\propto} S C_{p i} \cdot\left(\left(x_{i}-x_{0}\right) \cos \varphi_{i}-\left(y_{i}-y_{0}\right) \sin \varphi_{i}\right) \Delta s_{i}
\end{gathered}
$$

where $C_{p i}$ is the aerodynamic pressure coefficient distribution at $i$ th panel. $\Delta s_{i}$ is the length of the $i$ th panel, $\varphi_{i}$ is the local downwash angle, $S$ reference wing area and $x_{0}$ and $y_{0}$ are the coordinate position of the torsion spring. The results of geometric deformation showed that the geometricallyexact VLM is better-suited for describing the aerodynamic nonlinearity of the morphing trailing edge. Considering the deflection angle of the trailing edge, torsion mode, trailing edge deflection mode and angle of attack, the wing system showed a bifurcation but did not show divergence.

Liu et al. [153] developed a method for analyzing the static aeroelastic deformation of the flexible skin used on a continuous variable camber morphing wing. The changes in the aerodynamic characteristics of the airfoil and design parameters of the skin due to the static aeroelastic deformation of the flexible skin were discussed. To solve the fluid-solid coupled problem, a weak coupling method was used. The panel method using XFOIL was used for the aerodynamic analysis and Ansys was used for structural modeling. The results showed that the upper surface flexible skin bubbled under the air loads. The formed bubble had a powerful effect on the aerodynamic pressure near the surface of the local deformation. The aerodynamic characteristics were significantly affected by the static aeroelastic deformation of the flexible skin. At small angles of attack, the lift coefficient decreased and the drag coefficient increased. As the 
angle of attack increased, the effect of the flexible skin on aerodynamic characteristics of an airfoil became smaller. In addition, the drag coefficient of the airfoil and the deformation in the flexible skin increased sharply at speeds beyond a certain value. Rivero et al. [154] developed a 3D FSI routine for the FishBAC concept that coupled a 2D viscous corrected panel method (XFOIL) with a 3D Lifting-Line theory analysis to create a viscous corrected 3D wing aerodynamic solver. A previously developed multi-component Mindlin-Reissner plate model based composite analysis routine was then coupled with this aerodynamic model for the FishBAC morphing device. The Rayleigh-Ritz method was used to solve the differential equations in structural modeling. The developed FSI model showed good agreement with the other aerodynamic, structural and FSI tools. In addition, the results highlighted the FishBAC's ability to improve aerodynamic performance at a wide range of operating conditions. Airoldi et al. [155] presented a passively actuated morphing structural concept which could obtain a high-lift configuration. A composite chiral honeycomb core was used to achieve camber variations. A flexible skin was considered as the cover for the rib. FEM by Abaqus was used for structural analysis and XFOIL and DLM were used for the aerodynamic analysis. The results showed that the performance is achieved without triggering dynamic aeroelastic problems. Airoldi et al. [156] also presented numerical models referred to a morphing actuated aileron. This study focused on the investigation of static aeroelastic effect due to the interaction of the aerodynamic loads with the flexibility of the airfoil structure. A rib was modeled that consisted of an internal part made of a composite chiral honeycomb covered by a flexible skin. The structure and skin had adequate combination of flexural stiffness and inplane compliance. For the actuation, the skin was divided into several sections that can be compressed or elongated by a system of forces acting on the skin plane, assuming that the actuation was attained by SMA actuator or shape memory polymers (SMP) actuator. Abaqus was used for structural modeling and the aerodynamic modeling was carried out by a steady 2D discrete vortex method. The results showed that the morphing system could attain significant variations in the lift coefficient and exploited the fluid-structure interaction to reduce the actuation energy. Moreover, the chiral rib could undergo significant displacement with the capability of sustaining the air loads applied to the skin.

\subsubsection{Aeroelastic control}

Burdette and Martins [119] optimized the wing size and shape using a high fidelity aerostructural model. Several aerostructural optimizations were carried out to demonstrate the performance benefits of the morphing trailing edge. The MACH (MDO for Aircraft Configurations with High fidelity) framework was used for the aerodynamic and structural analysis. The ADflow was used as the aerodynamic solver while the Toolkit for Analysis of Composite Structures (TACS) was used for the structural analysis. Examining the fuel burn reduction was carried out by structural weight reduction achieved through adaptive maneuver load alleviation. The results showed that the cruise fuel burn could be reduced by more than $5 \%$ through the addition of the morphing trailing edge along the aft $40 \%$ of the wing. They also studied a smaller morphing device positioned along the aft $30 \%$ of the wing and concluded that the efficiency in reducing fuel burn increased as the size of the morphing device increased. Arena et al. [157] developed an innovative morphing aileron to increase both the in-cruise load control and the structural stability of a regional aircraft. The objective was to determine the aeroservoelastic impact of a true-scale prototype on a regional aircraft. The aeroelastic models/tools developed by Arena et al. [107] were used here. The results from the antisymmetric aeroelastic analysis showed that flutter occurred at $202.4 \mathrm{~m} / \mathrm{s}(81 \%$ 
of the 1.2 dive speed of the aircraft, $\mathrm{V}_{\mathrm{D}}$ ) in the control line failure condition. In this case, a typical coupling between the aileron fundamental mode with the wing bending mode generated the instability. The symmetric aeroelastic analysis showed that flutter started to occur at $61 \%$ of 1.2 $\mathrm{V}_{\mathrm{D}}$. Fichera et al. [158] designed and tested a high bandwidth actuator for camber morphing in which the actuator controled both the aeroelastic behavior and flight mechanics of the model. Camber morphing was achieved using a lightweight High-Bandwidth Morphing Actuator (HBMA) that used a tailored piezoelectric patch in a sandwich configuration with a linear trailing edge slider. Static loading tests were carried out by hanging weights on the trailing edge and the results were compared with the Abaqus FE model. The test proved that the actuator was able to morph the camber producing a maximum static deflection of its tip equal to $15 \mathrm{~mm}$, and to develop an equivalent torque of $0.1 \mathrm{Nm}$. Dynamic tests were carried out (stepped sign model tests) using the Siemens PLM system and showed that the bandwidth of HBMA was greater than $20 \mathrm{~Hz}$ and that was suitable for controlling first modes of most low-speed aeroelastic models. HBMA fulfilled the aeroelastic requirements in terms of bandwidth, deflection, and torque provided. In addition, Standford [159] conducted a Common Research Model (uCRM) aeroservoelastic optimization study for a transport wingbox using the VCCTEF to provide quasi-steady MLA. The weight of the wingbox, subjected to buckling, stress and hinge moment constraints, was minimized using the flap actuation design variables and patch-wise structural design variables. The open loop and closed loop maneuver loads were considered for the load alleviation and flutter suppression, but the flap actuation was not considered for the open-loop loads. The wing structure was modeled using shell FEs through a combination of discrete Kirchhoff triangles (DKT) and linear strain triangles (LST). Aerodynamic modeling was carried out using the VLM. The results showed that the VCCTEF was capable of substantial aeroelastically-feasible reductions in the structural weight. The open-loop case, using low values for flutter margin (unsteady cases) or safety factor (steady cases), allowed large mass reductions. Soneda et al. [160] investigated the aero-structural characteristics of a corrugated morphing wing to obtain preferred lift distributions considering necessary actuation energies. A 3D aero-structural analysis tool, with an actuation system, was developed by combining a VLM aerodynamic model with a nonlinear FEM structural solver using MSC.Marc. The actuation system was modeled by considering a simple mechanism with wires and servomotors which could induce large deformations in the corrugated morphing structures. The analysis was performed at uniformly-distributed design points. Response surfaces were created by radial basis function interpolation whilst gradient based methods were used to calculate the optimal setting of the parameters. The optimization results represented by the response surfaces were in good agreement with the aero-structural analysis results. Magar et al. [161] studied the vibration suppression and gust load alleviation through camber morphing of a thin plate profile representing a wing airfoil. The plate was designed using Arc-Miura origami design [162]. The parameters associated with the origami design were optimized to have high sensitivity in chordwise fold angle and a maximum camber of $10 \%$ chord. A linear controller was designed to achieve desired camber variation for vibration suppression. The morphing was achieved as a parabolic camber change. The quasi-steady thin airfoil theory was used for aerodynamic analysis. The system parameters were taken from the author's previous work [163]. The results showed that the desired vibration suppression was obtained at a 5\% camber for the tested conditions. Also, a $1 \%$ change in the camber could achieve the gust load alleviation. In addition, the proposed system was effective to control pitch and plunge degrees of freedom when excited with gust. 


\subsubsection{Observations}

Most of the studies belong to aeroelastic stability theme with a very limited number under aeroelastic control. For both themes, the majority of studies are numerical analysis using FE software for structural modeling with beam $[136,138,139]$ and plate models $[125,154]$ being the most popular. The DLM [126-129, 132, 140, 141, 155, 157] and panel method (2D and 3D) [130, 134-136, 139, 143-145, 147, 149, 150, 153-156], VLM [152, 159, 160], nonlinear lifting line theory [124], CFD [119] and thin airfoil theory [161] were used for aerodynamic modeling. The flow regime considered is mainly subsonic expect few studies that considered transonic flight conditions [119]. However, it is very important to take into account the nonlinear stall condition, transonic or supersonic conditions as they will have a different effect on the aeroelastic behavior of the concept, and might limit their usage. For both themes, the effect of the camber on aeroelasticity has mostly focused on the cruise condition with just a few considering maneuver flights (for aeroelastic stability) $[123,130]$. Table 7 provides a summary of the work discussed above on the aeroelasticity of wings with camber morphing.

\section{Aeroelastic Frameworks}

A number of researchers have focused on developing generic aeroelastic frameworks that can handle different/multiple morphing degrees of freedom. de Breuker et al. [11] developed a polymorphing framework to investigate the aeroelastic characteristics of a morphing wing. The objective of the developed framework was to maintain the ability of the wing to morph into any arbitrary shape, whilst reducing the number of design variables. This was achieved by discretizing the wing into an arbitrary number of segments. Then, morphing was carried out using inter-rib and intra-rib mechanisms. The inter-rib mechanism operated across a wing segment whereas the intrarib mechanism acted between two adjacent wing segments. As a result of these two morphing mechanisms the wing could achieve any shape with four morphing modes (wing sweep, wing twist, wing extension, and wing folding). The wing was assumed to be made of aluminum. The 3D structure of the wing was modeled using Timoshenko beam elements and the Weissinger method with Prandtl-Glauert compressibility correction was used as the aerodynamic model. They were coupled to obtain the aeroelastic solution. The functionality of the developed framework was demonstrated for folding and sweep morphing modes. The results showed that the developed framework was capable of predicting the actuation energy as well as the structural and aerodynamic performance. The actuation moment required to fold the outer part of the wing increased with increasing folding angle, due to an increase in aerodynamic loading. The results of sweep morphing showed that as the sweep changes from swept forward to straight configurations, the trimmed angle of attack reduced. The angle of attack increased when the wing configuration changed from straight to a swept forward condition, due to the reduction in the wing surface area perpendicular to the flow when the configuration changes. This phenomenon is caused by the aeroelastic effects during sweep morphing. Werter and de Breuker [12] developed an aeroelastic framework which was suitable for the optimization and analysis of general morphing wings. This was carried out using a two-level design approach. At the first level, the morphing wing model was developed and used as the input for the generic morphing optimization and the aeroelastic framework in the second level. At the second level, the aeroelastic framework was used to optimize 
the morphing configuration and the morphing parameters. Aeroelastic modeling was carried out using the potential flow coupled Timoshenko beam model. The aerodynamic flow around the wing was modeled using VLM. The aeroelastic framework developed was suitable for a morphing wing designed with a general distribution of camber, sweep, fold, span and twist morphing for minimum root bending moment and drag. The developed model consisted of induced and parasitic drag models, and static and dynamic models, and was able to estimate the required energy for morphing. The framework was applied to three different flight speeds of a UAV. The results showed that the tradeoff between the induced and parasitic drag depended on the flight speed. At high speeds, parasitic drag was dominant and at low speed, induced drag was dominant. In addition, Yang et al. [13] developed an aeroelastic framework for the generic design of morphing wings. The VLM was used for aerodynamic modeling and the FEM was used for structural modeling. For demonstration, the framework was applied to a regional aircraft jet wing (span $40 \mathrm{~m}$, aspect ratio 12, taper ratio 0.5, and LE sweep $10 \mathrm{deg}$.) for three morphing conditions: camber morphing only, twist and camber morphing and twist only at high speed (low $\mathrm{C}_{\mathrm{L}}$ ) and low speed (high $\mathrm{C}_{\mathrm{L}}$ ). The twist morphing example showed that at the low Mach number cases, the wingtip loading and consequently the root bending moment was higher than the high Mach number cases. To overcome this issue, large additional twist morphing at the tip was required. For the twist and camber condition, a relatively small change in the twist was required. The camber morphing alone example showed that large amounts of morphing are needed at low Mach numbers. To reduce the root bending moment, a large TE flap angle was required over the in-board areas to shift the spanwise loading in-board. The combination of the twist and camber morphing needed less effort than the twist or camber only morphing conditions in terms of LE and TE morphing angles.

Sun et al. [14] developed an aeroelastic optimization framework for morphing a regional aircraft wings. An inverse design based on the VLM was used to develop the optimization scheme. The structural analysis and optimization were carried out using the FEM by discretizing the wingbox beam into a number of elements. The study was conducted for a wing capable of changing its mean camber and twist. To determine the wing twist required to achieve a minimum weight wing design and stiffness distribution, a gradient approach based static aeroelastic optimization was developed. The morphing control strategy was discussed using an ATW structure scheme. The analysis results showed that for flat and thin wall cross-sections of the wingbox, the torsional stiffness varied linearly with moving deflections of the control surfaces. Preidikman et al. [15] developed a co-simulation computational framework to investigate the aeroelastic behavior of different aeronautical systems. The developed framework was used to investigate highly flexible structures subjected to low-subsonic flow undergoing complex motions in space. The extended version of the UVLM based nonlinear aerodynamic model was coupled with a nonlinear structural model based on a segregated formulation of Lagrange's equations. The Lagrange's equations were obtained with the Floating Frame of Reference Formalism. The structural model constructed allowed hybrid combinations of different models, such as models based on the FEM, the assumedmodes technique, and rigid-body dynamics. The developed framework was used to study the aeroelastic analysis of a joined-wing aircraft, a morphing wing and a micro-air-vehicle (MAV) inspired by biology. The results from the flapping aerial vehicle showed that the predicted results were in good agreement with the experiments conducted by other researchers [164] with $14 \%$ lower lift prediction. The other morphing wing considered was a seagull wing. The analysis showed that the flutter speed decreased linearly from $29.66 \mathrm{~m} / \mathrm{s}$ to $18 \mathrm{~m} / \mathrm{s}$ as the dihedral angle changed from $0^{\circ}$ to $45^{\circ}$. The joined-wing aircraft considered for the framework implementations 
was based on the SensorCraft concept [165]. The critical speed (flutter speed) obtained for the joined-wing aircraft configuration was $156 \mathrm{~m} / \mathrm{s}$. Unlusoy and Yaman [16] coupled an in-house developed PK algorithm with the commercially FEM software MSC.Patran to investigate morphing effects on the aeroelastic behavior of UAV wings. The Theodorsen's unsteady model was used for aerodynamic analysis. To investigate the effect of morphing on aeroelasticity, different morphing concepts were integrated into a UAV wing structure. The effect of span extension, sweep and planform area changes by chord extension, during cruise, loiter and climb flight conditions were investigated. The results showed that the effect of changes in planform area on flutter and divergence was not clearly identified. The highest flutter speed was obtained at the cruise configuration where the planform area was smaller than at climb and loitering configurations. An increment in span reduced the flutter speed dramatically, but this was not feasible in terms of structural dynamics. The change in the sweep of the wing had a positive effect on the flutter speed. A change in divergence and flutter speeds as high as $305 \%$ and $138 \%$ was observed during the transition between take-off, climb, cruise and loiter phases. Molinari et al. [17] presented a design methodology for the aero-structural optimization of morphing airfoils for adaptive wings. A multidisciplinary static aeroelastic tool was developed, based on a twodimensional panel method coupled with FE structural analysis and boundary layer models. The developed tool was capable of accounting for the interactions between aerodynamics, actuators, and structures. Figure 13 shows the working principle of static aeroelastic tool. The aerodynamic analysis was carried out using the 2D panel-based method with coupled boundary layer models, based on the C++ translation of XFOIL. MD.Nastran was used for the structural analysis. To evaluate the validity of the developed methodology, a camber morphing concept based on Dielectric Elastomer (DE) actuators was adopted. The trailing edge section was composed of a deformable plate with two segments of different thicknesses, connected to the rear spar of the wing-box. When the actuation force was applied, the first segment of the plate acted as the main control surface and the second segment acted as the trim tab to achieve the camber change. The length ratio between the complete movable surface and the trim tab, the chord-wise position of the rear wing-box spar and the thickness of both parts were the optimization parameters. The DEbased actuator patches were attached to the outer surface of the trailing edge section and when actuated the DEs expanded along the planar direction. This induced stresses in the underlying section and thus deformation occurred. The result showed that the concurrent optimization of the structural and aerodynamic parameters of an airfoil was more feasible and yield higher performance compared with the sequential (conventional approach) aerodynamic and structural optimization. This was because the sequential approach did not consider aero-structural coupling.

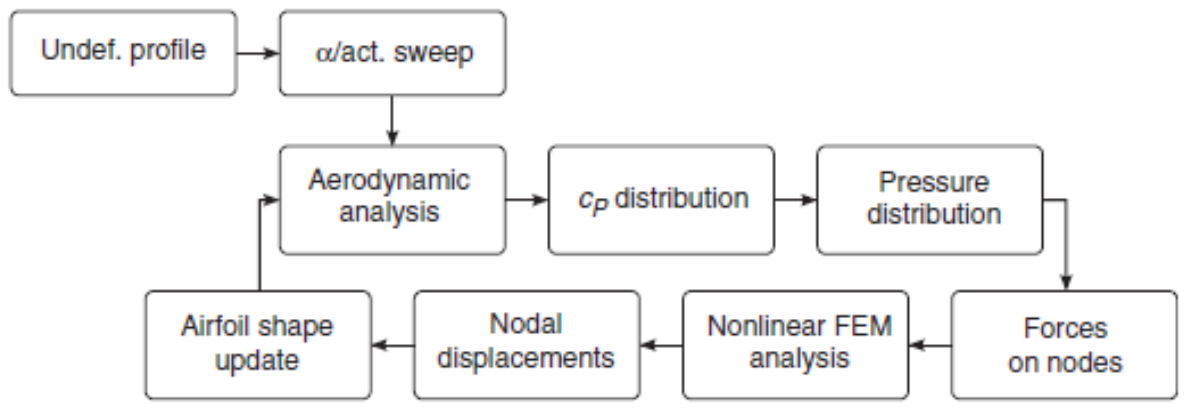

Figure 13. A Static Aeroelastic Framework [17]. 
Gamboa et al. [18] presented a multidisciplinary optimization tool to design a morphing wing. The tool was developed by coupling the structural morphing model with an aerodynamic shape optimization code, which was used to obtain a set of optimal wing shapes for minimum drag at different speeds. The aerodynamic shape optimization code was suitable for preliminary wing design. The optimization code used a coupled viscous 2D panel method formulation with a sequential quadratic programming optimization algorithm and a nonlinear lifting-line algorithm. Structural modeling was carried out using the FEM. The aerodynamic optimization highlighted a reduction in the wing drag of up to $30 \%$ and even greater levels could be obtained by morphing the wing with the concept presented. In addition, Tsushima et al. [19] developed two different aeroelastic frameworks (2D and 3D) with different fidelities for morphing wings with corrugated structures. One coupled XFOIL or a CFD code, "UTCart" developed by the Rinoie and Imamura Laboratory of the University of Tokyo, with nonlinear beam theory for aeroelastic analysis. The other used unsteady vortex-lattice aerodynamic loads and corotational shell FEM to study the aeroelastic characteristics of morphing wings involving large deformations. The study also numerically evaluated the difference in individual aerodynamic and structural solutions of the frameworks presented. The capability and feasibility of such a corrugated morphing under aerodynamic loads were demonstrated. The results showed that for the high aspect ratio case, the simple 2-D analysis framework with UTCart could provide sufficiently accurate aerodynamic characteristics for morphing wings with corrugated structures. Figure 14 shows the algorithm of the 3D aeroelastic framework.

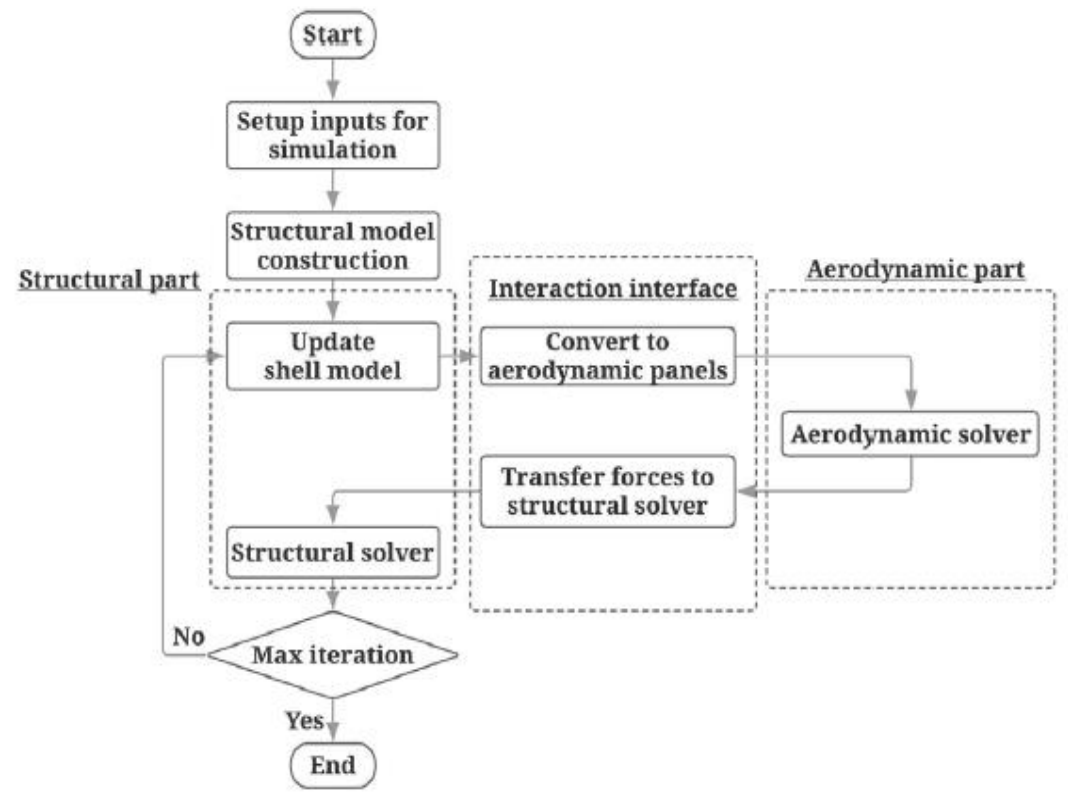

Figure 14. Algorithm of 3D aeroelastic analysis framework [19].

Cavagna et al. [20, 21] proposed a design framework called NeoCASS+ for morphing aircraft, particularly for active camber morphing concepts. The framework could be used directly from 
conceptual design to perform multi-fidelity analysis. The NeoCASS+ scheme was based on three components: The NeoCASS (Next generation Conceptual Aero-Structural Sizing Suite) [166, 167] which provided the structural sizing, aeroelastic analysis, and optimization capabilities, an aerodynamic optimization module, and a design tool called MorfeO (MOrphing aiRFoil dEsign and Optimization) for the optimal structural configuration morphing wings and to design the internal structure. The entire process was linked to the Class/Shape function Transformation (CST), a compact airfoil representation technique that was based on the approach proposed by Kulfan [168]. The CST allowed the deformation of the global shape of the airfoil without affecting its local regularity. The proposed framework was capable of quickly generating the full aeroelastic model of the aircraft. The active camber morphing concept was particularly emphasized and the effect of continuous spanwise and chordwise camber variation on trimmed configurations relevant to the load distribution and/or lift-to-drag ratio was evaluated.

\subsection{Observations}

The majority of aeroelastic frameworks used VLM [13, 14], panel method [17-19], Weissinger's method [11, 12], or theoretical models [16] for aerodynamic predictions. For structural analysis, FEM [13, 16-19], nonlinear [11, 12, 19] and linear beam[14] formulations were used. The majority of frameworks used linear models for structure and aerodynamics. In addition, very little effort was made to model the control aspects associated with the aeroelasticity of morphing wings. Most of the developed frameworks are for non-maneuver flight conditions and they didn't account for the interactions between aeroelasticity and flight dynamics of the flying vehicle in various maneuvers.

In terms of morphing degrees of freedom, some aeroelastic framework considered twist [11, $12,14]$, span $[11,12,16,18]$, dihedral $[11,12]$ and camber $[12,14,16-18]$. None of the existing frameworks considered thickness-to-chord or chord morphing concepts. It should be noted that some frameworks are able to account for multiple morphing degrees of freedom such as [11-14, $16,18]$ while other frameworks considered single degree of freedom such as [15, 17, 19-21]. Moreover, most of the frameworks ignored the effect of gust, turbulence, and stall conditions; while these are very important especially for load reduction morphing mechanisms such as wingtips. In addition, all the studies considered subsonic flow regime except one study [13] considered both subsonic and transonic flow conditions. Table 8 summarizes the developed frameworks for the aeroelastic analysis of aircraft equipped with morphing devices.

\section{Discussions and Trends}

It can be clearly seen that using morphing technologies to suppress flutter and for load alleviation is likely to continue and grow in the near future. For instance, Airbus considers flaredhinge folding wingtips for load alleviation to be a promising technology and has dedicated a significant research effort to it. Furthermore, Airbus has recently built a flying demonstrator to test and validate this technology [102]. Similarly, other studies have utilized wingtip devices to reduce wing root bending moment and to alleviate gust and maneuver loads. The same trend exists for other morphing degrees of freedom, such as utilizing span morphing wings for flutter suppression 
and camber morphing wing for gust and maneuver load alleviation and to eliminate aeroelastic instabilities. The trend is not limited to active morphing concepts but also work has been done on utilizing passive morphing concepts for aeroelastic purposes. For instance, the PTWT is utilized for load and gust alleviation [80] under subsonic speed with gust. Also, a study by Castrichini et al. [106] investigated a passive negative stiffness nonlinear hinge for a folding wingtip to improve the gust loads alleviation capability. This implies that utilizing morphing technologies for aeroelastic purposes is likely to increase the need to develop robust aeroservoelasticity tools capable of handling different types of structural, aerodynamic and control nonlinearities.

\subsection{Morphing skin and flexible structures/materials}

Most of the morphing concepts have used flexible/compliant skins. This includes latex sheets, elastomeric matrix composites (EMC), elastomeric silicone materials, and Carbon-Kevlar composite materials. These types of skin have a significant effect on the aerodynamic shape of the wing and on its structural properties. Most of these flexible skins exhibit nonlinear behavior that must be considered in aeroelastic modeling. Moreover, pretensioning the flexible skin reduces their impact on the aeroelastic behavior of the wing/concept. A very limited number of studies have accounted for the effect of flexible morphing skins on the aeroelastic behavior of morphing aircraft. For instance, the work by Ajaj et al. [40] investigated the aeroelasticity of compliant span morphing wings covered by an elastomeric skin, without accounting for the effect of skin. In contrast, the study by Liu et al. [153] considered the static aeroelastic deformation of the flexible skin on a continuous variable camber-morphing wing. It seems that the literature lacks comprehensive aeroelastic tools capable of handling flexible/compliant morphing skins with unconventional properties.

\subsection{Impact of actuation system/rates/forces}

The actuation loads, rates, and types of actuation systems used for a morphing concept can have a significant effect on the aeroelastic behavior [71]. Most studies assessed the aeroelasticity of morphing wings/airfoils in quasi-static conditions (i.e. before and after morphing) and not during morphing. This is mainly because of the additional complexity associated with the timedependent wing geometry [153]. A limited number of studies considered the effect of morphing rates. For example, Ajaj and Friswell [40] and Ajaj et al. [41] investigated the effect of morphing rate on the aeroelastic behavior of span morphing wings. Similarly, Li and Jin [51] investigated the morphing rate on the flutter speed of a span morphing wing under supersonic aerodynamic conditions. Ren and Zhipping [46] investigated the effect of morphing speed and wingspan on aeroelastic behavior. Sleesongsom and Bureerat [71] studied the impact of actuation on the aeroelastic behavior of a twist-morphing wing. Ni et al. [82] investigated the effect of morphing rate on the aeroelastic performance of a folding wing. Cheung et al. [104] studied the effect of actuation frequency on the wing root bending moment of a folding wingtip. Hu et al. [85] presented the effect of morphing rate and morphing modes (folding and unfolding) on the dynamic aeroelastic stability of the folding wing. Matthew et al. [92] investigated the influence of actuator stiffness on the flutter instabilities of a folding wing and Li et al. [140] presented the influence of morphing stiffness on the critical flutter speed of a camber morphing wing. In addition, Perara et 
al. [151] studied the effective stiffness of the TTAM on the dynamic and aeroservoelastic behavior of a camber morphing wing using vibration analysis.

Very few studies have considered the influence of the type of actuation system on the aeroelasticity of morphing wings. For example, Li et al. [140] numerically investigated the influence of the actuation beam on the critical flutter speed of a camber morphing wing. The results showed that the exclusion of actuation beams in the FE model reduced the critical flutter speed from $45.1 \mathrm{~m} / \mathrm{s}$ to $42.2 \mathrm{~m} / \mathrm{s}$. In addition, Perara et al. [151] numerically studied the presence of the servomotor for the actuation of a camber morphing wing on the bending and torsional frequency. The results showed that the servomotor has little influence on the bending frequency. On the other hand, the torsional frequency is increased due to the presence of the servomotor.

\subsection{Type of study}

Most of the research papers in the literature are either analytical or numerical studies. A representative example is Liska and Dowell [91] who presented an aeroelastic model and an analytical solution methodology to find the flutter solutions for a two-segment uniform folding wing. Very few studies conducted mechanical and wind-tunnel testing and validation such as Attar et al. [93], Wang et al. [94], Keidel et al. [130], Ai et al. [136], Arena et al. [126] and Li et al. [140]. Studies that involved flight-testing are extremely rare in the literature. A representative example is Wilson et al. [110] who conducted extensive wind-tunnel and flight tests to assess the load alleviation capability of the SAH. In addition, all of the studies in the literature did not account for uncertainties that may exist. These uncertainties include the modeling errors, underlying assumptions, sensors, and measurement noise.

\subsection{Effect of nonlinearities}

The majority of aeroelastic studies on morphing wings are linear. Few studies considered structural nonlinearities, whilst studies that account for aerodynamic nonlinearities are very rare. An example of structural nonlinearity is the nonlinear plate elements used in [83] to study aeroelasticity of a folding wing. Examples on aerodynamic nonlinearities include Gamboa et al. [18] who considered a nonlinear lifting-line algorithm, Previtali and Ermanni [147] and Mao et al. [152] who used the nonlinear ELLT to investigate the aeroelasticity of camber morphing wings.

\section{$4.52 D$ airfoils, 3D wings or Full aircraft?}

The number of aeroelastic studies on 3D morphing wings exceeds those that focused on 2D morphing airfoils. Most of the work on 2D morphing airfoils is associated with camber morphing such as the work done by Su [138], Murua et al. [142], and Bilgen et al. [144, 145]. The choice between 2D airfoils or 3D wings depends mainly on the degree of freedom and the morphing concept used. This has a significant effect on the structural and aerodynamic tools used and on the accuracy of the results.

It is evident from the literature that most of the studies focused on the aeroelasticity of morphing wings (airfoils and 3 dimensional wings) without considering the contribution of the entire aircraft and the coupling between aeroelasticity and flight mechanics. One reason behind such a trend is to simplify the aeroelastic analysis. Another reason is that most of the morphing 
concepts studied in literature are at the proof of concept stage and an aeroelastic model of the full aircraft is not vital at such a low maturity stage. Examples of studies that considered the full aircraft include the work done by Castrichini et al. [105-107], Fonte et al. [100], and Noviello et al. [101].

\subsection{Type of aircraft}

In the past, the aeroelasticity of morphing wings was studied on fighters, such as the F/A-18 in the Active Aeroelastic Wing (AAW) program [169, 170] and the F-16 in the Active Flexible Wing (AFW) program [171]. However, most of the recent studies focused on UAVs for a number of reasons such as low risks and costs. Moreover, UAVs are good testbeds to investigate morphing technologies and are subject to less stringent airworthiness/certification regulations. In addition, UAVs are more likely to be designed with multi-mission capabilities making morphing wings more suitable for this class of air-vehicle. It should be noted that a number of studies considered general wings without specifying the type of aircraft and their designated missions. Commercial transport aircraft have also been used in literature, especially for concepts related to dihedral morphing (folding wingtips) [81, 102].

\subsection{Flight speeds}

It can be clearly seen that the majority of studies on the aeroelasticity of morphing wings have focused on low subsonic speeds with a very limited number of studies focusing on transonic speeds $[13,95,114,119]$ and supersonic speeds $[51,115]$. This is mainly because the current trend is to apply morphing on small UAVs which tend to fly at low subsonic speeds. Furthermore, transonic aeroelasticity can lead to extremely complex flows due to the presence of shockwaves, which necessitate high-fidelity aerodynamic models to accurately capture the underlying physics.

\subsection{Types of actuation system}

Most of the research activities have focused on active morphing concepts. Few studies have focused on the aeroelasticity of passive morphing wings, such as the passive twist wingtip [80], SMA-based passive control for twist morphing [79], the "Z" configuration for HALE aircraft [96]. Some studies have focused on semi-active morphing wings but this is very rare. A representative example, is the SAH proposed by Castrichini et al. [108] where during cruise, the SAH allows the wingtip to remain in place using a blocking mechanism. When triggering events, such as a gust is detected, the wingtip is actively released and the tip device then acts as a passive load alleviation system that is purely driven by inertial and aerodynamic forces. After the gust load event is finished, an actuator brings the wingtip back to the initial position.

\subsection{Aerodynamic and structural solvers}

At low-subsonic speeds, the most popular aerodynamic methods/solvers are UVLM, DLM, and Theodorsen Unsteady Aerodynamic Theory/Strip Theory. In addition, XFOIL (the 2D panel method) and the 3D panel method were widely used. Different CFD codes, including DLR CODE and Star CCM+ pack, were also used. The nonlinear lifting line theory, higher-order panel code PAN AIR, two dimensional (2D) finite-state inflow theory, the Vortex Ring Method and Weissinger method have also been used. For the transonic flow conditions, the VLM and a finitevolume CFD solver ADflow were used whilst the piston theory was used for supersonic speeds. 
For structural modeling, it can be seen that beam (such as the Euler-Bernoulli, Timoshenko beam, and nonlinear models), plate, and shell models have been used to represent morphing structures. Beam was the most popular model used. Different fidelity levels were used in structural modelling ranging for low-fidelity equivalent models to high-fidelity detailed models using FEM solvers. The most used FEM software is MSC.Nastran/Patran followed by Abaqus and Ansys.

\subsection{Degrees of freedom}

Camber morphing has received the greatest attention compared to other morphing degrees of freedom. This is mainly because of the high effectiveness of camber in changing the aerodynamic forces and moments. In addition, morphing concepts to facilitate camber change are somewhat less complex when compared to morphing concepts for other degrees of freedom and they usually have low actuation requirements. Unlike other degrees of freedom, camber morphing provides benefits over a wide range of flight conditions and missions.

Following camber morphing, dihedral morphing (folding wing/wingtips, gull, spanwise bending) has received significant attention. It offers a number of advantages, such as drag reduction (through vorticity distribution), improved stall characteristics, and the ability to control wingspan. There seems to be significant interest in this degree of freedom (folding wingtip) for large transport aircraft (Airbus and Boeing) and for HALE UAVs (spanwise bending).

Both span morphing and twist morphing wings have received the same level of attention behind dihedral morphing. Finally, thickness-to-chord ratio, sweep, and chord morphing have received very little attention.

\section{Conclusions}

An extensive review of the aeroelasticity of morphing wings for fixed-wing aircraft has been presented. The review has focused on research activities performed during the last decade. The main conclusions and observations can be summarized as follows:

- Most of the studies were numerical/computational with a limited number of mechanical and wind-tunnel tests. Flight testing was extremely rare.

- The aeroelasticity of camber morphing received the greatest level of attention when compared to other morphing degrees of freedom.

- Most of the studies focused on UAVs and were limited to low subsonic speeds.

- There is a lack in modeling and accounting for the effect of morphing skins that usually exhibit highly nonlinear behavior.

- The sensitivity of the aeroelastic behavior of morphing wings to the type of actuation system has not been adequately addressed.

- Structural nonlinearities were considered, however aerodynamic and control nonlinearities have been given little attention, due to the associated complexity.

- Scalability of the aeroelastic properties and the behavior of morphing wing concepts have not been studied in the literature.

- Studies that couple flight dynamics with aeroelasticity (unrestrained bodies) are very rare in literature. 
- A number of morphing aeroelastic frameworks have been developed. Some frameworks focused on single dof (monomorphing) whilst others considered multiple dofs (polymorphing)

- There is a lack of comprehensive aeroelastic frameworks that can handle different types of nonlinearity together.

- None of the studies accounted for the different uncertainties that might exist when studying the aeroelasticity of morphing wings. This includes uncertainties in modeling, design parameters, flight conditions, and experimental data.

- Most studies have focused on quasi-static morphing scenarios (before morphing and after morphing) but the number of studies that consider dynamic situations (during morphing) has increased especially for span morphing.

- Most of the aerodynamic models used are based on low-fidelity methods. In contrast, the structural analysis for aeroelastic studies is more mature, where a variety of models have been used ranging from the low-fidelity, Euler-Bernoulli beam models, to the high-fidelity, very detailed FE models.

- Although failure of morphing wings can have a significant effect on the aeroelastic margins, this has not been yet addressed. In addition, different types of failure should be considered, such as flexible skin cracking, and actuation jamming.

- Most of the studies in the literature belong to the aeroelastic stability theme (i.e. to ensure that the morphing concepts satisfy certain aeroelastic requirements/constraints and that such requirements/constraints do not limit the potential benefits of morphing).

\section{Declaration}

- Funding: This work did not receive any funding.

- Conflicts of interest/Competing interests: The authors declare that they have no conflict of interest. 


\section{References}

[1] P. Argüelles, M. Bischoff, P. Busquin, B. Droste, R. Evans, W. Kröll, and J. Lagardere, "European Aeronautics: a vision for 2020 Advisory Council for Aeronautics Research in Europe (ACARE)," 2001.

[2] M. Darecki, C. Edelstenne, T. Enders, E. Fernandez, P. Hartman, J. Herteman, M. Kerkloh, I. King, P. Ky, and M. Mathieu, "Flightpath 2050: Europe's vision for aviation maintaining global leadership and serving society's needs." Publications Office of the European Union, Luxembourg, 2011. https://doi.org/10.2777/50266.

[3] T. A. Weisshaar, "Morphing aircraft technology-new shapes for aircraft design," PURDUE UNIV LAFAYETTE IN 2006.

[4] S. Joshi, Z. Tidwell, W. Crossley, and S. Ramakrishnan, "Comparison of morphing wing stategies based upon aircraft performance impacts," in 45th AIAA/ASME/ASCE/AHS/ASC Structures, Structural Dynamics \& Materials Conference, p. 1722, 2004. doi:https://doi.org/10.2514/6.20041722.

[5] S. Barbarino, O. Bilgen, R. M. Ajaj, M. I. Friswell, and D. J. Inman, "A review of morphing aircraft," Journal of intelligent material systems and structures, vol. 22, pp. 823-877, 2011. doi: https://doi.org/10.1177/1045389X11414084.

[6] R. M. Ajaj, C. S. Beaverstock, and M. I. Friswell, "Morphing aircraft: The need for a new design philosophy," Aerospace Science and Technology, vol. 49, pp. 154-166, 2016. doi: https://doi.org/10.1016/j.ast.2015.11.039.

[7] A.-M. R. McGowan, D. D. Vicroy, R. C. Busan, and A. S. Hahn, "Perspectives on Highly adaptive or morphing aircraft," presented at the NATO RTO AVT-168 Symposium, Lisbon, Portugal, 2009.

[8] Q. Ai, M. Azarpeyvand, X. Lachenal, and P. M. Weaver, "Aerodynamic and aeroacoustic performance of airfoils with morphing structures," Wind Energy, vol. 19, pp. 1325-1339, 2016. doi: https://doi.org/10.1002/we.1900.

[9] L. F. Campanile and S. Anders, "Aerodynamic and aeroelastic amplification in adaptive belt-rib airfoils," Aerospace Science and Technology, vol. 9, pp. 55-63, 2005. doi: https://doi.org/10.1016/j.ast.2004.07.007.

[10] X. Lachenal, S. Daynes, and P. M. Weaver, "Review of morphing concepts and materials for wind turbine blade applications," Wind energy, vol. 16, pp. 283-307, 2013. doi: https://doi.org/10.1002/we.531.

[11] R. De Breuker, M. M. Abdalla, and Z. Gürdal, "A generic morphing wing analysis and design framework," Journal of Intelligent Material Systems and Structures, vol. 22, pp. 1025-1039, 2011. doi: https://doi.org/10.1177/1045389X11414958.

[12] N. Werter and R. De Breuker, "A framework for the aeroelastic analysis and design of generic morphing wings," in 23rd AIAA/AHS Adaptive Structures Conference, 2015. doi:https://doi.org/10.2514/6.2015-0268.

[13] J. Yang, J. E. Cooper, R. K. Nangia, and J. C. Simpson, "Optimization framework for design of morphing wings," in 14th AIAA aviation technology, integration, and operations conference, 2014. doi:https://doi.org/10.2514/6.2014-2722.

[14] R. Sun, D. Yan, R. K. Nangia, and J. E. Cooper, "Optimization design for aero-elastic morphing wings," in 2017 9th International Conference on Modelling, Identification and Control (ICMIC), pp. 25-30, 2017. doi:https://doi.org/10.1109/ICMIC.2017.8321654.

[15] S. Preidikman, B. Roccia, M. Verstraete, L. Ceballos, and B. Balachandran, "A Computational Aeroelastic Framework for Studying Non-conventional Aeronautical Systems," in International Symposiu on Multibody Systems and Mechatronics, pp. 325-334, 2017. doi:https://doi.org/10.1007/978-3-319-67567-1_31. 
[16] L. Ünlüsoy and Y. Yaman, "Aeroelastic behaviour of UAV wings due to morphing," Aircraft Engineering and Aerospace Technology, 2017. doi: https://doi.org/10.1108/aeat-12-2014-0217.

[17] G. Molinari, M. Quack, V. Dmitriev, M. Morari, P. Jenny, and P. Ermanni, "Aero-structural optimization of morphing airfoils for adaptive wings," Journal of Intelligent Material Systems and Structures, vol. 22, pp. 1075-1089, 2011. doi: https://doi.org/10.1177/1045389X11414089.

[18] P. Gamboa, J. Vale, F. Lau, and A. Suleman, "Optimization of a morphing wing based on coupled aerodynamic and structural constraints," AIAA journal, vol. 47, pp. 2087-2104, 2009. doi: https://doi.org/10.2514/6.2007-1890.

[19] N. Tsushima, H. Arizono, K. Soneda, T. Yokozeki, T. Imamura, and W. Su, "Structural and Aerodynamic Models for Aeroelastic Analysis of Corrugated Morphing Wings," in AIAA Scitech 2020 Forum, 2020. doi:https://doi.org/10.2514/6.2020-0215.

[20] L. Cavagna, A. DE GASPARI, S. Ricci, and L. Riccobene, "NeoCASS+, a conceptual design and simulation framework for morphing aircraft," in 3rd CEAS Air \& Space Conference and 21st AIDAA Congress, Venezia, Italia., pp. 922-933, 2011.

[21] L. Cavagna, A. De Gaspari, L. Riccobene, and S. Ricci, "NeoCASS+, A Conceptual Design and Simulation Framework for Morphing Aircraft," Aerotecnica Missili \& Spazio, vol. 92, pp. 52-60, 2013. doi: https://doi.org/10.1007/BF03404663.

[22] D. Li, S. Zhao, A. Da Ronch, J. Xiang, J. Drofelnik, Y. Li, L. Zhang, Y. Wu, M. Kintscher, and H. P. Monner, "A review of modelling and analysis of morphing wings," Progress in Aerospace Sciences, vol. 100, pp. 46-62, 2018. doi: https://doi.org/10.1016/j.paerosci.2018.06.002.

[23] S. Daynes and P. M. Weaver, "Stiffness tailoring using prestress in adaptive composite structures," Composite Structures, vol. 106, pp. 282-287, $2013 . \quad$ doi: https://doi.org/10.1016/j.compstruct.2013.05.059.

[24] S. Barbarino, E. S. Flores, R. M. Ajaj, I. Dayyani, and M. I. Friswell, "A review on shape memory alloys with applications to morphing aircraft," Smart materials and structures, vol. 23, 2014. doi: https://doi.org/10.1088/0964-1726/23/6/063001.

[25] I. Dayyani, A. Shaw, E. S. Flores, and M. I. Friswell, "The mechanics of composite corrugated structures: A review with applications in morphing aircraft," Composite Structures, vol. 133, pp. 358-380, 2015. doi: https://doi.org/10.1016/j.compstruct.2015.07.099.

[26] J. Sun, Q. Guan, Y. Liu, and J. Leng, "Morphing aircraft based on smart materials and structures: A state-of-the-art review," Journal of Intelligent material systems and structures, vol. 27, pp. 22892312, 2016. doi: https://doi.org/10.1177/1045389X16629569.

[27] Z. Min, V. K. Kien, and L. J. Richard, "Aircraft morphing wing concepts with radical geometry change," The IES Journal Part A: Civil \& Structural Engineering, vol. 3, pp. 188-195, 2010. doi: https://doi.org/10.1080/19373261003607972.

[28] A. Sofla, S. Meguid, K. Tan, and W. Yeo, "Shape morphing of aircraft wing: Status and challenges," Materials \& Design, vol. 31, pp. 1284-1292, 2010. doi: https://doi.org/10.1016/j.matdes.2009.09.011.

[29] S. Vasista, L. Tong, and K. Wong, "Realization of morphing wings: a multidisciplinary challenge," Journal of aircraft, vol. 49, pp. 11-28, 2012. doi: https://doi.org/10.2514/1.C031060.

[30] M. Sinapius, H. Monner, M. Kintscher, and J. Riemenschneider, "DLR's morphing wing activities within the European network," Mechanics, vol. 10, pp. 416-426, 2014. doi: https://doi.org/10.1016/j.piutam.2014.01.036

[31] I. K. Kuder, A. F. Arrieta, W. E. Raither, and P. Ermanni, "Variable stiffness material and structural concepts for morphing applications," Progress in Aerospace Sciences, vol. 63, pp. 33-55, 2013. doi: https://doi.org/10.1016/j.paerosci.2013.07.001.

[32] N. Hu and R. Burgueño, "Buckling-induced smart applications: recent advances and trends," Smart Materials and Structures, vol. 24, 2015. doi: https://doi.org/10.1088/0964-1726/24/6/063001. 
[33] S. Daynes and P. M. Weaver, "Review of shape-morphing automobile structures: concepts and outlook," in Proceedings of the Institution of Mechanical Engineers, Part D: Journal of Automobile Engineering, pp. 1603-1622, 2013. doi:https://doi.org/10.1177/0954407013496557.

[34] J. R. Wright and J. E. Cooper, Introduction to aircraft aeroelasticity and loads vol. 20: John Wiley \& Sons, 2008, ISBN:978-0470-85840-0.

[35] E. Pendleton, P. Flick, D. Paul, D. Voracek, E. Reichenbach, and K. Griffin, "The X-53 a summary of the active aeroelastic wing flight research program," in 48th AIAA/ASME/ASCE/AHS/ASC Structures, Structural Dynamics, and Materials Conference, 2007. doi:https://doi.org/10.2514/6.2007-1855.

[36] S. B. Cumming, M. S. Smith, A. Ali, T. T. Bui, J. Ellsworth, and C. A. Garcia, "Aerodynamic flight test results for the adaptive compliant trailing edge," in AIAA Atmospheric Flight Mechanics Conference, 2016. doi:https://doi.org/10.2514/6.2016-3855.

[37] M. S. Smith, T. T. Bui, C. A. Garcia, and S. B. Cumming, "Longitudinal aerodynamic modeling of the adaptive compliant trailing edge flaps on a GIII aircraft and comparisons to flight data," in AIAA Atmospheric Flight Mechanics Conference, 2016. doi:https://doi.org/10.2514/6.2016-3703.

[38] N. Nguyen, U. Kaul, S. Lebofsky, E. Ting, D. Chaparro, and J. Urnes, "Development of variable camber continuous trailing edge flap for performance adaptive aeroelastic wing," presented at the SAE AeroTech Congress \& Exhibition, Seattle, WA; United States, 2015. doi:https://doi.org/10.4271/2015-01-2565.

[39] N. Tsushima, H. Arizono, T. Yokozeki, and W. Su, "Nonlinear aeroelasticity of morphing wings with corrugated structures," in AIAA Scitech 2019 Forum, 2019. doi:https://doi.org/10.2514/6.2019-0219.

[40] R. M. Ajaj and M. I. Friswell, "Aeroelasticity of compliant span morphing wings," Smart materials and structures, vol. 27, p. 105052, 2018. doi: https://doi.org/10.1088/1361-665x/aad219.

[41] R. M. Ajaj, F. K. Omar, T. T. Darabseh, and J. Cooper, "Flutter of Telescopic Span Morphing Wings," International Journal of Structural Stability and Dynamics, vol. 19, 2019. doi: https://doi.org/10.1142/s0219455419500615.

[42] C. Huang, Y. Chao, W. Zhigang, and T. Changhong, "Variations of flutter mechanism of a spanmorphing wing involving rigid-body motions," Chinese Journal of Aeronautics, vol. 31, pp. 490497, 2018. doi: https://doi.org/10.1016/j.cja.2017.12.014.

[43] E. Widmayer Jr, "Some low-speed studies of the effects of wing location on wing-deformationbody-freedom flutter," 1952.

[44] T. A. Weisshaar and T. A. Zeiler, "Dynamic stability of flexible forward swept wing aircraft," Journal of Aircraft, vol. 20, pp. 1014-1020, 1983. doi: https://doi.org/10.2514/6.1982-1325.

[45] M. Love, P. Zink, P. Wieselmann, and H. Youngren, "Body freedom flutter of high aspect ratio flying wings," in 46th AIAA/ASME/ASCE/AHS/ASC Structures, Structural Dynamics and Materials Conference, 2005. doi:https://doi.org/10.2514/6.2005-1947.

[46] R. Huang and Z. Qiu, "Transient aeroelastic responses and flutter analysis of a variable-span wing during the morphing process," Chinese Journal of Aeronautics, vol. 26, pp. 1430-1438, 2013. doi: https://doi.org/10.1016/j.cja.2013.07.047.

[47] P. Gamboa, P. Santos, J. Silva, and P. Santos, "Flutter analysis of a composite variable-span wing," in 4th international conference on integrity, reliability and failure, Funchal, pp. 23-27, 2013

[48] S. Murugan, J. H. Fincham, M. I. Friswell, and D. Inman, "Aeroelastic Modeling of Morphing Aircraft Wings," in 4th Aircraft Structural Design Conference, Belfast (UK), 2014

[49] R. M. Ajaj, E. S. Flores, M. I. Friswell, G. Allegri, B. Woods, A. Isikveren, and W. Dettmer, "The Zigzag wingbox for a span morphing wing," Aerospace Science and Technology, vol. 28, pp. 364375, 2013. doi: https://doi.org/10.1016/j.ast.2012.12.002. 
[50] R. M. Ajaj, M. I. Friswell, M. Bourchak, and W. Harasani, "Span morphing using the GNATSpar wing," Aerospace Science and Technology, vol. 53, pp. 38-46, 2016. doi: https://doi.org/10.1016/j.ast.2016.03.009.

[51] W. Li and D. Jin, "Flutter suppression and stability analysis for a variable-span wing via morphing technology," Journal of Sound and Vibration, vol. 412, pp. 410-423, 2018. doi: https://doi.org/10.1016/j.jsv.2017.10.009.

[52] D. Perkins, J. Reed, and E. Havens, "Morphing wing structures for loitering air vehicles," in 45th AIAA/ASME/ASCE/AHS/ASC Structures, Structural Dynamics \& Materials Conference, p. 1888, 2004. doi:https://doi.org/10.2514/6.2004-1888.

[53] O. Léon, E. Hayden, and F. Gandhi, "Rotorcraft operating envelope expansion using extendable chord sections," in Proceedings of American Helicopter Society 65th Annual Forum, p. 29, 2009

[54] O. Léon and F. Gandhi, "Rotor power reduction using multiple spanwise-segmented, optimallyactuated trailing-edge flaps," in 35th European Rotorcraft Forum 2009, Hamburg, Germany, 2009

[55] S. Barbarino, F. Gandhi, and S. D. Webster, "Design of extendable chord sections for morphing helicopter rotor blades," Journal of Intelligent Material Systems and Structures, vol. 22, pp. 891905, 2011. doi: https://doi.org/10.1177/1045389X11414077.

[56] M. Khoshlahjeh, E. Sung Bae, and F. Gandhi, "Helicopter performance improvement with variable chord morphing rotors," in Proceedings of the 36th European Rotorcraft Forum, Paris, France, 2010.

[57] M. Khoshlahjeh and F. Gandhi, "Extendable chord rotors for helicopter envelope expansion and performance improvement," Journal of the American Helicopter Society, vol. 59, pp. 1-10, 2014. doi: https://doi.org/10.4050/JAHS.59.012007.

[58] J. A. Shortal and B. Maggin, "Effect of sweepback and aspect ratio on longitudinal stability characteristics of wings at low speeds," NATIONAL ADVISORY COMMITTEE FOR AERONAUTICS LANGLEY FIELD VA LANGLEY ...1946.

[59] L. W. Hunton and J. K. Dew, "Measurements of the Damping in Roll of Large-scale Swept-forward and Swept-back Wings," 1947.

[60] R. Kress, "Variable sweep wing design," in Aircraft Prototype and Technology Demonstrator Symposium, p. 1051, 1983. doi:https://doi.org/10.2514/6.1983-1051.

[61] R. PERRY, "Variable-sweep aircraft-A case history of multiple re-innovation," in 3rd Annual Meeting, p. 983, 1966. doi:https://doi.org/10.2514/6.1966-983.

[62] E. C. Polhamus and A. D. Hammond, "Aerodynamic Research Relative to Variable-Sweep Multimission Aircraft," Langley Research Center, NASA, 1967.

[63] F. Sabri and S. Meguid, "Flutter boundary prediction of an adaptive morphing wing for unmanned aerial vehicle," International Journal of Mechanics and Materials in Design, vol. 7, p. 307, 2011. doi: https://doi.org/10.1007/s10999-011-9169-z.

[64] A. Sofla, S. Meguid, and K. Tan, "Novel morphing wing design using antagonistic shape memory alloy actuation," in ASME 2010 International Mechanical Engineering Congress and Exposition, pp. 33-36, 2011. doi:https://doi.org/10.1115/IMECE2010-38851.

[65] F. Sabri, S. Meguid, A. Lakis, and K. Tan, "Aeroelastic behaviour of a novel morphing wing using shape memory alloys," in International Forum on Aeroelasticity and Structural Dynamics, Paris, 2011

[66] Z. Hui, Y. Zhang, and G. Chen, "Aerodynamic performance investigation on a morphing unmanned aerial vehicle with bio-inspired discrete wing structures," Aerospace Science and Technology, vol. 95, p. 105419, 2019. doi: https://doi.org/10.1016/j.ast.2019.105419.

[67] R. Pecora, F. Amoroso, and L. Lecce, "Effectiveness of wing twist morphing in roll control," Journal of aircraft, vol. 49, pp. 1666-1674, 2012. doi: https://doi.org/10.2514/1.C000328. 
[68] M. Amoozgar, S. A. Fazelzadeh, M. I. Friswell, and D. H. Hodges, "Aeroelastic Stability Analysis of Tailored Pretwisted Wings," AIAA Journal, vol. 57, pp. 4458-4466, 2019. doi: https://doi.org/10.2514/1.J058575.

[69] B. Jenett, S. Calisch, D. Cellucci, N. Cramer, N. Gershenfeld, S. Swei, and K. C. Cheung, "Digital morphing wing: active wing shaping concept using composite lattice-based cellular structures," Soft robotics, vol. 4, pp. 33-48, 2017. doi: https://doi.org/10.1089/soro.2016.0032.

[70] N. B. Cramer, D. W. Cellucci, O. B. Formoso, C. E. Gregg, B. E. Jenett, J. H. Kim, M. Lendraitis, S. S. Swei, G. T. Trinh, and K. V. Trinh, "Elastic shape morphing of ultralight structures by programmable assembly," Smart Materials and Structures, vol. 28, 2019. doi: https://doi.org/10.1088/1361-665x/ab0ea2.

[71] S. Sleesongsom and S. Bureerat, "Effect of actuating forces on aeroelastic characteristics of a morphing aircraft wing," in Applied Mechanics and Materials, pp. 308-317, 2011. doi:https://doi.org/10.4028/www.scientific.net/AMM.52-54.308.

[72] R. M. Ajaj, M. I. Friswell, W. Dettmer, G. Allegri, and A. Isikveren, "Performance and control optimisations using the adaptive torsion wing," The Aeronautical Journal, vol. 116, pp. 1061-1077, 2012. doi: https://doi.org/10.1017/S000192400000748X.

[73] R. M. Ajaj, M. I. Friswell, and E. S. Flores, "On the effectiveness of active aeroelastic structures for morphing aircraft," The Aeronautical Journal, vol. 117, pp. 1167-1176, 2013. doi: https://doi.org/10.1017/S0001924000008769.

[74] R. M. Ajaj, M. I. Friswell, W. Dettmer, A. Isikveren, and G. Allegri, "Conceptual modeling of an adaptive torsion wing structure," in 52nd AIAA/ASME/ASCE/AHS/ASC Structures, Structural Dynamics and Materials Conference 19th AIAA/ASME/AHS Adaptive Structures Conference 13t, p. 1883, 2011. doi:https://doi.org/10.2514/6.2011-1883.

[75] R. M. Ajaj, M. I. Friswell, D. Smith, A. Isikveren, and G. Allegri, "Roll control of a UAV using an adaptive torsion structure," in 52nd AIAA/ASME/ASCE/AHS/ASC Structures, Structural Dynamics and Materials Conference 19th AIAA/ASME/AHS Adaptive Structures Conference 13t, p. 1834, 2011. doi:https://doi.org/10.2514/6.2011-1834.

[76] D. Smith, A. Isikveren, R. M. Ajaj, and M. I. Friswell, "Multidisciplinary design optimization of an active nonplanar polymorphing wing," in 27th International Congress of The Aeronautical Sciences (ICAS), 2010

[77] R. M. Ajaj, M. I. Friswell, D. Smith, and A. Isikveren, "A conceptual wing-box weight estimation model for transport aircraft," The Aeronautical Journal, vol. 117, pp. 533-551, 2013. doi: https://doi.org/10.1017/S0001924000008174.

[78] R. M. Ajaj, M. I. Friswell, W. G. Dettmer, G. Allegri, and A. T. Isikveren, "Dynamic modelling and actuation of the adaptive torsion wing," Journal of intelligent material systems and structures, vol. 24, pp. 2045-2057, 2013. doi: https://doi.org/10.1177/1045389X12444493.

[79] G. C. Silva, F. J. Silvestre, M. V. Donadon, O. S. Santos, A. B. Guimarães Neto, R. G. A. da Silva, T. d. S. S. Versiani, P. J. Gonzalez, and R. M. Bertolin, "Active and Passive Control for Acceleration Reduction of an Aeroelastic Typical Wing Section," Journal of Vibration and Control, vol. 24, pp. 2673-2687, 2018. doi: https://doi.org/10.1177/1077546317728147.

[80] S. Guo, D. Los Monteros, J. Espinosa, and Y. Liu, "Gust alleviation of a large aircraft with a passive twist wingtip," Aerospace, vol. 2, pp. 135-154, $2015 . \quad$ doi: https://doi.org/10.3390/aerospace2020135.

[81] T. Wilson, A. Azabal, A. Castrichini, J. Cooper, R. M. Ajaj, and M. Herring, "Aeroelastic behaviour of hinged wing tips," presented at the International Forum on Aeroelasticity and Structural Dynamics, IFASD 2017, Como -Italy, 2017.

[82] Y. Ni, C. Hou, X. Wan, and M. Zhao, "Transient Aeroelastic Responses of Folding Wing in Morphing Motion," in International Conference on Advances in Mechanical Engineering and Industrial Informatics, AMEII 2015, Zhengzhou, Henan, China, 2015. 
[83] P. Li, Y. Ni, C. Hou, X. Wan, and M. Zhao, "Nonlinear Aeroelastic Modeling of a Folding Wing Structure," Journal of Physics: Conference Series, vol. 1215, 2019. doi: https://doi.org/10.1088/1742-6596/1215/1/012009.

[84] W. Rodden, J. Giesing, and T. Kalman, "New method for nonplanar configurations," in AGARD Conference Proceedings., 1971

[85] W. Hu, Z. Yang, and Y. Gu, "Aeroelastic study for folding wing during the morphing process," Journal of Sound and Vibration, vol. 365, pp. 216-229, 2016. doi: https://doi.org/10.1016/j.jsv.2015.11.043.

[86] W. Zhang, S. Lv, and Y. Ni, "Parametric aeroelastic modeling based on component modal synthesis and stability analysis for horizontally folding wing with hinge joints," Nonlinear Dynamics, vol. 92, pp. 169-179, 2018. doi: https://doi.org/10.1007/s11071-017-3956-5.

[87] M. L. Verstraete, B. A. Roccia, D. T. Mook, and S. Preidikman, "A co-simulation methodology to simulate the nonlinear aeroelastic behavior of a folding-wing concept in different flight configurations," Nonlinear Dynamics, vol. 98, pp. 907-927, 2019. doi: https://doi.org/10.1007/s11071-019-05234-9.

[88] B. Carnahan, H. Luther, and J. O. Wilkes, Applied Numerical Methods. New York: Wiley, 1969

[89] Y. Zhao and H. Hu, "Parameterized aeroelastic modeling and flutter analysis for a folding wing," Journal of Sound and Vibration, vol. 331, pp. 308-324, 2012. doi: https://doi.org/10.1016/j.jsv.2011.08.028.

[90] Y. Zhao and H. Hu, "Prediction of transient responses of a folding wing during the morphing process," Aerospace Science and Technology, vol. 24, pp. 89-94, 2013. doi: https://doi.org/10.1016/j.ast.2011.09.001.

[91] S. Liska and E. H. Dowell, "Continuum aeroelastic model for a folding-wing configuration," AIAA Journal, vol. 47, pp. 2350-2358, 2009. doi: https://doi.org/10.2514/1.40475.

[92] M. P. Snyder, B. Sanders, F. E. Eastep, and G. J. Frank, "Vibration and flutter characteristics of a folding wing," Journal of Aircraft, vol. 46, pp. 791-799, 2009. doi: https://doi.org/10.2514/1.34685.

[93] P. J. Attar, D. Tang, and E. H. Dowell, "Nonlinear aeroelastic study for folding wing structures," AIAA journal, vol. 48, pp. 2187-2195, 2010. doi: https://doi.org/10.2514/1.44868.

[94] I. Wang, S. C. Gibbs, and E. H. Dowell, "Aeroelastic model of multisegmented folding wings: theory and experiment," Journal of aircraft, vol. 49, pp. 911-921, 2012. doi: https://doi.org/10.2514/1.C031589.

[95] J. Cooper, I. Chekkal, R. Cheung, C. Wales, N. Allen, S. Lawson, A. Peace, R. Cook, P. Standen, and S. Hancock, "Design of a morphing wingtip," Journal of Aircraft, vol. 52, pp. 1394-1403, 2015. doi: https://doi.org/10.2514/1.C032861.

[96] P. Mardanpour and D. H. Hodges, "Passive morphing of flying wing aircraft: Z-shaped configuration," Journal of Fluids and Structures, vol. 44, pp. 17-30, 2014. doi: https://doi.org/10.1016/j.jfluidstructs.2013.09.020.

[97] Y. Y. Jung and J. H. Kim, "Aeroelastic Behavior of Morphing Wing in Flutter Regions," Applied Mechanics and Materials, vol. 284-287, pp. 442-445, 2013. doi: https://doi.org/10.4028/www.scientific.net/AMM.284-287.442.

[98] R. De Breuker, M. Abdalla, and Z. Gürdal, "Design of morphing winglets with the inclusion of nonlinear aeroelastic effects," The Aeronautical Journal, vol. 115, pp. 713-728, 2011. doi: https://doi.org/10.1017/S0001924000006461.

[99] C. Liauzun, D. Le Bihan, J.-M. David, D. Joly, and B. Paluch, "Study of morphing winglet concepts aimed at improving load control and the aeroelastic behavior of civil transport aircraft," Journal Aerospace Lab, 2018.

[100] F. Fonte, G. Iannaccone, N. Cimminiello, I. Dimino, and S. Ricci, "Active Load Control of a Regional Aircraft Wing Equipped With Morphing Winglets," in ASME 2018 Conference on Smart 
Materials, Adaptive Structures and Intelligent Systems, 2018. doi:https://doi.org/10.1115/SMASIS2018-8167.

[101] M. C. Noviello, I. Dimino, F. Amoroso, and R. Pecora, "Preliminary Assessment of Morphing Winglet and Flap Tabs Influence on the Aeroelastic Stability of Next Generation Regional Aircraft," in ASME 2018 Conference on Smart Materials, Adaptive Structures and Intelligent Systems, 2018. doi:https://doi.org/10.1115/SMASIS2018-8138.

[102] T. Wilson, M. Herring, J. Pattinson, J. Cooper, A. Castrichini, A. Rafic, and H. Dhoru, "An aircraft wing with a moveable wing tip device for load alleviation," 2019, U.S. Patent Application No. $16 / 067,221$.

[103] R. C. Cheung, D. Rezgui, J. E. Cooper, and T. Wilson, "Testing of a Hinged Wingtip Device for Gust Loads Alleviation," Journal of Aircraft, vol. 55, pp. 2050-2067, 2018. doi: https://doi.org/10.2514/1.C034811.

[104] R. C. Cheung, D. Rezgui, J. E. Cooper, and T. Wilson, "Testing of folding wing-tip for gust load alleviation in high aspect ratio wing," in AIAA Scitech 2019 Forum, 2019. doi:https://doi.org/10.2514/6.2019-1863.

[105] A. Castrichini, V. Hodigere Siddaramaiah, D. Calderon, J. E. Cooper, T. Wilson, and Y. Lemmens, "Nonlinear folding wing tips for gust loads alleviation," Journal of Aircraft, vol. 53, pp. 1391-1399, 2016. doi: https://doi.org/10.2514/1.C033474.

[106] A. Castrichini, J. E. Cooper, T. Wilson, A. Carrella, and Y. Lemmens, "Nonlinear negative stiffness wingtip spring device for gust loads alleviation," Journal of Aircraft, vol. 54, pp. 627-641, 2017. doi: https://doi.org/10.2514/1.C033887.

[107] A. Castrichini, V. H. Siddaramaiah, D. Calderon, J. Cooper, T. Wilson, and Y. Lemmens, "Preliminary investigation of use of flexible folding wing tips for static and dynamic load alleviation," The Aeronautical Journal, vol. 121, pp. 73-94, 2017. doi: https://doi.org/10.1017/aer.2016.108.

[108] A. Castrichini, T. Wilson, F. Saltari, F. Mastroddi, N. Viceconti, and J. Cooper, "Aeroelastics Flight Dynamics Coupling Effects of the Semi-Aeroelastic Hinge Device," Journal of Aircraft, pp. 1-9, 2019. doi: https://doi.org/10.2514/1.C035602.

[109] F. Saltari, C. Riso, G. D. Matteis, and F. Mastroddi, "Finite-element-based modeling for flight dynamics and aeroelasticity of flexible aircraft," Journal of Aircraft, vol. 54, pp. 2350-2366, 2017. doi: https://doi.org/10.2514/1.C034159.

[110] T. Wilson, J. Kirk, J. Hobday, and A. Castrichini, "Small scale flying demonstration of semi aeroelastic hinged wing tips," presented at the International Forum on Aeroelasticity and Structural Dynamics, IFASD 2019 Savannah, Georgia, USA, 9-13 June , 2019

[111] S. Courchesne, A. Popov, and R. Botez, "New aeroelastic studies for a morphing wing," in 48th AIAA Aerospace Sciences Meeting including The New Horizons Forum and Aerospace Exposition, 2010. doi:https://doi.org/10.2514/6.2010-56.

[112] L. Grigorie, A. Popov, R. Botez, M. Mamou, and Y. Mébarki, "Controller and aeroelasticity analysis for a morphing wing," in AIAA atmospheric flight mechanics conference, 2011. doi:https://doi.org/10.2514/6.2011-6460.

[113] A. V. Popov, M. Labib, J. Fays, and R. M. Botez, "Closed-loop control simulations on a morphing wing," Journal of Aircraft, vol. 45, pp. 1794-1803, 2008. doi: https://doi.org/10.2514/1.37073.

[114] O. Rhodes and M. Santer, "Aeroelastic optimization of a morphing 2d shock control bump," in 53rd AIAA/ASME/ASCE/AHS/ASC Structures, Structural Dynamics and Materials Conference 20th AIAA/ASME/AHS Adaptive Structures Conference 14th AIAA, p. 1577, 2012. doi:https://doi.org/10.2514/6.2012-1577.

[115] E. R. Jinks, P. J. Bruce, and M. J. Santer, "The Use of Actuated Flexible Plates for Adaptive Shock Control Bumps," in 53rd AIAA Aerospace Sciences Meeting, p. 1241, 2015. doi:https://doi.org/10.2514/6.2015-1241. 
[116] M. J. Abzug and E. E. Larrabee, Airplane stability and control: a history of the technologies that made aviation possible vol. 14: Cambridge University Press, 2005, ISBN:0521021286.

[117] D. Raymer, Aircraft design: a conceptual approach: American Institute of Aeronautics and Astronautics, Inc., 2012, ISBN:1600869114.

[118] E. Stanewsky, "Adaptive wing and flow control technology," Progress in Aerospace Sciences, vol. 37, pp. 583-667, 2001. doi: https://doi.org/10.1016/S0376-0421(01)00017-3.

[119] D. A. Burdette and J. R. Martins, "Design of a transonic wing with an adaptive morphing trailing edge via aerostructural optimization," Aerospace Science and Technology, vol. 81, pp. 192-203, 2018. doi: https://doi.org/10.1016/j.ast.2018.08.004.

[120] S. P. MUHAMMED, "A compliant polymorphing wing for small UAVs," Chinese Journal of Aeronautics, 2020. doi: https://doi.org/10.1016/j.cja.2020.03.027.

[121] B. K. S. Woods and M. I. Friswell, "Preliminary investigation of a fishbone active camber concept," in Smart Materials, Adaptive Structures and Intelligent Systems, pp. 555-563, 2012. doi:https://doi.org/10.1115/SMASIS2012-8058.

[122] B. K. Woods, O. Bilgen, and M. I. Friswell, "Wind tunnel testing of the fish bone active camber morphing concept," Journal of Intelligent Material Systems and Structures, vol. 25, pp. 772-785, 2014. doi: https://doi.org/10.1177/1045389X14521700.

[123] G. Molinari, M. Quack, A. F. Arrieta, M. Morari, and P. Ermanni, "Design, realization and structural testing of a compliant adaptable wing," Smart Materials and Structures, vol. 24, p. 105027, 2015. doi: https://doi.org/10.1088/0964-1726/24/10/105027.

[124] A. C. Henry, G. Molinari, J. R. Rivas-Padilla, and A. F. Arrieta, "Smart morphing wing: optimization of distributed piezoelectric actuation," AIAA journal, vol. 57, pp. 2384-2393, 2019. doi: https://doi.org/10.2514/1.J057254.

[125] N. Tsushima, T. Yokozeki, W. Su, and H. Arizono, "Geometrically nonlinear static aeroelastic analysis of composite morphing wing with corrugated structures," Aerospace Science and Technology, vol. 88, pp. 244-257, 2019. doi: https://doi.org/10.1016/j.ast.2019.03.025.

[126] M. Arena, F. Amoroso, R. Pecora, G. Amendola, and I. Dimino, "Numerical and experimental validation of a full scale servo-actuated morphing aileron model," Smart Materials and Structures, vol. 27, 2018. doi: https://doi.org/10.1088/1361-665x/aad7d9.

[127] M. Arena, A. Concilio, and R. Pecora, "Aero-servo-elastic design of a morphing wing trailing edge system for enhanced cruise performance," Aerospace Science and Technology, vol. 86, pp. 215235, 2019. doi: https://doi.org/10.1016/j.ast.2019.01.020.

[128] R. Pecora, M. Magnifico, F. Amoroso, and E. Monaco, "Multi-parametric flutter analysis of a morphing wing trailing edge," The Aeronautical Journal, vol. 118, pp. 1063-1078, 2014. doi: https://doi.org/10.1017/s000192400000974x.

[129] F. Rea, R. Pecora, F. Amoroso, M. Arena, M. C. Noviello, and G. Amendola, "Aeroelastic Stability Analysis of a Wind Tunnel Wing Model Equipped with a True Scale Morphing Aileron," International Journal of Mechanical Engineering and Robotics Research, vol. 6, pp. 440-450, 2017. doi: https://doi.org/10.18178/ijmerr.6.6.440-450.

[130] D. Keidel, G. Molinari, and P. Ermanni, "Aero-structural optimization and analysis of a cambermorphing flying wing: Structural and wind tunnel testing," Journal of Intelligent Material Systems and Structures, vol. 30, pp. 908-923, 2019. doi: https://doi.org/10.1177/1045389X19828501.

[131] S. A. Brandt, J. J. Bertin, R. J. Stiles, and R. Whitford, Introduction to aeronautics: a design perspective, 2nd \& 3rd ed. Reston, VA: American Institute of Aeronautics and Astronautics, 2004

[132] N. Precup, M. Mor, and E. Livne, "An Active Variable Camber Continuous Trailing Edge Flapped Wing Wind Tunnel Model for Aeroelastic" In-Flight" Shape Optimization Tests," in 2018 Multidisciplinary Analysis and Optimization Conference, 2018. doi:https://doi.org/10.2514/6.2018-3106. 
[133] E. Livne, N. Precup, and M. Mor, "Design, construction, and tests of an aeroelastic wind tunnel model of a variable camber continuous trailing edge flap (VCCTEF) concept wing," in 32nd AIAA Applied Aerodynamics Conference, 2014. doi:https://doi.org/10.2514/6.2014-2442.

[134] U. Fasel, D. Keidel, G. Molinari, and P. Ermanni, "Aeroservoelastic Optimization of Morphing Airborne Wind Energy Wings," in AIAA Scitech 2019 Forum, 2019. doi:https://doi.org/10.2514/6.2019-1217.

[135] U. Fasel, P. Tiso, D. Keidel, G. Molinari, and P. Ermanni, "Reduced-order dynamic model of a morphing airborne wind energy aircraft," AIAA journal, vol. 57, pp. 3586-3598, 2019. doi: https://doi.org/10.2514/1.J058019.

[136] Q. Ai, P. M. Weaver, and M. Azarpeyvand, "Design and mechanical testing of a variable stiffness morphing trailing edge flap," Journal of Intelligent Material Systems and Structures, vol. 29, pp. 669-683, 2018. doi: https://doi.org/10.1177/1045389X17721028.

[137] Q. Ai, H. Kamliya Jawahar, and M. Azarpeyvand, "Experimental investigation of aerodynamic performance of airfoils fitted with morphing trailing edges," in 54th AIAA aerospace sciences meeting, p. 1563, 2016. doi:https://doi.org/10.2514/6.2016-1563.

[138] W. Su, "Development of an Aeroelastic Formulation for Deformable Airfoils Using Orthogonal Polynomials," AIAA Journal, pp. 2793-2807, 2017. doi: https://doi.org/10.2514/1.J055665.

[139] S. Murugan, B. Woods, and M. I. Friswell, "Hierarchical modeling and optimization of camber morphing airfoil," Aerospace Science and Technology, vol. 42, pp. 31-38, 2015. doi: https://doi.org/10.1016/j.ast.2014.10.019.

[140] D. Li, S. Guo, and J. Xiang, "Modeling and nonlinear aeroelastic analysis of a wing with morphing trailing edge," in Proceedings of the Institution of Mechanical Engineers, Part G: Journal of Aerospace Engineering, pp. 619-631, 2013. doi:https://doi.org/10.1177/0954410012438341.

[141] D. Li, S. Guo, Y. He, and J. Xiang, "Nonlinear aeroelastic analysis of a morphing flap," International Journal of Bifurcation and Chaos, vol. 22, p. 1250099, 2012. doi: https://doi.org/10.1142/S021812741250099X.

[142] J. Murua, R. Palacios, and J. Peiró, "Camber effects in the dynamic aeroelasticity of compliant airfoils," Journal of Fluids and Structures, vol. 26, pp. 527-543, 2010. doi: https://doi.org/10.1016/j.jfluidstructs.2010.01.009.

[143] G. Seber and E. Sakarya, "Nonlinear modeling and aeroelastic analysis of an adaptive camber wing," Journal of aircraft, vol. 47, pp. 2067-2074, 2010. doi: https://doi.org/10.2514/1.C000312.

[144] O. Bilgen, M. I. Friswell, K. Kochersberger, and D. Inman, "Surface actuated variable-camber and variable-twist morphing wings using piezocomposites," in 52nd AIAA/ASME/ASCE/AHS/ASC Structures, Structural Dynamics and Materials Conference 19th AIAA/ASME/AHS Adaptive Structures Conference 13t, 2011. doi:https://doi.org/10.2514/6.2011-2072.

[145] O. Bilgen, E. I. Saavedra Flores, and M. I. Friswell, "Optimization of surface-actuated piezocomposite variable-camber morphing wings," in ASME 2011 Conference on Smart Materials, Adaptive Structures and Intelligent Systems, pp. 315-322, 2011. doi:https://doi.org/10.1115/smasis2011-4971.

[146] O. Bilgen, K. B. Kochersberger, D. J. Inman, and O. J. Ohanian III, "Novel, bidirectional, variablecamber airfoil via macro-fiber composite actuators," Journal of Aircraft, vol. 47, pp. 303-314, 2010. doi: https://doi.org/10.2514/1.45452.

[147] F. Previtali and P. Ermanni, "Performance of a non-tapered 3D morphing wing with integrated compliant ribs," Smart materials and structures, vol. 21, 2012. doi: https://doi.org/10.1088/09641726/21/5/055008.

[148] A. Hasse, I. Zuest, and L. F. Campanile, "Modal synthesis of belt-rib structures," Proceedings of the Institution of Mechanical Engineers, Part C: Journal of Mechanical Engineering Science, vol. 225, pp. 722-732, 2011. doi: https://doi.org/10.1243/09544062JMES2329. 
[149] A. Varello, A. Lamberti, and E. Carrera, "Static aeroelastic response of wing-structures accounting for in-plane cross-section deformation," International Journal of Aeronautical and Space Sciences, vol. 14, pp. 310-323, 2013. doi: https://doi.org/10.5139/ijass.2013.14.4.310.

[150] M. Berci, V. Toropov, R. Hewson, and P. Gaskell, "Multidisciplinary multifidelity optimisation of a flexible wing aerofoil with reference to a small UAV," Structural and Multidisciplinary Optimization, vol. 50, pp. 683-699, 2014. doi: https://doi.org/10.1007/s00158-014-1066-2.

[151] M. Perera and S. Guo, "Structural and dynamic analysis of a seamless aeroelastic wing," in 51st AIAA/ASME/ASCE/AHS/ASC Structures, Structural Dynamics, and Materials Conference 18th AIAA/ASME/AHS Adaptive Structures Conference 12th, 2010. doi:https://doi.org/10.2514/6.2010-2878.

[152] S. Mao, C. Xie, L. Yang, and C. Yang, "Static Aeroelastic Characteristics of Morphing TrailingEdge Wing Using Geometrically Exact Vortex Lattice Method," International Journal of Aerospace Engineering, vol. 2019, 2019. doi: https://doi.org/10.1155/2019/5847627.

[153] L. Liu, W. Yin, F. Dai, Y. Liu, and J. Leng, "Static aeroelastic deformation of flexible skin for continuous variable trailing-edge camber wing," in Active and Passive Smart Structures and Integrated Systems 2011, 2011. doi:https://doi.org/10.1117/12.880323.

[154] A. E. Rivero, J. E. Cooper, and B. Woods, "Numerically Efficient Three-Dimensional FluidStructure Interaction Analysis for Composite Camber Morphing Aerostructures," in AIAA Scitech 2020 Forum, 2020. doi:https://doi.org/10.2514/6.2020-1298.

[155] A. Airoldi, M. Crespi, G. Quaranti, and G. Sala, "Design of a morphing airfoil with composite chiral structure," Journal of Aircraft, vol. 49, pp. 1008-1019, 2012. doi: https://doi.org/10.2514/1.C031486.

[156] A. Airoldi, G. Quaranta, A. Beltramin, and G. Sala, "Design of a morphing actuated aileron with chiral composite internal structure," Advances in aircraft and spacecraft science, vol. 1, p. 331, 2014. doi: https://doi.org/10.12989/aas.2014.13.5.331.

[157] M. Arena, R. Palumbo, R. Pecora, F. Amoroso, G. Amendola, and I. Dimino, "Flutter clearance investigation of camber-morphing aileron tailored for a regional aircraft," Journal of Aerospace Engineering, vol. 32, 2018. doi: https://doi.org/10.1061/(asce)as.1943-5525.0000973.

[158] S. Fichera, I. Isnardi, and J. E. Mottershead, "High-bandwidth morphing actuator for aeroelastic model control," Aerospace, vol. 6, p. 13, 2019. doi: https://doi.org/10.3390/aerospace6020013.

[159] B. K. Stanford, "Static and dynamic aeroelastic tailoring with variable-camber control," Journal of Guidance, Control, and Dynamics, pp. 2522-2534, 2016. doi: https://doi.org/10.2514/1.G000413.

[160] K. Soneda, T. Yokozeki, T. Imamura, and N. Tsushima, "Aero-structural Analysis of Corrugated Morphing Wing with Spanwise Camber Change," in AIAA Scitech 2020 Forum, 2020. doi:https://doi.org/10.2514/6.2020-0450.

[161] K. T. Magar, K. Fuchi, A. M. Pankonien, R. V. Beblo, and G. W. Reich, "Active Control of Origami Inspired Camber Morphing Airfoil for Gust Load Alleviation," in ASME 2018 Conference on Smart Materials, Adaptive Structures and Intelligent Systems, 2018. doi:https://doi.org/10.1115/SMASIS2018-8040.

[162] J. M. Gattas, W. Wu, and Z. You, "Miura-base rigid origami: parameterizations of first-level derivative and piecewise geometries," Journal of Mechanical design, vol. 135, 2013. doi: https://doi.org/10.1115/1.4025380.

[163] K. S. Thapa Magar, G. W. Reich, A. M. Pankonien, and B. Smyers, "Active Gust Alleviation using Artificial Hair Sensors and Feedforward Control," in AIAA Guidance, Navigation, and Control Conference, p. 1485, 2017. doi:https://doi.org/10.2514/6.2017-1485.

[164] S. N. Fry, R. Sayaman, and M. H. Dickinson, "The aerodynamics of hovering flight in Drosophila," Journal of Experimental Biology, vol. 208, pp. 2303-2318, 2005. doi: https://doi.org/10.1242/jeb.01612. 
[165] R. Cavallaro and L. Demasi, "Challenges, ideas, and innovations of joined-wing configurations: a concept from the past, an opportunity for the future," Progress in Aerospace Sciences, vol. 87, pp. 1-93, 2016. doi: https://doi.org/10.1016/j.paerosci.2016.07.002.

[166] L. Cavagna, S. Ricci, and L. Travaglini, "Structural sizing and aeroelastic optimization in aircraft conceptual design using NeoCASS suite," in 13th AIAA/ISSMO Multidisciplinary Analysis Optimization Conference, pp. 1-26, 2010. doi:https://doi.org/10.2514/6.2010-9076.

[167] L. Cavagna, S. Ricci, and L. Travaglini, "NeoCASS: an integrated tool for structural sizing, aeroelastic analysis and MDO at conceptual design level," Progress in Aerospace Sciences, vol. 47, pp. 621-635, 2011. doi: https://doi.org/10.1016/j.paerosci.2011.08.006.

[168] B. M. Kulfan, "Universal parametric geometry representation method," Journal of aircraft, vol. 45, pp. 142-158, 2008. doi: https://doi.org/10.2514/1.29958.

[169] R. Clarke, M. Allen, R. Dibley, J. Gera, and J. Hodgkinson, "Flight test of the F/A-18 active aeroelastic wing airplane," in AIAA atmospheric flight mechanics conference and exhibit, 2005. doi:https://doi.org/10.2514/6.2005-6316.

[170] E. W. Pendleton, D. Bessette, P. B. Field, G. D. Miller, and K. E. Griffin, "Active aeroelastic wing flight research program: technical program and model analytical development," Journal of Aircraft, vol. 37, pp. 554-561, 2000. doi: https://doi.org/10.2514/2.2654.

[171] G. D. Miller, "Active flexible wing (AFW) technology," ROCKWELL INTERNATIONAL LOS ANGELES CA NORTH AMERICAN AIRCRAFT OPERATIONS1988. 


\section{Appendix}

Table 1. Studies on span morphing.

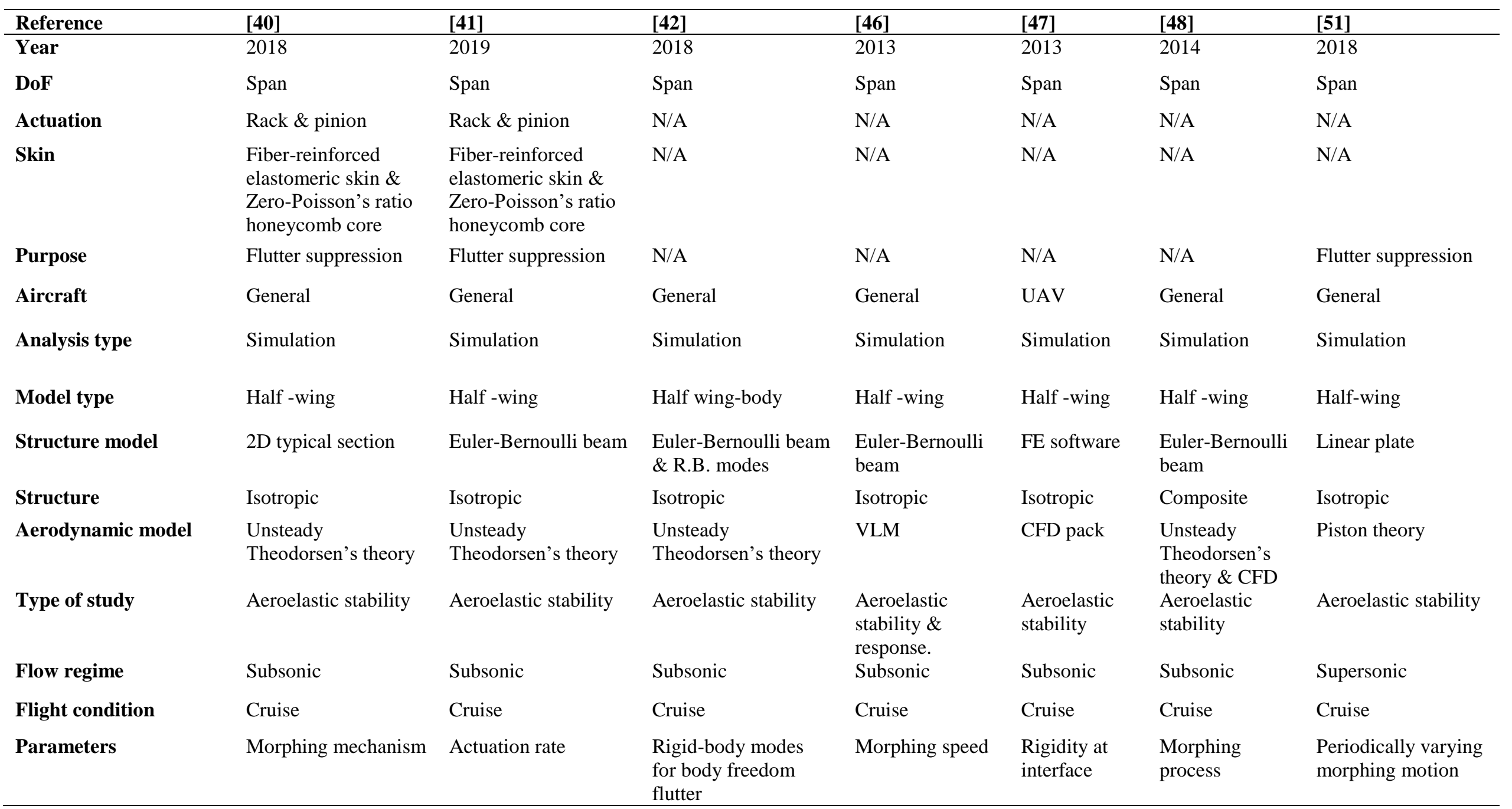


Table 2. Studies on chord morphing.

\begin{tabular}{|c|c|c|c|c|c|}
\hline Reference & [53] & [54] & [55] & [56] & [57] \\
\hline Year & 2009 & 2009 & 2011 & 2010 & 2014 \\
\hline DoF & Chord & Chord & Chord & Chord & Chord \\
\hline Actuation & N/A & N/A & Rotor speed & N/A & N/A \\
\hline Skin & $\begin{array}{l}\text { Isotropic with a slit } \\
\text { at trailing edge }\end{array}$ & N/A & Silicon rubber & $\begin{array}{l}\text { Isotropic with a slit } \\
\text { at trailing edge }\end{array}$ & $\begin{array}{l}\text { Isotropic with a slit } \\
\text { at trailing edge }\end{array}$ \\
\hline Purpose & $\begin{array}{l}\text { Reduction in main } \\
\text { rotor power }\end{array}$ & $\begin{array}{l}\text { Reduction in } \\
\text { main rotor power }\end{array}$ & $\begin{array}{l}\text { Reduction in } \\
\text { main rotor power }\end{array}$ & $\begin{array}{l}\text { Reduction in main } \\
\text { rotor power }\end{array}$ & $\begin{array}{l}\text { Reduction in main } \\
\text { rotor power }\end{array}$ \\
\hline Aircraft & Helicopter & Helicopter & Helicopter & Helicopter & Helicopter \\
\hline Analysis type & Simulation & Simulation & $\begin{array}{l}\text { Simulation \& } \\
\text { experiment }\end{array}$ & Simulation & Simulation \\
\hline Model type & Rotor with blades & Rotor with blades & Blade & Rotor with blades & Rotor with blades \\
\hline Structure model & Beam formulation & $2 \mathrm{D}$ & FE software & $2 \mathrm{D}$ & Beam formulation \\
\hline Structure & Moderate deflection & Rigid & Cellular structure & Rigid & Moderate deflection \\
\hline $\begin{array}{l}\text { Aerodynamic } \\
\text { model }\end{array}$ & $\begin{array}{l}\text { Unsteady-Airfoil } \\
\text { tables }\end{array}$ & CFD & VLM & CFD & $\begin{array}{l}\text { Unsteady-Airfoil } \\
\text { tables }\end{array}$ \\
\hline Type of study & $\begin{array}{l}\text { Aerodynamic } \\
\text { performance }\end{array}$ & $\begin{array}{l}\text { Aerodynamic } \\
\text { performance }\end{array}$ & Skin deformation & $\begin{array}{l}\text { Aerodynamic } \\
\text { performance }\end{array}$ & $\begin{array}{l}\text { Aerodynamic } \\
\text { performance }\end{array}$ \\
\hline Flow regime & Subsonic-stall & Subsonic-stall & Subsonic-stall & Subsonic-stall & Subsonic-stall \\
\hline Flight condition & Forward flight & Forward flight & Forward flight & Forward flight & Forward flight \\
\hline Parameters & $\begin{array}{l}\text { Amount of chord } \\
\text { extension }\end{array}$ & $\begin{array}{l}\text { Actuation } \\
\text { frequency }\end{array}$ & $\begin{array}{l}\text { Chord extension } \\
\text { value }\end{array}$ & $\begin{array}{l}\text { Amount of chord } \\
\text { extension }\end{array}$ & $\begin{array}{l}\text { Amount of chord } \\
\text { extension }\end{array}$ \\
\hline
\end{tabular}


Table 3. Studies on sweep morphing.

\begin{tabular}{lll}
\hline Reference & {$[63]$} & {$[66]$} \\
\hline Year & 2011 & 2019 \\
DoF & Sweep & Sweep \\
Actuation & SMA & Pulley \& servomotor \\
Skin & N/A & Bionic feathers \\
Purpose & N/A & Flight performance \\
Aircraft & UAV & UAV \\
Analysis type & Simulation & Simulation \& Experiment \\
Model type & Half wing & \\
Structure model & Euler-Bernoulli beam & Full aircraft \\
Structure & Isotropic & Isotropic \\
Aerodynamic model & Unsteady Theodorsen's & CFD \\
theory & Aeroelastic stability & Aeroelastic stability \\
Type of study & Subsonic & Subsonic \\
Flow regime & Cruise & Cruise \\
Flight condition & Planform configuration & Actuation \\
Parameters & & \\
& & \\
\hline
\end{tabular}


Table 4. Studies on twist morphing.

\begin{tabular}{|c|c|c|c|c|c|c|c|}
\hline Reference & [67] & [70] & [71] & {$[72,73]$} & [78] & [79] & {$[80]$} \\
\hline Year & 2012 & 2019 & 2011 & 2012,2013 & 2012 & 2017 & 2015 \\
\hline DoF & Twist & Twist & Twist & Twist & Twist & Twist & Twist \\
\hline Actuation & $\begin{array}{l}\text { Electro- } \\
\text { mechanical }\end{array}$ & $\begin{array}{l}\text { Servomotor \& } \\
\text { Torque rod }\end{array}$ & N/A & N/A & N/A & Servomechanism & N/A \\
\hline Skin & Composite & PEI (Ultem) film & N/A & $\begin{array}{l}\text { Aluminum } \\
\text { 2024-T3 }\end{array}$ & Aluminum 2024-T3 & N/A & Composite \\
\hline Purpose & Roll control & $\begin{array}{l}\text { Control } \\
\text { efficiency }\end{array}$ & Aircraft control & $\begin{array}{l}\text { Aerodynami } \\
\text { c efficiency } \\
\& \text { roll } \\
\text { control }\end{array}$ & Roll control & Flutter suppression & Load alleviation \\
\hline Aircraft & HALE & $\begin{array}{l}\text { Blended wing- } \\
\text { body }\end{array}$ & General & UAV & UAV & General & Civil \\
\hline Analysis type & Simulation & Simulation & Simulation & Simulation & Simulation & $\begin{array}{l}\text { Simulation \& } \\
\text { Experiment }\end{array}$ & Simulation \\
\hline Model type & Half wing & Full wing & Wing section & Half wing & Half wing & Wing section & Whole aircraft \\
\hline Structure model & FE software & FE software & FE software & FE model & $\begin{array}{l}\text { Lagrangian } \\
\text { mechanics }\end{array}$ & N/A & FE software \\
\hline Structure & Composite & Anisotropic & Isotropic & Isotropic & Isotropic & Carbon fiber & Composite \\
\hline Aerodynamic model & Quasi-steady & XFOIL\& VLM & $\begin{array}{l}\text { Vortex ring } \\
\text { method }\end{array}$ & $\begin{array}{l}\text { Tornado } \\
\text { VLM }\end{array}$ & $\begin{array}{l}\text { Unsteady } \\
\text { Theodorsen's theory }\end{array}$ & $\begin{array}{l}\text { Unsteady time } \\
\text { domain } \\
\text { formulation }\end{array}$ & Unsteady DLM \\
\hline Type of study & Flight dynamics & $\begin{array}{l}\text { Static } \\
\text { aeroelasticity }\end{array}$ & $\begin{array}{l}\text { Aeroelastic \& } \\
\text { mechanical } \\
\text { characteristics }\end{array}$ & $\begin{array}{l}\text { Aeroelastic } \\
\text { response }\end{array}$ & Aeroelastic response & $\begin{array}{l}\text { Aeroelastic } \\
\text { stability }\end{array}$ & $\begin{array}{l}\text { Aeroelastic } \\
\text { response }\end{array}$ \\
\hline Flow regime & Subsonic & Subsonic & Subsonic & Subsonic & Subsonic & Subsonic & Subsonic \& gust \\
\hline Flight condition & Roll & Cruise & Cruise & Cruise & Cruise & Cruise & Cruise \\
\hline Parameters & Twist value & $\begin{array}{l}\text { Modularity of } \\
\text { the structure }\end{array}$ & Actuation force & Actuation & $\begin{array}{l}\text { Actuation speed \& } \\
\text { forces }\end{array}$ & $\begin{array}{l}\text { Active \& Passive } \\
\text { control } \\
\text { architecture }\end{array}$ & $\begin{array}{l}\text { Passive twist } \\
\text { wingtip }\end{array}$ \\
\hline
\end{tabular}


Table 5. Studies on dihedral/gull/folding Wingtips/spanwise bending.

\begin{tabular}{|c|c|c|c|c|c|c|c|c|}
\hline Reference & {$[81]$} & {$[82]$} & {$[83]$} & {$[85]$} & [86] & [87] & [89] & {$[90]$} \\
\hline Year & 2016 & 2015 & 2019 & 2016 & 2018 & 2019 & 2012 & 2013 \\
\hline DoF & Wingtip & Folding wing & Folding wing & Folding wing & Folding wing & Folding wing & Folding wing & Folding wing \\
\hline Actuation & N/A & N/A & N/A & N/A & N/A & N/A & N/A & N/A \\
\hline Skin & N/A & N/A & N/A & N/A & N/A & N/A & N/A & N/A \\
\hline Purpose & Load alleviation & N/A & N/A & N/A & N/A & N/A & N/A & N/A \\
\hline Aircraft & Civil & Civil & Civil & Civil & General & General & General & General \\
\hline Analysis type & Simulation & Simulation & Simulation & Simulation & Simulation & Simulation & Simulation & Simulation \\
\hline Model type & Full wing & Half wing & Half wing & Half wing & Half-wing & Full wing & Half wing & Half wing \\
\hline $\begin{array}{l}\text { Structure } \\
\text { model }\end{array}$ & FE software & FE software & $\begin{array}{l}\text { FE software \& } \\
\text { free-play }\end{array}$ & $\begin{array}{l}\text { Multi body } \\
\text { dynamics }\end{array}$ & $\begin{array}{l}\text { FE software \& } \\
\text { free-play in hinge }\end{array}$ & $\begin{array}{l}\text { Linear Euler- } \\
\text { Bernoulli beam }\end{array}$ & $\begin{array}{l}\text { Plate } \\
\text { substructures }\end{array}$ & $\begin{array}{l}\text { Craig-Bampton } \\
\text { with floating } \\
\text { frame method }\end{array}$ \\
\hline Structure & Isotropic & Isotropic & Isotropic & Isotropic & Isotropic & Isotropic & Isotropic & Isotropic \\
\hline $\begin{array}{l}\text { Aerodynamic } \\
\text { model }\end{array}$ & DLM & DLM & DLM & DLM & DLM & UVLM & DLM & CFD \\
\hline Type of study & $\begin{array}{l}\text { Aeroelastic } \\
\text { response }\end{array}$ & $\begin{array}{l}\text { Aeroelastic } \\
\text { response }\end{array}$ & $\begin{array}{l}\text { Aeroelastic } \\
\text { response }\end{array}$ & $\begin{array}{l}\text { Aeroelastic } \\
\text { response }\end{array}$ & $\begin{array}{l}\text { Aeroelastic } \\
\text { stability }\end{array}$ & $\begin{array}{l}\text { Aeroelastic } \\
\text { stability \& } \\
\text { response }\end{array}$ & $\begin{array}{l}\text { Aeroelastic } \\
\text { stability }\end{array}$ & $\begin{array}{l}\text { Aeroelastic } \\
\text { response }\end{array}$ \\
\hline Flow regime & $\begin{array}{l}\text { Subsonic \& } \\
\text { gust }\end{array}$ & Subsonic & Subsonic & Subsonic & Subsonic & Subsonic & Subsonic & Subsonic \\
\hline $\begin{array}{l}\text { Flight } \\
\text { condition }\end{array}$ & Cruise & Cruise & Cruise & Cruise & Cruise & Cruise & Cruise & Cruise \\
\hline Parameters & $\begin{array}{l}\text { Flared hinge \& } \\
\text { hinge stiffness }\end{array}$ & $\begin{array}{l}\text { Morphing } \\
\text { velocity }\end{array}$ & $\begin{array}{l}\text { Clearance \& } \\
\text { free-play of } \\
\text { the folding } \\
\text { segment }\end{array}$ & Morphing rate & $\begin{array}{l}\text { Modal damping \& } \\
\text { folding angle }\end{array}$ & Fold angle & Fold angle & Morphing process \\
\hline
\end{tabular}




\begin{tabular}{|c|c|c|c|c|c|c|c|c|}
\hline Reference & [91] & [92] & [93] & [94] & [95] & {$[96]$} & [97] & [98] \\
\hline Year & 2009 & 2009 & 2010 & 2012 & 2015 & 2014 & 2013 & 2011 \\
\hline DoF & Folding wing & Folding wing & Folding wing & Folding wing & Wingtip & Folding wing & Folding wing & Winglet \\
\hline Actuation & N/A & N/A & N/A & N/A & N/A & $\begin{array}{l}\text { Passive (aero \& } \\
\text { thrust) }\end{array}$ & N/A & $\begin{array}{l}\text { Inter \& intra-rib } \\
\text { mechanisms }\end{array}$ \\
\hline Skin & N/A & N/A & N/A & N/A & Aluminum alloy & N/A & N/A & Flexible \\
\hline Purpose & N/A & $\begin{array}{l}\text { Flight } \\
\text { performance }\end{array}$ & $\begin{array}{l}\text { Flight } \\
\text { performance }\end{array}$ & N/A & $\begin{array}{l}\text { Flight } \\
\text { performance }\end{array}$ & $\begin{array}{l}\text { Flight } \\
\text { performance }\end{array}$ & N/A & $\begin{array}{l}\text { Drag reduction } \\
\& \text { limit the root } \\
\text { bending moment }\end{array}$ \\
\hline Aircraft & General & General & General & General & $\begin{array}{l}\text { Turbo-fan } \\
\text { aircraft }\end{array}$ & HALE & General & General \\
\hline Analysis type & Simulation & Simulation & $\begin{array}{l}\text { Simulation \& } \\
\text { Experiment }\end{array}$ & $\begin{array}{l}\text { Simulation \& } \\
\text { Experiment }\end{array}$ & Simulation & Simulation & Simulation & Simulation \\
\hline Model type & Half wing & Half aircraft & $\begin{array}{l}\text { Half wing \& } \\
\text { fuselage }\end{array}$ & Half wing & Wing section & Full wing & Half wing & Half wing \\
\hline Structure model & Plate & FE software & Nonlinear plate & $\begin{array}{l}\text { Beam } \\
\text { substructures }\end{array}$ & FE pack & $\begin{array}{l}\text { Nonlinear large } \\
\text { deflection beam }\end{array}$ & FEM & Beam model \\
\hline Structure & Isotropic & Isotropic & Isotropic & Isotropic & Isotropic & Isotropic & $\begin{array}{l}\text { Isotropic \& } \\
\text { Composite }\end{array}$ & Isotropic \\
\hline $\begin{array}{l}\text { Aerodynamic } \\
\text { model }\end{array}$ & $\begin{array}{l}\text { Unsteady } \\
\text { Theodorsen's } \\
\text { theory }\end{array}$ & DLM & 3D VLM & $\begin{array}{l}\text { Unsteady } \\
\text { Theodorsen's } \\
\text { theory }\end{array}$ & CFD \& DLM & Unsteady Peter's & DLM & $\begin{array}{l}\text { Weissinger's } \\
\text { method }\end{array}$ \\
\hline Type of study & $\begin{array}{l}\text { Aeroelastic } \\
\text { stability }\end{array}$ & $\begin{array}{l}\text { Aeroelastic } \\
\text { stability }\end{array}$ & $\begin{array}{l}\text { Aeroelastic } \\
\text { stability \& } \\
\text { response }\end{array}$ & $\begin{array}{l}\text { Aeroelastic } \\
\text { stability }\end{array}$ & Load alleviation & $\begin{array}{l}\text { Aeroelastic } \\
\text { stability \& } \\
\text { response }\end{array}$ & $\begin{array}{l}\text { Aeroelastic } \\
\text { response }\end{array}$ & $\begin{array}{l}\text { Static } \\
\text { aeroelasticity }\end{array}$ \\
\hline Flow regime & Subsonic & Subsonic & Subsonic & Subsonic & Transonic & Subsonic & Subsonic & Subsonic \\
\hline Flight condition & Cruise & Cruise & Cruise & Cruise & Cruise & Cruise & Cruise & $\begin{array}{l}\text { Cruise, climb \& } \\
\text { descent }\end{array}$ \\
\hline Parameters & $\begin{array}{l}\text { Unsteadiness of } \\
\text { aerodynamics } \\
\& \text { fold angle }\end{array}$ & $\begin{array}{l}\text { Fold angle \& } \\
\text { hinge stiffness }\end{array}$ & Fold angle & $\begin{array}{l}\text { Fold angle \& } \\
\text { number of } \\
\text { folding } \\
\text { segments }\end{array}$ & Morphing angle & $\begin{array}{l}\text { Thrust \& fold } \\
\text { angle }\end{array}$ & $\begin{array}{l}\text { Fold angle \& } \\
\text { hinge stiffness }\end{array}$ & $\begin{array}{l}\text { Folding, shearing } \\
\& \text { winglet twist } \\
\text { angle }\end{array}$ \\
\hline
\end{tabular}




\begin{tabular}{|c|c|c|c|c|c|c|c|c|}
\hline Reference & [99] & [100] & [101] & [103] & [104] & [105] & [106] & [107] \\
\hline Year & 2018 & 2018 & 2018 & 2018 & 2019 & 2016 & 2016 & 2017 \\
\hline DoF & Winglet & Winglet & Wingtip \& flap tabs & Wingtip & Wingtip & Wingtip & Wingtip & Wingtip \\
\hline Actuation & N/A & EMA & EMA & N/A & N/A & N/A & Piezoelectric & N/A \\
\hline Skin & Composite & Conformal skin & Conformal skin & N/A & N/A & N/A & N/A & N/A \\
\hline Purpose & $\begin{array}{l}\text { Load control } \\
\& \text { aeroelastic } \\
\text { behavior }\end{array}$ & Load alleviation & Load alleviation & Load alleviation & $\begin{array}{l}\text { Load } \\
\text { alleviation }\end{array}$ & Load alleviation & Load alleviation & Load alleviation \\
\hline Aircraft & Civil & Civil regional & Civil regional & Civil & Civil & Civil & Civil & Civil \\
\hline Analysis type & Simulation & Simulation & Simulation & $\begin{array}{l}\text { Simulation \& } \\
\text { Experiment }\end{array}$ & Experiment & Simulation & Simulation & Simulation \\
\hline Model type & Full aircraft & Full aircraft & Full aircraft & Half wing & Half wing & Full aircraft & Full aircraft & Full aircraft \\
\hline Structure model & FE software & FE software & FE software & FE software & N/A & $\begin{array}{l}\text { Multi body } \\
\text { dynamics }\end{array}$ & $\begin{array}{l}\text { FE software \& } \\
\text { nonlinear hinge }\end{array}$ & FE software \\
\hline Structure & Composite & Composite & Composite & Isotropic & N/A & Isotropic & Isotropic & Isotropic \\
\hline $\begin{array}{l}\text { Aerodynamic } \\
\text { model }\end{array}$ & DLM & DLM & DLM & DLM & N/A & DLM & DLM & DLM \\
\hline Type of study & $\begin{array}{l}\text { Aeroelastic } \\
\text { response }\end{array}$ & $\begin{array}{l}\text { Aeroelastic } \\
\text { response }\end{array}$ & Aeroelastic stability & $\begin{array}{l}\text { Aeroelastic } \\
\text { response }\end{array}$ & $\begin{array}{l}\text { Aeroelastic } \\
\text { response }\end{array}$ & $\begin{array}{l}\text { Aeroelastic } \\
\text { response }\end{array}$ & Aeroelastic response & $\begin{array}{l}\text { Aeroelastic stability } \\
\& \text { response }\end{array}$ \\
\hline Flow regime & Subsonic & Subsonic & Subsonic & Subsonic \& gust & $\begin{array}{l}\text { Subsonic \& } \\
\text { gust }\end{array}$ & Subsonic \& gust & Subsonic \& gust & Subsonic \& gust \\
\hline Flight condition & Cruise & $\begin{array}{l}\text { Symmetric \& } \\
\text { anti-symmetric } \\
\text { Maneuver }\end{array}$ & Cruise & Cruise & Cruise & Cruise & Cruise & Cruise \\
\hline Parameters & $\begin{array}{l}\text { Winglet } \\
\text { deflection }\end{array}$ & $\begin{array}{l}\text { Winglet } \\
\text { deflection }\end{array}$ & $\begin{array}{l}\text { Layout, mass, stiffness } \\
\& \text { actuator damping of } \\
\text { movable parts }\end{array}$ & Hinge stiffness & $\begin{array}{l}\text { Wingtip } \\
\text { hinge } \\
\text { orientation }\end{array}$ & $\begin{array}{l}\text { Nonlinearity in } \\
\text { hinge }\end{array}$ & Hinge nonlinearity & $\begin{array}{l}\text { Wingtip deflection } \\
\& \text { mass, hinge } \\
\text { stiffness \& damping }\end{array}$ \\
\hline
\end{tabular}




\begin{tabular}{lll}
\hline Reference & {$[\mathbf{1 0 8}]$} & {$[\mathbf{1 1 0}]$} \\
\hline Year & 2019 & 2019 \\
DoF & Wingtip & Wingtip \\
Actuation & N/A & Lock \& clutched actuator \\
Skin & N/A & CFRP stiffened with \\
Purpose & Flight performance \& & Aohacell foam \\
Aircraft & load alleviation & \& load alleviation \\
Analysis type & Civil & Demonstrator UAV \\
Model type & Simulation & Experiment \& flight test \\
Structure model & Full aircraft & Full aircraft \\
Structure & FE software & N/A \\
Aerodynamic model & DLM & Isotropic \& composite \\
Type of study & N/A \\
Flow regime & Aeroelastic response & Load alleviation \\
Parameters & Subsonic \& gust & Subsonic \\
& Cruise & Cruise \\
& & Fold angle \\
\hline
\end{tabular}


Table 6. Studies on thickness-to-chord morphing.

\begin{tabular}{lllll}
\hline Reference & {$[\mathbf{1 1 1}]$} & {$[\mathbf{1 1 2}]$} & {$[\mathbf{1 1 4}]$} & {$[\mathbf{1 1 5}]$} \\
\hline Year & 2010 & 2011 & 2012 & 2015 \\
DoF & Thickness & Thickness & Thickness & Thickness \\
Actuation & SMA & SMA & N/A & Linear actuators \\
Skin & N/A & N/A & $\begin{array}{l}7075(\mathrm{~T} 6) \text { grade } \\
\text { aluminum }\end{array}$ & N/A \\
Purpose & Drag reduction & Drag reduction & Drag reduction & N/A \\
Aircraft & General & General & General & General \\
Analysis type & Simulation & Simulation \& & Simulation & Experiment \\
Model type & Half wing & Half wing & Cross-section & Plate \\
Structure model & FE software & FE software & FE pack & N/A \\
Structure & Isotropic & Isotropic & Isotropic & Isotropic \\
Aerodynamic model & DLM & DLM & CFD & N/A \\
Type of study & Aeroelastic & Aeroelastic & Static & Aeroelastic \\
& stability & stability & aeroelasticity & response \\
Flow regime & Subsonic & Subsonic & Transonic & Supersonic \\
Flight condition & Cruise & Cruise & Cruise & Cruise \\
Parameters & Skin flexibility & Flight speed & Thickness change & Actuation \\
\hline
\end{tabular}


Table 7. Studies on camber morphing.

\begin{tabular}{|c|c|c|c|c|c|c|c|c|}
\hline Reference & [119] & [123] & {$[124]$} & [125] & [126] & [127] & {$[128]$} & [129] \\
\hline Year & 2018 & 2015 & 2019 & 2019 & 2018 & 2019 & 2014 & 2017 \\
\hline DoF & Camber & Camber & Camber & Camber & Camber & Camber & Camber & Camber \\
\hline Actuation & N/A & Piezoelectric & Piezoelectric & N/A & Servo actuator & $\begin{array}{l}\text { Servo } \\
\text { actuator }\end{array}$ & Electromechanical & Electromechanical \\
\hline Skin & N/A & Composite & Composite & Corrugated & Multi-segment & N/A & N/A & Composite \\
\hline Purpose & $\begin{array}{l}\text { Flight } \\
\text { Performance }\end{array}$ & $\begin{array}{l}\text { Flight } \\
\text { performance }\end{array}$ & Roll control & $\begin{array}{l}\text { Flight } \\
\text { performance }\end{array}$ & Flight performance & $\begin{array}{l}\text { Flight } \\
\text { performance }\end{array}$ & Flight performance & Flight performance \\
\hline Aircraft & Civil & General & General & General & Civil & Civil & Civil & civil \\
\hline Analysis type & Simulation & Simulation & Simulation & Simulation & $\begin{array}{l}\text { Simulation \& } \\
\text { Experiment }\end{array}$ & Simulation & Simulation & Simulation \\
\hline Model type & Full aircraft & Full wing & Half wing & Half wing & Full wing & Full wing & Full wing & Half wing \\
\hline Structure model & FE software & FE software & FE software & Nonlinear plate & FE software & FE software & FE software & FE software \\
\hline Structure & Isotropic & Composite & Composite & $\begin{array}{l}\text { Corrugated \& } \\
\text { composite }\end{array}$ & Isotropic & Isotropic & Isotropic & Composite \\
\hline Aerodynamic model & CFD & CFD & $\begin{array}{l}\text { Nonlinear } \\
\text { lifting line }\end{array}$ & UVLM & DLM & DLM & DLM & DLM \\
\hline Type of study & $\begin{array}{l}\text { Aeroelastic } \\
\text { response }\end{array}$ & $\begin{array}{l}\text { Aeroelastic } \\
\text { response }\end{array}$ & $\begin{array}{l}\text { Static } \\
\text { aeroelasticity }\end{array}$ & $\begin{array}{l}\text { Aeroelastic } \\
\text { response }\end{array}$ & $\begin{array}{l}\text { Static aeroelasticity } \\
\& \text { aeroelastic } \\
\text { stability }\end{array}$ & $\begin{array}{l}\text { Aeroelastic } \\
\text { stability }\end{array}$ & Aeroelastic stability & Aeroelastic stability \\
\hline Flow regime & Transonic & Subsonic & Subsonic & Subsonic & Subsonic & Subsonic & Subsonic & Subsonic \\
\hline Flight condition & Cruise & $\begin{array}{l}\text { Cruise \& } \\
\text { maneuver }\end{array}$ & Cruise & Cruise & Cruise & Cruise & Cruise & Cruise \\
\hline Parameters & $\begin{array}{l}\text { Application of } \\
\text { morphing } \\
\text { device }\end{array}$ & $\begin{array}{l}\text { Deformation } \\
\& \text { actuation }\end{array}$ & $\begin{array}{l}\text { Deformation } \\
\& \text { actuation }\end{array}$ & $\begin{array}{l}\text { Composite \& } \\
\text { corrugated } \\
\text { parameters }\end{array}$ & $\begin{array}{l}\text { Stiffness, damping } \\
\& \text { failure of } \\
\text { actuator }\end{array}$ & $\begin{array}{l}\text { Actuator } \\
\text { jamming }\end{array}$ & $\begin{array}{l}\text { Actuator failure } \& \\
\text { trailing edge stiffness } \\
\& \text { inertia }\end{array}$ & $\begin{array}{l}\text { Actuator jamming, mass } \\
\text { \& stiffness }\end{array}$ \\
\hline
\end{tabular}




\begin{tabular}{|c|c|c|c|c|c|c|c|c|}
\hline Reference & {$[130]$} & [132] & {$[134,135]$} & [136] & [138] & [139] & {$[140,141]$} & [142] \\
\hline Year & 2019 & 2018 & 2019 & 2018 & 2017 & 2015 & 2013 & 2010 \\
\hline DoF & Camber & Camber & Camber & Camber & Camber & Camber & Camber & Camber \\
\hline Actuation & Electromechanical & Servo actuator & $\begin{array}{l}\text { Electromechanic } \\
\text { al }\end{array}$ & Servo actuator & N/A & Servo & Eccentric curved beam & N/A \\
\hline Skin & N/A & Fiberglass & Corrugated & Composite & N/A & Composite & Composite & N/A \\
\hline Purpose & $\begin{array}{l}\text { Flight performance \& } \\
\text { control }\end{array}$ & $\begin{array}{l}\text { Flight } \\
\text { performance }\end{array}$ & $\begin{array}{l}\text { Flight } \\
\text { performance }\end{array}$ & N/A & N/A & $\begin{array}{l}\text { Flight } \\
\text { performance }\end{array}$ & Flight performance & $\begin{array}{l}\text { Flight } \\
\text { performance }\end{array}$ \\
\hline Aircraft & UAV & Civil & AWE wing & General & General & General & General & General \\
\hline $\begin{array}{l}\text { Analysis } \\
\text { type }\end{array}$ & $\begin{array}{l}\text { Simulation \& } \\
\text { Experiment }\end{array}$ & $\begin{array}{l}\text { Simulation \& } \\
\text { Experiment }\end{array}$ & Simulation & Simulation & Simulation & Simulation & Simulation & Simulation \\
\hline Model type & Full wing & Half wing & Full wing & Half wing & Cross-section & Cross-section & Half wing & Cross-section \\
\hline $\begin{array}{l}\text { Structure } \\
\text { model }\end{array}$ & FE software & $\begin{array}{l}\text { FE software with } \\
\text { large deformation }\end{array}$ & FE software & Beam & Beam & Beam & FE software & FE software \\
\hline Structure & Isotropic & Composite & Composite & Composite & Isotropic & Isotropic & Composite & Isotropic \\
\hline $\begin{array}{l}\text { Aerodynam } \\
\text { ic model }\end{array}$ & 3D panel & DLM & 3D panel & $\begin{array}{l}\text { XFOIL \& 2D viscous } \\
\text { panel }\end{array}$ & $\begin{array}{l}\text { Unsteady } \\
\text { Peter's }\end{array}$ & $\begin{array}{l}\text { XFOIL \& 2D } \\
\text { viscous panel }\end{array}$ & DLM & $\begin{array}{l}\text { 2D Peter's for } \\
\text { flexible airfoil }\end{array}$ \\
\hline $\begin{array}{l}\text { Type of } \\
\text { study }\end{array}$ & Static aeroelasticity & $\begin{array}{l}\text { Static } \\
\text { aeroelasticity \& } \\
\text { stability }\end{array}$ & Flight dynamics & Static aeroelasticity & $\begin{array}{l}\text { Static } \\
\text { aeroelasticity } \\
\& \text { aeroelastic } \\
\text { stability }\end{array}$ & $\begin{array}{l}\text { Static } \\
\text { aeroelasticity }\end{array}$ & $\begin{array}{l}\text { Static aeroelasticity \& } \\
\text { aeroelastic stability }\end{array}$ & $\begin{array}{l}\text { Aeroelastic } \\
\text { stability }\end{array}$ \\
\hline $\begin{array}{l}\text { Flow } \\
\text { regime }\end{array}$ & Subsonic & Subsonic & Subsonic & Subsonic & Subsonic & Subsonic & Subsonic & Subsonic \\
\hline $\begin{array}{l}\text { Flight } \\
\text { condition }\end{array}$ & $\begin{array}{l}\text { Cruise with pitch \& roll } \\
\text { maneuver }\end{array}$ & Cruise & Cruise & Cruise & Cruise & Cruise & Cruise & Cruise \\
\hline Parameters & $\begin{array}{l}\text { Deformation, actuation } \\
\& \text { internal structure }\end{array}$ & $\begin{array}{l}\text { Deformation \& } \\
\text { actuation }\end{array}$ & $\begin{array}{l}\text { Deformation \& } \\
\text { control strategies }\end{array}$ & $\begin{array}{l}\text { Structure stiffness, } \\
\text { deformation \& } \\
\text { actuation }\end{array}$ & $\begin{array}{l}\text { Camber } \\
\text { deformation } \\
\text { flexibility }\end{array}$ & $\begin{array}{l}\text { Ply angle \& } \\
\text { camber } \\
\text { deformation }\end{array}$ & Actuation nonlinearity & $\begin{array}{l}\text { Trailing edge } \\
\text { stiffness \& elastic } \\
\text { axis position }\end{array}$ \\
\hline
\end{tabular}




\begin{tabular}{|c|c|c|c|c|c|c|c|c|}
\hline Reference & [143] & {$[144,145]$} & [147] & [149] & {$[150]$} & [151] & [152] & {$[153]$} \\
\hline Year & 2010 & 2011 & 2012 & 2013 & 2014 & 2010 & 2019 & 2011 \\
\hline DoF & Camber & Camber & Camber & Camber & Camber & Camber & Camber & Camber \\
\hline Actuation & $\begin{array}{l}\text { Servo } \\
\text { actuator }\end{array}$ & $\begin{array}{l}\text { Piezoelectric } \\
(\mathrm{MFC})\end{array}$ & SMA & N/A & N/A & TTAM & Piezoelectric & N/A \\
\hline Skin & N/A & N/A & Composite & N/A & N/A & Composite & N/A & Flexible skin \\
\hline Purpose & $\begin{array}{l}\text { Flight } \\
\text { performance }\end{array}$ & $\begin{array}{l}\text { Flight } \\
\text { performance }\end{array}$ & $\begin{array}{l}\text { Flight } \\
\text { performance }\end{array}$ & Flight performance & Flight performance & N/A & Flight performance & N/A \\
\hline Aircraft & General & General & General & General & UAV & UAV & General & General \\
\hline Analysis type & Simulation & Simulation & Simulation & Simulation & Simulation & $\begin{array}{l}\text { Simulation \& } \\
\text { Experiment }\end{array}$ & Simulation & Simulation \\
\hline Model type & Half wing & Cross-section & Half wing & Cross-section & Cross-section & Wing section & Cross-section & Cross-section \\
\hline Structure model & FE software & FE software & FE software & $\begin{array}{l}\text { 1D CUF } \\
\text { formulation }\end{array}$ & Discretized & FE pack & Discretized & FE pack \\
\hline Structure & Isotropic & Isotropic & Composite & Isotropic & Isotropic & Composite & Isotropic & Isotropic \\
\hline $\begin{array}{l}\text { Aerodynamic } \\
\text { model }\end{array}$ & $\begin{array}{l}\text { High-order } \\
\text { panel method }\end{array}$ & Panel method & 3D panel method & 3D panel method & Panel method & N/A & VLM & XFOIL \\
\hline Type of study & $\begin{array}{l}\text { Static } \\
\text { aeroelasticity }\end{array}$ & $\begin{array}{l}\text { Static } \\
\text { aeroelasticity }\end{array}$ & $\begin{array}{l}\text { Static } \\
\text { aeroelasticity }\end{array}$ & Static aeroelasticity & $\begin{array}{l}\text { Static aeroelasticity } \\
\& \text { stability }\end{array}$ & $\begin{array}{l}\text { Aeroelastic } \\
\text { response }\end{array}$ & Static aeroelasticity & $\begin{array}{l}\text { Static } \\
\text { aeroelasticity }\end{array}$ \\
\hline Flow regime & Subsonic & Subsonic & Subsonic & Subsonic & Subsonic & Subsonic & Subsonic & Subsonic \\
\hline Flight condition & Cruise & Cruise & Cruise & Cruise & Cruise & Cruise & Cruise & Cruise \\
\hline Parameters & $\begin{array}{l}\text { Camber } \\
\text { deformation }\end{array}$ & $\begin{array}{l}\text { Camber } \\
\text { deformation }\end{array}$ & $\begin{array}{l}\text { Camber } \\
\text { deformation \& 3D } \\
\text { coupling effects }\end{array}$ & $\begin{array}{l}\text { Camber } \\
\text { deformation }\end{array}$ & $\begin{array}{l}\text { Camber deformation } \\
\& \text { shape }\end{array}$ & $\begin{array}{l}\text { Stiffness of } \\
\text { actuation }\end{array}$ & $\begin{array}{l}\text { Aerodynamic } \\
\text { formulation }\end{array}$ & Air loads \\
\hline
\end{tabular}




\begin{tabular}{|c|c|c|c|c|c|c|c|c|}
\hline Reference & [154] & [155] & {$[156]$} & [157] & {$[158]$} & [159] & {$[160]$} & {$[161]$} \\
\hline Year & 2020 & 2012 & 2014 & 2018 & 2019 & 2016 & 2020 & 2018 \\
\hline DoF & Camber & Camber & Camber & Camber & Camber & Camber & Camber & Camber \\
\hline Actuation & $\begin{array}{l}\text { Pulley \& } \\
\text { tendons }\end{array}$ & N/A & $\begin{array}{l}\text { SMA \& } \\
\text { SMP } \\
\text { actuators }\end{array}$ & Servo actuator & Piezoelectric actuator & SMA & $\begin{array}{l}\text { Servomotor \& } \\
\text { wires }\end{array}$ & Linear actuation \\
\hline Skin & Silicon skin & Flexible skin & Flexible skin & N/A & $\begin{array}{l}\text { Composite \& } \\
\text { Aluminum }\end{array}$ & Elastomeric & Aluminum & N/A \\
\hline Purpose & $\begin{array}{l}\text { Flight } \\
\text { performance }\end{array}$ & $\begin{array}{l}\text { Flight } \\
\text { performance }\end{array}$ & $\begin{array}{l}\text { Flight } \\
\text { Performance }\end{array}$ & $\begin{array}{l}\text { Structural stability, } \\
\text { Load \& roll control \& } \\
\text { Flight performance }\end{array}$ & $\begin{array}{l}\text { Control aeroelastic } \\
\text { behavior \& flight } \\
\text { mechanics }\end{array}$ & $\begin{array}{l}\text { Load alleviation } \\
\& \text { flutter } \\
\text { suppression }\end{array}$ & Load control & N/A \\
\hline Aircraft & UAV & General & General & Civil & General & Civil & UAV & General \\
\hline Analysis type & Simulation & Simulation & Simulation & Simulation & $\begin{array}{l}\text { Simulation \& } \\
\text { Experiment }\end{array}$ & Simulation & Simulation & Simulation \\
\hline Model type & Wing section & Wing section & $\begin{array}{l}\text { Cross- } \\
\text { section }\end{array}$ & Full wing & Cross-section & Half wing & Full wing & Cross-section \\
\hline Structure & Composite & Isotropic & Isotropic & Isotropic & $\begin{array}{l}\text { Composite \& } \\
\text { Isotropic }\end{array}$ & Isotropic & Isotropic & Isotropic \\
\hline $\begin{array}{l}\text { Aerodynamic } \\
\text { model }\end{array}$ & $\begin{array}{l}\text { XFOIL \& 3D } \\
\text { lifting line } \\
\text { theory }\end{array}$ & $\begin{array}{l}\text { XFOIL \& } \\
\text { DLM }\end{array}$ & XFOIL & DLM & N/A & VLM & VLM & $\begin{array}{l}\text { Quasi-steady thin airfoil } \\
\text { theory }\end{array}$ \\
\hline Type of study & $\begin{array}{l}\text { Aerodynamic } \\
\& \text { aeroelastic } \\
\text { responses }\end{array}$ & $\begin{array}{l}\text { Aeroelastic } \\
\text { response }\end{array}$ & $\begin{array}{l}\text { Aeroelastic } \\
\text { response }\end{array}$ & Aeroelastic stability & Load tests & $\begin{array}{l}\text { Static } \\
\text { aeroelasticity \& } \\
\text { aeroelastic } \\
\text { stability }\end{array}$ & Load control & Aeroelastic response \\
\hline Flow regime & Subsonic & Subsonic & Subsonic & Subsonic & Subsonic & Subsonic & Subsonic & Subsonic \\
\hline Flight condition & Cruise & Cruise & Cruise & Cruise & N/A & Cruise & Cruise & Cruise \\
\hline Parameters & $\begin{array}{l}\text { Actuation } \\
\text { Torque }\end{array}$ & Actuation & Actuation & $\begin{array}{l}\text { Mass balancing ratio, } \\
\text { actuation line stiffness } \\
\& \text { actuator jamming }\end{array}$ & Actuation capability & $\begin{array}{l}\text { Camber } \\
\text { deformation }\end{array}$ & $\begin{array}{l}\text { Actuation } \\
\text { energy }\end{array}$ & Camber change \\
\hline
\end{tabular}


Table 8. Studies on aeroelasticity frameworks for morphing.

\begin{tabular}{|c|c|c|c|c|c|c|c|c|c|c|}
\hline Reference & [11] & [12] & [13] & [14] & [15] & [16] & [17] & {$[18]$} & [19] & {$[20,21]$} \\
\hline Year & 2011 & 2015 & 2014 & 2017 & 2017 & 2017 & 2011 & 2009 & 2020 & 2011,2013 \\
\hline DoF & $\begin{array}{l}\text { Shear, twist, } \\
\text { span \& } \\
\text { folding }\end{array}$ & $\begin{array}{l}\text { Shear, twist, } \\
\text { span, folding } \\
\text { \& camber }\end{array}$ & $\begin{array}{l}\text { Twist, } \\
\text { camber \& } \\
\text { span }\end{array}$ & $\begin{array}{l}\text { Twist \& } \\
\text { camber }\end{array}$ & Dihedral & $\begin{array}{l}\text { Span \& } \\
\text { camber }\end{array}$ & Camber & $\begin{array}{l}\text { Camber \& } \\
\text { span }\end{array}$ & Camber & Camber \\
\hline Aircraft & General & UAV & Civil regional & General & $\begin{array}{l}\text { General \& } \\
\text { MAV }\end{array}$ & UAV & General & UAV & General & General \\
\hline Model type & Full wing & Full wing & Full wing & Half wing & Full wing & Full wing & Full wing & Full wing & $\begin{array}{l}\text { Wing } \\
\text { section }\end{array}$ & $\begin{array}{l}\text { Wing } \\
\text { section }\end{array}$ \\
\hline $\begin{array}{l}\text { Structure } \\
\text { model }\end{array}$ & $\begin{array}{l}\text { Nonlinear } \\
\text { beam }\end{array}$ & $\begin{array}{l}\text { Nonlinear } \\
\text { beam }\end{array}$ & FEM & Linear beam & $\begin{array}{l}\text { Lagrange } \\
\text { based } \\
\text { nonlinear } \\
\text { formulation }\end{array}$ & FE software & FE software & FE software & $\begin{array}{l}\text { FE } \\
\text { software \& } \\
\text { nonlinear } \\
\text { beam }\end{array}$ & N/A \\
\hline Structure & Isotropic & Isotropic & Isotropic & Isotropic & Isotropic & Isotropic & Composite & Composite & $\begin{array}{l}\text { Isotropic \& } \\
\text { composite }\end{array}$ & N/A \\
\hline $\begin{array}{l}\text { Aerodynamic } \\
\text { model }\end{array}$ & $\begin{array}{l}\text { Weissinger's } \\
\text { method }\end{array}$ & $\begin{array}{l}\text { Weissinger's } \\
\text { method }\end{array}$ & VLM & VLM & UVLM & $\begin{array}{l}\text { Unsteady } \\
\text { Theodorsen's } \\
\text { theory }\end{array}$ & 2D panel & $\begin{array}{l}\text { Viscous 2D } \\
\text { panel }\end{array}$ & $\begin{array}{l}\text { UVLM, } \\
\text { XFOIL \& } \\
\text { UTCart }\end{array}$ & N/A \\
\hline $\begin{array}{l}\text { Type of } \\
\text { study }\end{array}$ & $\begin{array}{l}\text { Static } \\
\text { aeroelasticity }\end{array}$ & $\begin{array}{l}\text { Static } \\
\text { aeroelasticity } \\
\& \text { aeroelastic } \\
\text { stability }\end{array}$ & $\begin{array}{l}\text { Aeroelastic } \\
\text { response \& } \\
\text { aerodynamic } \\
\text { characteristics }\end{array}$ & $\begin{array}{l}\text { Static } \\
\text { aeroelasticity }\end{array}$ & $\begin{array}{l}\text { Aeroelastic } \\
\text { stability \& } \\
\text { response }\end{array}$ & $\begin{array}{l}\text { Aeroelastic } \\
\text { stability }\end{array}$ & $\begin{array}{l}\text { Static } \\
\text { aeroelasticity }\end{array}$ & $\begin{array}{l}\text { Static } \\
\text { aeroelasticity }\end{array}$ & $\begin{array}{l}\text { Aeroelastic } \\
\text { response }\end{array}$ & $\begin{array}{l}\text { Aeroelasti } \\
\text { c response }\end{array}$ \\
\hline Flow regime & Subsonic & Subsonic & $\begin{array}{l}\text { Subsonic \& } \\
\text { transonic }\end{array}$ & Subsonic & Subsonic & Subsonic & Subsonic & Subsonic & Subsonic & Subsonic \\
\hline $\begin{array}{l}\text { Flight } \\
\text { condition }\end{array}$ & Cruise & Cruise & Cruise & Cruise & Cruise & $\begin{array}{l}\text { Takeoff, } \\
\text { climb, cruise } \\
\& \text { loiter }\end{array}$ & Cruise & Cruise & Cruise & Cruise \\
\hline
\end{tabular}




\section{List of Acronyms}

\begin{tabular}{|c|c|}
\hline AAW & Active Aeroelastic Wing \\
\hline ACARE & Advisory Council for Aeronautics Research in Europe \\
\hline AFW & Active Flexible Wing \\
\hline AIC & Aerodynamic Influence Coefficient \\
\hline ATE & Active Trailing Edge \\
\hline ATED & Active Trailing Edge Device \\
\hline ATW & Adaptive Torsion Wing \\
\hline AWE & Airborne Wind Energy \\
\hline CFRP & Carbon fiber Reinforced Polymer \\
\hline CUF & Carrera Unified Formulation \\
\hline CUFXFLR5 & Carrera Unified Formulation-XFLR5 \\
\hline $\mathrm{DE}$ & Dielectric Elastomer \\
\hline DIC & Digital Image Correlation \\
\hline DKT & Discrete Kirchhoff Triangle \\
\hline DLM & Doublet Lattice Method \\
\hline ELLT & Extended Lifting Line Theory \\
\hline EMA & Electro-Mechanical Actuation \\
\hline EMC & Elastomeric Matrix Composite \\
\hline FE & Finite Element \\
\hline FEM & Finite Element Method \\
\hline FFAST & Future Fast Aeroelastic Simulation Technology \\
\hline FHA & Fault and Hazard Analysis \\
\hline FishBAC & FishBone Active Camber \\
\hline FSI & Fluid-Structure Interaction \\
\hline GA & Genetic Algorithm \\
\hline HALE & High Altitude Long Endurance \\
\hline HBMA & High Bandwidth Morphing Actuator \\
\hline LST & Linear Strain Triangles \\
\hline MACH & Mdo for Aircraft Configuration with High fidelity \\
\hline
\end{tabular}




\begin{tabular}{ll} 
MAV & Micro-air-vehicle \\
MFC & Macro Fiber Composite \\
MLA & Maneuver Load Alleviation \\
MP & Mathematical Programming \\
NATASHA & Nonlinear Aeroelastic Trim And Stability of Hale Aircraft \\
PAPA & Pitch And Plunge Apparatus \\
PEI & Polyetherimide \\
PTWT & Passive Twist Wingtip \\
RTO & Research and Technology Organization \\
SAH & Semi-Aeroelastic Hinge \\
SAS & Stability Augmented System \\
SAW & Seamless Aeroelastic Wing \\
SMA & Shape Memory Alloys \\
SMP & Shape Memory Polymers \\
TACS & Toolkit for Analysis Composite Structures \\
TRA & Technology Reference Aircraft \\
TTAM & Torque Tube Actuation Mechanism \\
UAV & Unmanned Aerial Vehicle \\
UVLM & Unsteady Vortex-Lattice Method \\
VCCTEF & Variable Camber Continuous Trailing Edge Flap \\
VLM & Vortex Lattice Method \\
\hline
\end{tabular}

\section{Nomenclature}

$\begin{array}{ll}\text { A } & \text { structural inertia matrix } \\ \text { B } & \text { aerodynamic damping matrix } \\ \text { C } & \text { aerodynamic stiffness matrix } \\ \text { D } & \text { structural damping matrix } \\ \text { E } & \text { structural stiffness matrix } \\ \rho & \text { air density } \\ V & \text { air speed }\end{array}$




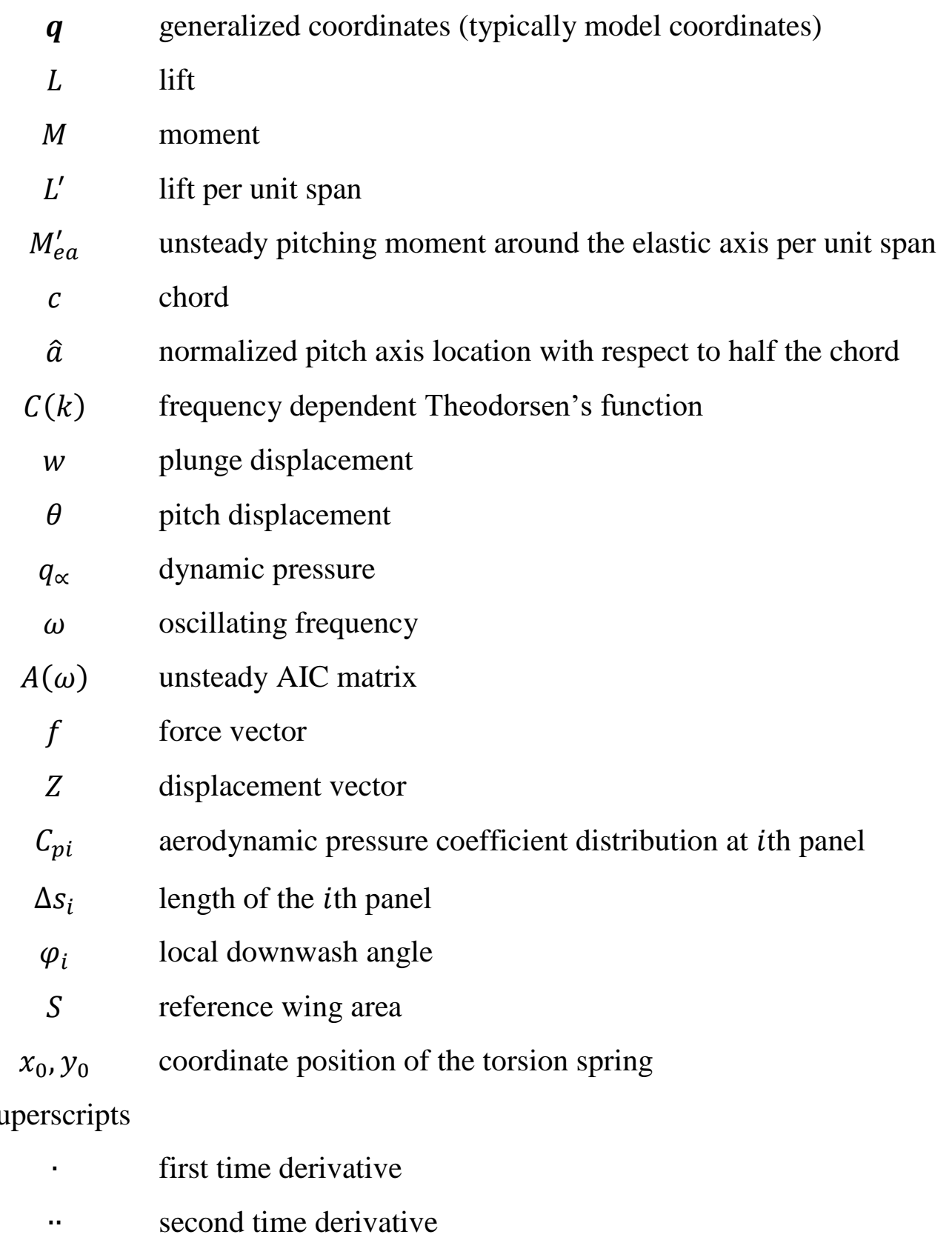

